UNIVERSIDADE DE SÃO PAULO

ESCOLA DE ENFERMAGEM

CARLA MARIA MALUF FERRARI

ADESÃO AO TRATAMENTO E QUALIDADE DE VIDA DE INDIVÍDUOS COM EPILEPSIA EM TRATAMENTO AMBULATORIAL 
CARLA MARIA MALUF FERRARI

\title{
ADESÃO AO TRATAMENTO E QUALIDADE DE VIDA DE INDIVÍDUOS COM EPILEPSIA EM TRATAMENTO AMBULATORIAL
}

\author{
Tese apresentada a Escola de Enfermagem \\ da Universidade de São Paulo para obtenção \\ do título de Doutor em Ciências \\ Área de concentração: \\ Enfermagem na Saúde do Adulto \\ Orientadora: \\ Profa Dra Regina Márcia Cardoso de Sousa
}

\section{SÃO PAULO}


AUTORIZO A REPRODUÇÃO E DIVULGAÇÃO TOTAL OU PARCIAL DESTE TRABALHO, POR QUALQUER MEIO CONVENCIONAL OU ELETRÔNICO, PARA FINS DE ESTUDO E PESQUISA, DESDE QUE CITADA A FONTE.

Assinatura:

Data:

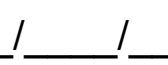

\section{Catalogação na Publicação (CIP) \\ Biblioteca "Wanda de Aguiar Horta" \\ Escola de Enfermagem da Universidade de São Paulo}

Ferrari, Carla Maria Maluf

Adesão ao tratamento e qualidade de

vida de indivíduos com epilepsia em tratamento ambulatorial /

Carla Maria Maluf Ferrari. -- São Paulo, 2011.

$130 \mathrm{p}$.

Tese (Doutorado) - Escola de Enfermagem da Universidade de São Paulo.

Orientadora: Prof ${ }^{a}$ Dr $^{\mathrm{a}}$ Regina Márcia Cardoso de Sousa

1. Epilepsia 2. Cooperação do paciente 3. Medicação oral 4. Complexidade 5. Terapêutica 6. Qualidade de vida

7. Assistência ambulatorial I. Título. 


\section{FOLHA DE APROVAÇÃO}

Nome: Carla Maria Maluf Ferrari

Título: Adesão ao tratamento e qualidade de vida de indivíduos com epilepsia em tratamento ambulatorial.

Tese apresentada à Escola de Enfermagem a Universidade de São Paulo para obtenção o título de Doutor em Ciências

Aprovada em:

Banca Examinadora

Prof. Dr.

Julgamento:

Prof. Dr. Julgamento:

Prof. Dr.

Julgamento:

Prof. Dr.

Julgamento:
Instituição:

Assinatura:

Instituição:

Assinatura:

Instituição:

Assinatura:

Instituição:

Assinatura: 


\section{Dedicatória}

Primeiramente, dedico esse trabalho ao meu pai Nader Maluf (in memória) e à minha querida mãe Antônia Croce Maluf, já que sem o investimento educacional que me proporcionaram não teria conseguido concluir o percurso percorrido até aqui.

Queria destacar um agradecimento especial àquela que me transmitiu amor e apoio durante toda minha vida: Obrigada Mãe! Mesmo não compreendendo mais o que acontece ao seu redor, você certamente é um exemplo de carinho e dedicação! EV TE AMO MUITO!

Depois, não posso deixar de citar a minha família querida: meus filhos Giulianna e Leonardo e meu querido marido Fausto que tiveram a paciência $e$ compreensão necessária para que eu finalizasse o trabalho, sempre me apoiando em todos os momentos durante a realização deste estudo. Realmente, se não fosse o ombro companheiro de vocês e a felicidade de saber que após um dia difícil os encontraria em casa, não teria conseguido.

Muito obrigada a essa família maravilhosa que eu amo demais!!!

Por fim, dedico ao meu irmão Alfredo que, em muitos momentos, escutou-me pacientemente $e$ soube lidar com meus limites e aos meus sogros tão queridos e especiais. 


\section{Agradecimentos Especiais}

À minha orientadora Profa Dra Regina Márcia Cardoso de Souza pela sua experiência e competência impar que foram essenciais para a realização deste estudo. Tornamo-nos parceiras e acabamos formando uma equipe, sem a qual não teria sido possivel a finalização do trabalho.

Às minhas queridas amigas Iolanda, Pollyanna, Rosimeire, Roseanne e Cristina

Sou eternamente grata a vocês, já que me ajudaram na coleta dos dados, sem esperar nada em troca, sempre estiveram presentes me apoiando $e$ incentivando, escutaram os pacientes com inúmeros problemas e, assim, não foram apenas profissionais, mas também companheiras carinhosas e nunca deixaram de me ajudar!!!

Sinceramente, não existem palavras que expressem tamanho agradecimento por terem acreditado nesse trabalho, e, principalmente, em mim.

Muito, muito, muito, muito.... OBRIGADA! Pessoas como vocês são raras nos dias de hoje. Espero um dia poder retribuir todo esse apoio $e$ quero que saibam que eu me sinto muito feliz $e$ honrada em tê-las conhecido.

Finalmente, à minha querida amiga Acácia de tantas horas. Amiga MUITO OBRIGADA! Também não tenho palavras para te agradecer. Você esteve presente em muitos momentos que precisei, soube esclarecer minhas dúvidas e angústias e não deixou que eu desistisse. 


\section{Agradecimentos}

Ao Dr. Luiz Henrique Martins Castro pelo apoio, oportunidade e confiança no meu trabalho.

As Doutoras Carmen, Rosa e Ináh pelo incentivo e pela contribuição.

À querida Márcia, pelo acolhimento e pela amizade.

À equipe da secretaria do ambulatório da neurologia pelo apoio durante o período de coleta de dados.

As minhas queridas amigas Maristela, Verónica, Regina, Claudia Darco, Rosana, Silvia, Luciane, Simone Oliveira, Simone Murayama e Rita que foram essenciais para que eu seguisse em frente.

Ao Horácio pela valiosa colaboração no entendimento das traduções

Aos pacientes que contribuiram e tornaram o trabalho possivel.

A todos aqueles que de alguma forma influenciaram o estudo, ajudaram-me e apoiaram-me nas horas que precisei. 
"O correr da vida embrulha tudo. A vida é assim: esquenta e esfria Aperta e dai afrouxa Sossega e depois desinquieta O que ela quer da gente é coragem". João Guimarães Rosa

"Se enxerguei mais longe, foi por que me apoiei sobre os ombros de gigantes" 
Ferrari CMM. Adesão ao tratamento e qualidade de vida de indivíduos com epilepsia em tratamento ambulatorial [tese]. São Paulo: Escola de Enfermagem, Universidade de São Paulo, 2011.

\section{RESUMO}

Os objetivos deste estudo foram explicitar a complexidade do tratamento medicamentoso, a adesão ao tratamento e a qualidade de vida de indivíduos com epilepsia, além de evidenciar as associações da adesão e qualidade de vida com as características do paciente, doença, terapêutica e suporte social. Foi realizado estudo prospectivo, transversal, com indivíduos com epilepsia em assistência ambulatórial. A casuística foi de 385 pacientes, idade de 18 anos ou mais, alfabetizados, independentes nas atividades da vida diária, sem deficiência mental ou alteração psíquica ativa diagnosticada. A adesão ao tratamento foi avaliada com o teste de Morisky e a qualidade de vida pelo Quality of Life in Epilepsy Inventory-31 (QOLIE31). Em uma primeira etapa foram realizados testes de associação entre as variáveis dependentes e cada variável independente isoladamente. Após, a análise conjunta das variáveis foi feita por meio de regressão logística quando a variável resposta foi adesão e por meio de regressão linear múltipla para qualidade de vida. A idade média dos participantes foi de 39,7 anos $(\mathrm{dp}=12,6)$, a maioria do sexo feminino $(53,5 \%)$, com diagnóstico de epilepsia focal sintomática $(79,5 \%)$, em uso de politerapia $(71,1 \%)$, apresentando crises nos últimos seis meses que precederam a investigação (79\%) e tempo médio de tratamento de 21,5 anos $(\mathrm{dp}=13,2)$. A complexidade terapêutica do tratamento medicamentoso para epilepsia mensurada pelo Índice de Complexidade do Tratamento Medicamentoso em Epilepsia (ICTME) variou de 2,0 a 44 pontos e a média foi de $14,7(\mathrm{dp}=8,0)$. A adesão ao tratamento foi alta para $33,8 \%$ dos participantes deste estudo, média para $60,5 \%$ e baixa para $5,7 \%$. O escore total do QOLIE-31 foi de 64,2 (dp=18,19) e entre os domínios do QOLIE-31 os valores médios mais baixos foram $53,2(\mathrm{dp}=31,38)$ no domínio preocupação com as crises, seguido de $61,3(\mathrm{dp}=32,61)$ no domínio efeito da medicação. O mais alto valor médio foi $69,8(\mathrm{dp}=25,74)$ no domínio aspecto social. O resultado da regressão logística multivariada para não adesão ao tratamento medicamentoso evidenciou que indivíduos do sexo feminino e que apresentavam controle das crises tiveram menor probabilidade de não adesão terapêutica perante aos do sexo masculino e sem controle das crises. A não adesão foi menos freqüente nos mais velhos e o aumento de um ano na idade diminui a probabilidade de não adesão em $3 \%$. A probabilidade de não adesão ocorrer foi $6 \%$ maior a cada aumento de um ponto no ICTME. Para qualidade de vida, a análise conjunta das diversas características evidenciou que indivíduos da raça branca e amarela, inseridos no mercado de trabalho e que tinham percepção que suas crises estavam controladas tiveram pontuações mais elevadas em relação aos que não apresentavam essas características. Por outro lado, aqueles que recebiam apoio de familiares ou amigos apresentaram menores escores nesse questionário em relação aos demais. Os resultados deste estudo destacaram principalmente as características sócio-demográficas e referentes ao controle da crise com fatores associados à adesão e qualidade de vida do paciente epiléptico. Vale também destacar que o aumento da complexidade terapêutica confirmou seu impacto negativo na adesão ao tratamento

Palavras-chave: epilepsia, adesão ao tratamento medicamentoso, complexidade, terapêutica, qualidade de vida, assistência ambulatorial 
Ferrari CMM. Treatment adherence and Quality of Life of individuals with epilepsy in an outpatient treatment program.[thesis]São Paulo: School of Nursing, University of São Paulo, 2011

\begin{abstract}
The study aimed to clarify the complexity of drug treatment, treatment adherence and quality of life of individuals with epilepsy, and also highlights the associations of adherence and quality of life with patient characteristics, disease, therapeutic and social support. This was a prospective, transversal study of individuals with epilepsy in outpatient care. The sample consisted of 385 patients, aged 18 years or older, literate, independent in their daily living activities, without mental or active psychological changes diagnosed. Adherence to treatment was assessed by using the Morisky test and quality of life by the Quality of Life in Epilepsy Inventory-31 (QOLIE-31). In the first step, association tests were performed between dependent variables and each independent variable alone. After, an analysis of the variables was performed by logistic regression when the dependent variable was in adherence and through multiple linear regression for quality of life. The average age of participants was 39.7 years $(\mathrm{SD}=12.6)$, mostly females $(53.5 \%)$ with symptomatic focal epilepsy (79.5\%), and on multiple AEDs (71.1\%), with crises in the last six months preceding the research $(79 \%)$ and mean treatment of 21.5 years $(\mathrm{SD}=13.2)$.

The complexity of therapeutic drug treatment for epilepsy measured by the Epilepsy Medication Treatment Complexity Index (EMTCI) ranged from 2.0 to 44 points and averaged $14.7(\mathrm{SD}=8.0)$. Treatment compliance was high for $33.8 \%$ of this study's participants, $60.5 \%$ for medium and low was $5.7 \%$. The total score of QOLIE-31 was $64.2(\mathrm{SD}=18.19)$ and between the domains of QOLIE-31, the lowest average values were $53.2(\mathrm{sd}=31.38)$ in the domain concerned with the crises, followed by 61.3 $(\mathrm{SD}=32.61)$ in the domain effect of the medication. The highest average value was $69.8(\mathrm{SD}=25.74)$ in the domain social aspect. The result of multivariate logistic regression for non-adherence to drug treatment showed that female subjects who had control of the seizures, were less likely to face Non-adherence than the male and with uncontrolled seizures. Non-adherence was less frequent in older and one-year increase in age decreases the probability of non-adherence by $3 \%$. The probability of non-compliance occurrence was 6\% higher for each increase of one point in EMTCI. For quality of life, joint analysis showed that several characteristics among whites and asian, entered the labor market and had the perception that their seizures were controlled had the highest scores compared to those without these characteristics.

On the other hand, those who received support from family or friends had lower scores on this questionnaire in relation to others. The results of this study highlighted mainly the socio-demographic characteristics and for control of the crisis, factors associated with adherence and quality of life of epileptic patients. Note also that the increasing complexity of therapy confirmed its negative impact on treatment adherence.
\end{abstract}

Key-words: Epilepsy, medication adherence, complexity, treatment, quality of life, ambulatory care. 


\section{LISTA DE ILUSTRAÇÕES}

Gráfico 1 - Porcentagem de pacientes, segundo prescrição dos diferentes tipos de DAEs. São Paulo, 2009-2010.

Gráfico 2 - Porcentual de respostas afirmativas às questões do Teste de Morisky. São Paulo, 2009-2010.

\section{LISTA DE TABELAS}

Tabela 1 - Distribuição dos pacientes ( $\mathrm{n}=385)$, segundo a idade, sexo, vínculo conjugal, raça e religião. São Paulo, 2009-2010.

Tabela 2 - Distribuição dos pacientes $(n=385)$, segundo a escolaridade e situação ocupacional. São Paulo, 2009-2010.

Tabela 3 - Distribuição dos pacientes segundo informação sobre a renda per capita (R\$). São Paulo, 2009-2010.

Tabela 4 - Distribuição dos pacientes ( $\mathrm{n}=385$ ), segundo o diagnóstico médico, tempo que conhece o diagnóstico, tempo de tratamento e número de DAEs prescritas. São Paulo, 2009-2010.

Tabela 5 - Distribuição dos pacientes $(n=385)$, segundo a frequência das crises nos últimos 30 dias, controle de crise, percepção quanto ao controle das crises e apoio de familiares ou de amigos. São Paulo, 2009-2010.

Tabela 6 - Distribuição dos pacientes ( $\mathrm{n}=385)$, segundo informação sobre a facilidade de agendamento de consulta médica periódica e extra frequência das consultas (dias), qualidade do atendimento médico e percepção de seu estado de saúde, após início do tratamento ambulatorial. São Paulo, 2009-2010.

Tabela 7 - Distribuição dos pacientes $(\mathrm{n}=385)$ segundo forma de aquisição das DAEs e procedimento quando falta da medicação. São Paulo, 2009-2010.

Tabela 8 - Distribuição dos pacientes, segundo a complexidade do tratamento medicamentoso, mensurada pelo ICTME. São Paulo, 2009 - 2010.

Tabela 9 - Estatística descritiva da complexidade terapêutica pelo ICTME, segundo a quantidade de DAEs prescritas aos pacientes (n=385). São Paulo, 2009-2010 ......59

Tabela 10 - Distribuição dos pacientes com epilepsia quanto à adesão ao tratamento medicamentoso, segundo o Teste de Morisky. São Paulo, 2009-2010.

Tabela 11 - Estatística descritiva da pontuação total de cada domínio e questão 31 do QOLIE-31. São Paulo, 2009-2010. 
Tabela 12 - Comparação entre os grupos de alta e media/baixa adesão em relação ao sexo, ao vínculo conjugal, à raça, à religião, à escolaridade e à situação ocupacional. São Paulo, 2009-2010.

Tabela 13 - Comparação entre os grupos de alta e média/baixa adesão em relação ao diagnóstico médico, à presença de crise nos últimos 30 dias, ao controle de crises, à percepção do paciente quanto ao controle de crises e ao número de DAEs. São Paulo, 2009-2010.

Tabela 14 - Comparação entre os grupos de alta e média/baixa adesão em relação ao apoio de familiares ou amigos, à facilidade de agendamento de consulta médica periódica e extra, à qualidade do atendimento médico e à percepção do estado de saúde, após início do tratamento ambulatorial. São Paulo, 20092010 .

Tabela 15 - Comparação entre os grupos de alta e média/baixa adesão em relação à forma de aquisição das DAEs e ao procedimento quando falta a medicação. São Paulo, 2009-2010.

Tabela 16 - Comparação entre os grupos de alta e média/baixa adesão em relação à idade, à renda per capita, ao tempo que conhece o diagnóstico, ao tempo de tratamento, à frequência das consultas e à pontuação do ICTME. São Paulo, 2009-2010.

Tabela 17 - Modelo de regressão logística múltipla para estimativa de associação com a não adesão. São Paulo, 2009-2010.

Tabela 18 - Comparação entre as médias do escore total do QOLIE-31 em relação ao sexo, ao vínculo conjugal, à raça, à religião, à escolaridade e à situação ocupacional. São Paulo, 2009-2010.

Tabela 19 - Comparação entre as médias do escore total do QOLIE-31 em relação ao diagnóstico médico, à presença de crise, ao controle de crises, à percepção do paciente quanto ao controle de crises, ao número das DAEs e à adesão ao tratamento (Teste de Morisky). São Paulo, 2009-2010.

Tabela 20 - Comparação entre as médias do escore total do QOLIE-31 em relação ao apoio de familiares ou amigos, facilidade de agendamento de consulta médica periódica e extra, qualidade do atendimento médico e percepção do estado de saúde, após início do tratamento ambulatorial. São Paulo, 20092010 .

Tabela 21 - Comparação entre as médias do escore total do QOLIE-31 em relação à forma de aquisição das DAEs e procedimento quando falta a medicação. São Paulo, 2009-2010.

Tabela 22 - Correlação entre as médias do escore total do QOLIE-31 e idade, renda per capita, tempo que conhece o diagnóstico, tempo de tratamento, frequência de consultas e ICTME. São Paulo 2009-2010.

Tabela 23 - Regressão linear para o escore total do QOLIE-31. São Paulo, 2009 -2010. 


\section{SUMÁRIO}

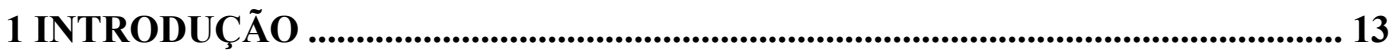

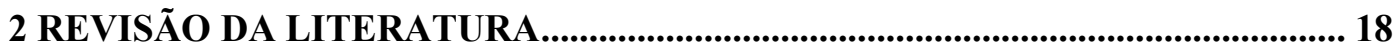

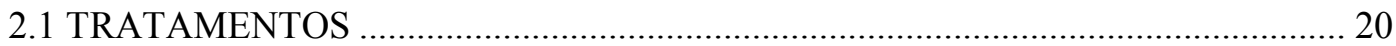

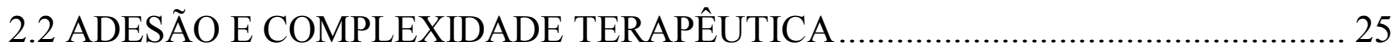

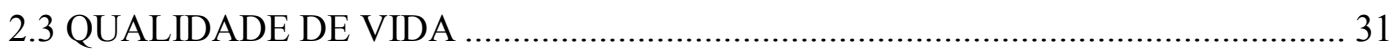

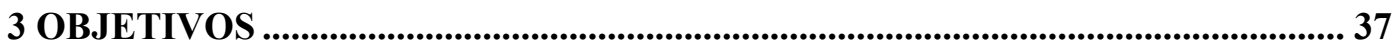

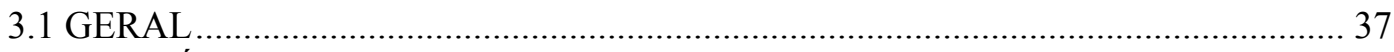

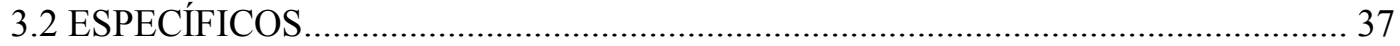

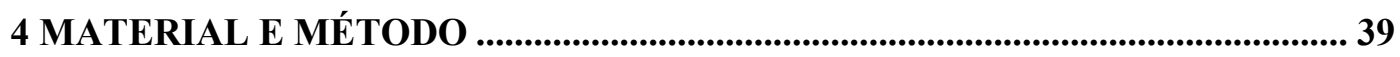

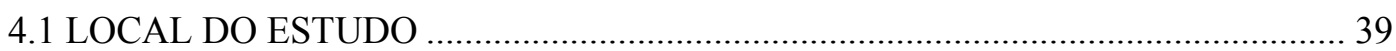

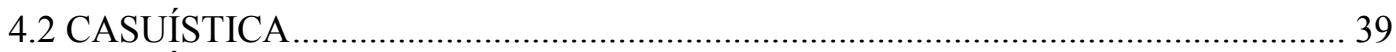

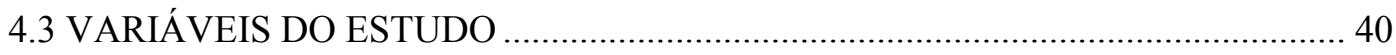

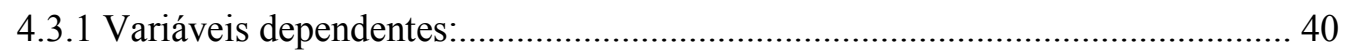

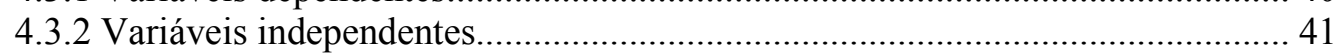

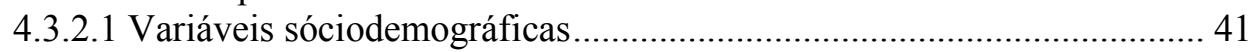

4.3.2.2 Variáveis relacionadas à doença...................................................... 42

4.3.2.3 Variável relacionada ao apoio familiar................................................. 43

4.3.2.4 Variáveis relacionadas à terapêutica medicamentosa............................. 43

4.3.2.5 Variáveis relacionadas ao Sistema de Saúde:........................................ 44

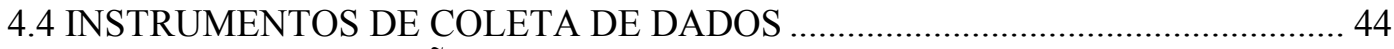

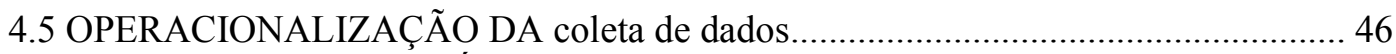

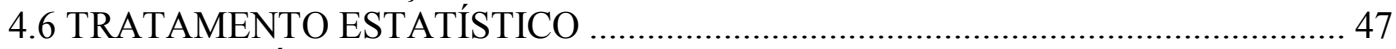

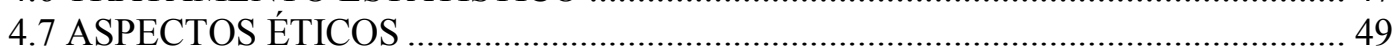

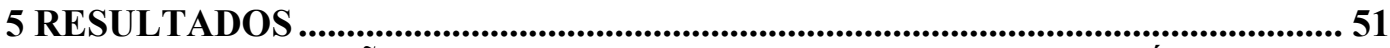

5.1 CARACTERIZAÇÃO DA AMOSTRA ATENDIDA NO AMBULATÓRIO E

LIGA DE EPILEPSIA. ................................................................................................ 51

5.2 COMPLEXIDADE TERAPÊUTICA, ADESÃO AO TRATAMENTO

MEDICAMENTOSO E QUALIDADE DE VIDA DOS PACIENTES COM

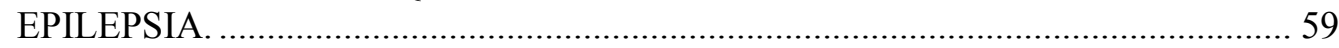

5.3 FATORES ASSOCIADOS A NÃO-ADESÃO AO TRATAMENTO

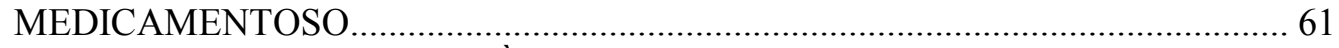

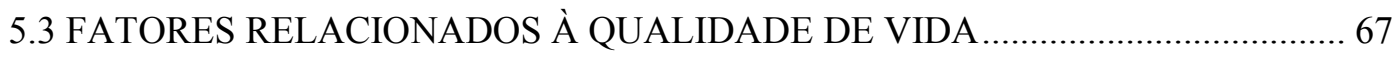

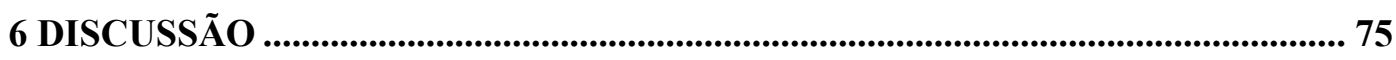

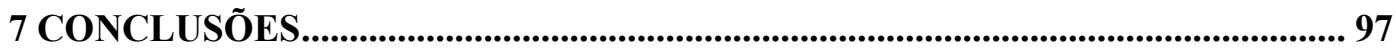

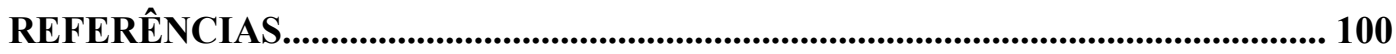

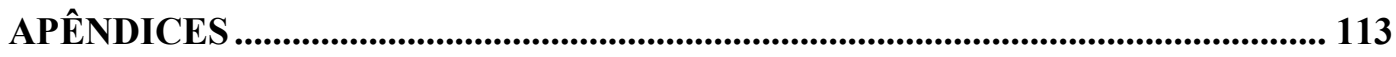

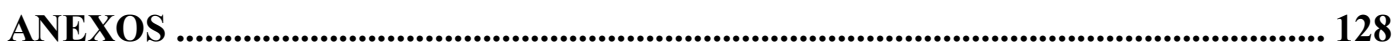




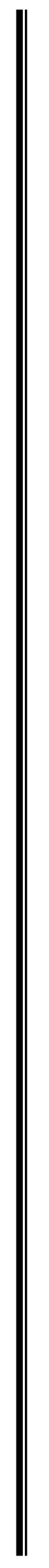

Introdução 
Carla Maria Maluf Ferrari

\section{INTRODUÇÃO}

A epilepsia é uma das doenças crônicas neurológicas mais comuns, sendo, geralmente associada à depressão, ansiedade, estigma e os pacientes sofrem consequências diretas decorrentes das crises, como: perda de emprego, esquecimentos de compromissos importantes relacionados ao trabalho ou à escola, mudanças na produtividade e concentração. Muitos abandonam o trabalho e a escola em razão do constrangimento dos outros presenciarem uma crise ${ }^{(1)}$.

Apesar dos avanços no tratamento para o controle das crises, as drogas antiepilépticas (DAEs) continuam a ser o tratamento de escolha para a maioria das pessoas com a doença, estas são capazes de abolir ou reduzir a frequência das crises em cerca de $67 \%$ dos casos. Após 1 ano de tratamento medicamentoso um entre dois pacientes com epilepsia recém-diagnosticada tem o controle total das crises; um entre seis pacientes apresenta redução na frequência e um entre três não tem o controle das crises com as DAEs ${ }^{(2)}$.

A escolha da medicação deve ser feita com base nas características individuais do paciente, sua aderência e tolerância ao tratamento ${ }^{(3)}$. O objetivo do uso dessas drogas é o controle das crises, porém os efeitos colaterais da medicação, como a toxicidade do Sistema Nervoso Central e reações de hipersensibilidade, ocorrem em indivíduos submetidos a esse tratamento ${ }^{(2,4)}$. Consequentemente, muitos pacientes relatam dificuldade em seguir corretamente o esquema terapêutico, além disso pessoas com doenças crônicas, como a epilepsia, precisam incorporar em sua rotina diária, cuidados com a medicação e tratamento que devem ser parte importante em suas vidas ${ }^{(4)}$.

Nesse contexto, a adesão ao tratamento medicamentoso torna-se um dos maiores problemas de saúde de âmbito mundial decorrente das dificuldades do paciente de se ajustar às exigências do tratamento por um período prolongado ${ }^{(5)}$. Estimativas apontam para um índice de 30\%-50\% de não-adesão ao tratamento medicamentoso, entre os indivíduos com epilepsia ${ }^{(4)}$. 
Carla Maria Maluf Ferrari

Os enfermeiros, particularmente, porque têm em relação aos demais profissionais de saúde um maior contato com os pacientes, detêm grande parte da responsabilidade de apoiar e ajudá-los na adesão ao tratamento e a superar as dificuldades, fornecendo orientação eficiente, facilitando, sempre que possível e ajustando as peculiaridades da terapêutica à rotina da vida do paciente. Além disso, o enfermeiro é considerado o profissional da equipe de saúde mais familiarizado com os problemas da adesão e complexidade terapêutica, uma vez que administra medicações e, de modo geral, possui uma ampla experiência na abordagem a pacientes com doenças crônicas, tais como: diabetes mellitus, hipertensão arterial, epilepsia ou HIV positivo, sendo, por conseguinte, um profissional adequado para intervir nesses problemas.

$\mathrm{Na}$ prática clínica desses profissionais, pacientes não aderentes reportam dificuldade no controle das crises em relação àqueles que tomam seus medicamentos corretamente, portanto o interesse primordial no tratamento dos indivíduos com epilepsia é a conscientização da importância de seguir corretamente o esquema terapêutico $^{(6)}$.

Estudos que analisaram a não adesão terapêutica entre indivíduos com epilepsia vêm indicando quatro fatores principais relacionados com o comportamento desses pacientes, quanto ao regime terapêutico proposto: fatores relacionados ao paciente (características demográficas e socioeconômicas, percepções e crenças em relação à doença); relacionados à doença (frequência e gravidade das crises), relacionados à medicação (números de doses diárias e efeitos colaterais) e os fatores, que envolvem a relação médico-paciente ${ }^{(7)}$. Entre esses fatores estão problemas com o esquecimento quanto a tomada do medicamento, o alto custo das DAEs e complexidade terapêutica, que contribuem para não adesão ao tratamento medicamentoso ${ }^{(4)}$.

Tendo em vista facilitar a adesão ao tratamento, diretrizes quanto ao uso de (DAEs) sugerem preferencialmente a monoterapia, porém muitos pacientes precisam de várias medicações para controlar suas crises, tornando o esquema terapêutico complexo $^{(8)}$. 
Carla Maria Maluf Ferrari

Pesquisadores que analisaram a adesão terapêutica entre indivíduos com epilepsia e com outras doenças crônicas consideram que a complexidade terapêtica é um dos principais fatores para a não adesão ao tratamento ${ }^{(2)}$. Estudos clínicos vêm mostrando a relação entre essas variáveis em pacientes HIV positivo, assim como em pacientes diabéticos: nesses grupos, a adesão ao tratamento é menor quanto maior for a complexidade do regime terapêutico ${ }^{(9,10)}$.

DiIorio et al. (2003) ${ }^{(11)}$ afirmam que a complexidade envolve a soma do número de medicamentos, dos comprimidos e doses diárias das medicações, as orientações especiais, tais como, tomar o medicamento em jejum, cuidados no preparo da medicação, triturar ou partir os comprimidos, e outras orientações ${ }^{(8,11,12)}$. Para as autoras, uma das estratégias para controlar ou reduzir a frequência das crises é tomar a medicação corretamente ${ }^{(11,12)}$.

A percepção do controle das crises ou sua redução e o impacto da doença na vida são fatores determinantes da qualidade de vida do indivíduo com epilepsia ${ }^{(13)}$. A epilepsia afeta cada pessoa de forma diferente e quando comparada com outras doenças crônicas tem um impacto maior na saúde mental e social do que na física (13). Pesquisas que relacionaram a não adesão ao tratamento antiepiléptico com as crises, qualidade de vida e produtividade evidenciaram que os indivíduos com epilepsia apresentam escores significativamente piores em relação à saúde mental, cognição, produtividade pessoal, atenção e concentração, ao serem avaliados com questionários de qualidade de vida Short Form Health Survey (SF-12) e de saúdetrabalho Health Work Questionnaire (HWQ) $)^{(7)}$, além disso, pacientes que apresentam crises mais frequêntes tiveram uma percepção pior do estado de saúde e menores índices de qualidade de vida global $^{(7,14,15)}$.

Nos últimos anos, qualidade de vida é um indicador nos julgamentos clínicos de doenças específicas e tem sido incluída como indicador para avaliação da eficácia, eficiência e impacto de determinados tratamentos entre pacientes com doenças crônicas diversas. É também uma avaliação do impacto físico e psicossocial que as doenças ou incapacidades podem acarretar às pessoas e, por isso, permite um melhor conhecimento do paciente e de sua adaptação ao problema do que outros indicadores (16) 
No que tange aos aspectos relacionados à adesão ao tratamento de pacientes com epilepsia, a qualidade de vida e a associação dessas variáveis com as características do paciente, doença e terapêutica, encontra-se uma vasta literatura internacional, porém faltam estudos em populações brasileiras que analisem esses aspectos. Frente a essa lacuna de conhecimento e tendo em vista a importância das especificidades culturais e sociais nos resultados dessas análises, pretendeu-se nesta pesquisa descrever, em nosso meio, a complexidade, a adesão ao tratamento e a qualidade de vida de indivíduos com epilepsia, além de identificar os fatores associados a não adesão ao tratamento e analisar a relação entre qualidade de vida e características do paciente, doença e tratamento.

Conhecer em nossa realidade a complexidade terapêutica, a adesão e os fatores envolvidos no tratamento permite testar intervenções que otimizem a adesão e, talvez, melhorar o controle da epilepsia em pacientes tratados ambulatorialmente. Espera-se, portanto, com os resultados deste estudo obter subsídios para o desenvolvimento de estratégias que visem a melhorar a adesão terapêutica e, conseqüentemente, a qualidade de vida de pacientes epilépticos. 


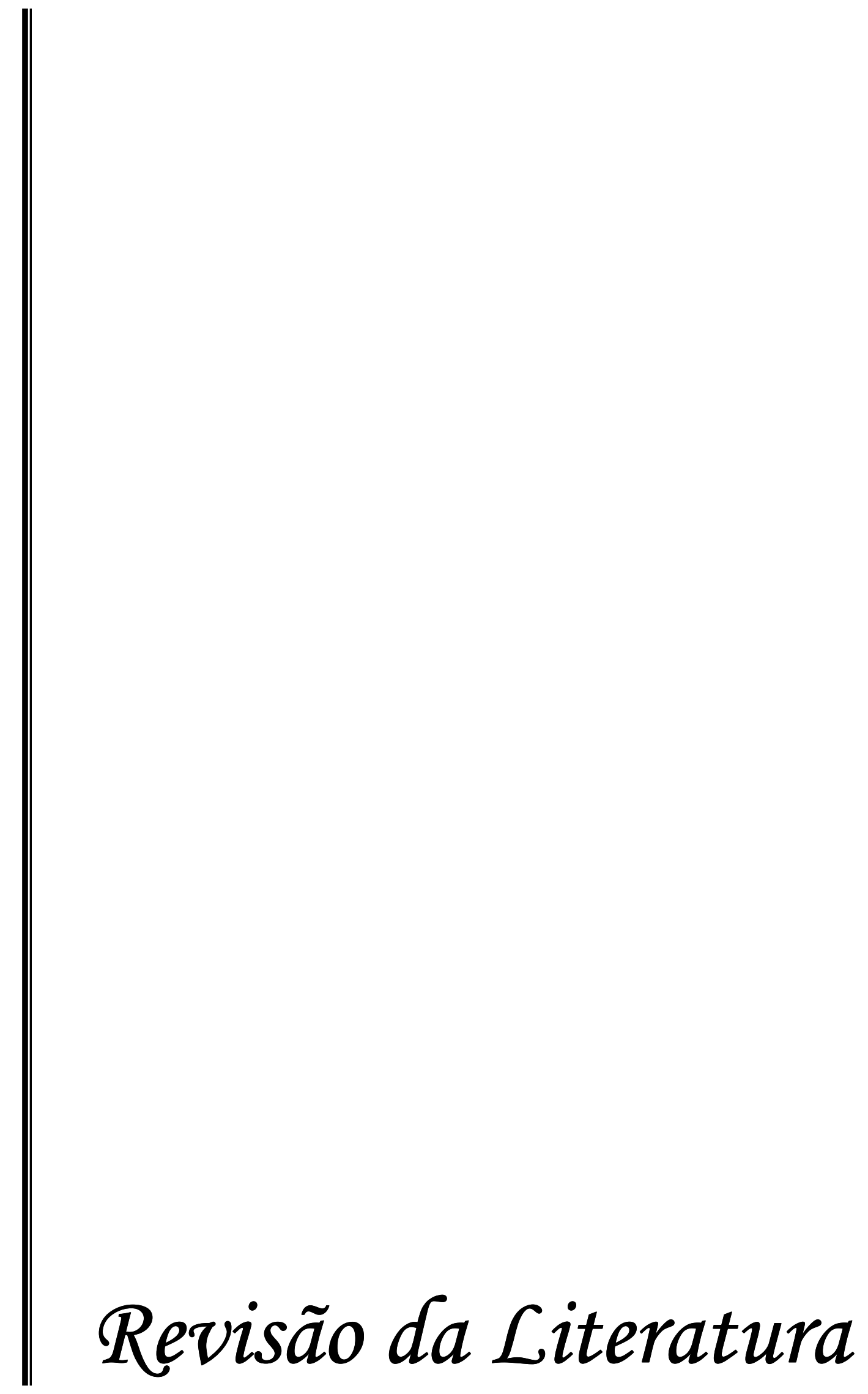


Carla Maria Maluf Ferrari

\section{REVISÃO DA LITERATURA}

Alguns autores descrevem a epilepsia mais como uma síndrome do que como uma doença. É uma condição crônica ou um grupo de doenças que tem em comum a crise epiléptica na ausência de condições tóxico-metabólicas ou febris. As crises epilépticas são eventos clínicos transitórios que refletem a disfunção temporária de um conjunto de neurônios de parte do encéfalo. Os sintomas de uma crise dependem da área do cérebro envolvida ${ }^{(17,18)}$.

Entre as possíveis causas da epilepsia, estão as lesões cerebrais decorrentes de traumatismos cranianos, tumores e distúrbios cerebrais degenerativos, as infecções (meningite, por exemplo), o abuso de bebidas alcoólicas ou de drogas e as complicações durante o parto. A maior parte dos casos não tem uma origem clara, ou seja, não é determinada por uma lesão, mas, sim, por fatores genéticos ${ }^{(3)}$.

Segundo Yacubian $(2002)^{(19)}$, durante a avaliação de uma pessoa com crise epiléptica deve ser considerada sua idade, a ocorrência e características da crise além da história detalhada referida pelo mesmo ou por alguém que testemunhou a crise. Dados do exame físico, análise dos exames complementares tais como: Eletrencefalograma, Ressonância Nuclear Magnética e de Vídeoeletrencefalograma também são importantes para o diagnóstico e classificação das crises.

Segundo a Classificação Internacional das Crises Epilépticas de 1981, existem três grupos de crises: as parciais ou focais, que são caracterizadas clínica e eletrencefalograficamente pela ativação de uma parte do cérebro e são subdivididas em crises parciais simples, quando há preservação da consciência e crises parciais complexas, quando o comprometimento da consciência ocorre; as crises generalizadas são aquelas em que desde o início existe o envolvimento de grandes áreas de ambos os hemisférios cerebrais e há ainda as crises não classificáveis que não se enquadram nos dois subgrupos anteriores ${ }^{(19)}$.

Recentemente, as diferentes condições neurológicas que têm em comum a recorrência de crises epilépticas foram organizadas e classificadas em síndromes epilépticas. Nessa classificação das Epilepsias e Síndromes Epilépticas (International 
Carla Maria Maluf Ferrari

League Against Epilepsy, Commission 1989) ${ }^{(20)}$, consideram-se quatro grupos: epilepsias e síndromes parciais ou focais idiopáticas, sintomáticas e criptogênicas; epilepsias e síndromes generalizadas idiopáticas, sintomática e criptogênica; epilepsias e síndromes indeterminadas focais ou generalizadas e as síndromes especiais.

Nesta última classificação também são consideradas síndromes focais as em que a semiologia ictal ou os achados da investigação indicam a localização de sua origem. Nas síndromes generalizadas, os sinais e sintomas sugerem início difuso, e nas síndromes indeterminadas não há dados para essa definição. $\mathrm{Na}$ epilepsia idiopática, não existe uma lesão cerebral e, provavelmente está relacionada à predisposição genética. Idiopático é um termo que significa que a própria epilepsia é a doença e não um sintoma de outra condição. Na epilepsia sintomática, as crises representam um sintoma de lesão estrutural no encéfalo e o diagnóstico do grupo exige a constatação de sinais clínicos que documentam a patologia cerebral. $\mathrm{Na}$ epilepsia criptogênica, a etiologia é desconhecida ou indeterminada por meio de métodos diagnósticos atualmente disponíveis, porém há dados que sugerem que estas provavelmente, sejam relacionadas a uma lesão cerebral. Indivíduos com síndromes especiais apresentam crises relacionadas a situações, tais como: ingestão de álcool, modificações hormonais, privação de sono e estresse ${ }^{(21) .}$

A taxa de prevalência da epilepsia é bem maior que a incidência, pois é uma doença crônica, com baixo índice de mortalidade, sua incidência anual varia de 30 a 50 novos casos em cada 100 mil indivíduos (0,03 a 0,05\%). Já o índice de prevalência da epilepsia ativa, que inclui apenas casos com crises nos últimos 5 anos, está estimado em cinco a nove em cada mil pessoas $(0,5 \text { a } 0,9 \%)^{(3)}$.

A epilepsia é considerada a segunda causa mais frequente de distúrbio neurológico em adultos jovens, é um sério problema de saúde, acometendo indivíduos de todas as idades, raças e classes socioeconômicas ${ }^{(22)}$. Nas últimas décadas, observou-se um grande avanço em seu tratamento e as DAEs, o tratamento cirúrgico, a dieta cetogênica e a estimulação do nervo vago são as modalidades de terapia utilizadas para tratamento dos indivíduos com a doença ${ }^{(23)}$. 
Carla Maria Maluf Ferrari

\subsection{TRATAMENTOS}

As DAEs constituem o tratamento de eleição para os indivíduos com epilepsia e oferecem um controle satisfatório das crises na maioria dos pacientes $(2,24)$.

O diagnóstico preciso do tipo de crise que o paciente apresenta para a escolha do medicamento apropriado, é fundamental ${ }^{(2,19,2022)}$.

A escolha da DAE entre os fármacos de primeira linha precisa ser individualizada, sobretudo em função do perfil do paciente, incluindo a eficácia para a síndrome epiléptica e as crises, tolerabilidade, segurança, facilidade de uso, a farmacocinética, interações medicamentosas com drogas para tratamento de outras comorbidades e o custo ${ }^{(2,24)}$.

Novas drogas têm chegado ao mercado. Atualmente, as substâncias mais usadas para tratar a epilepsia são: carbamazepina, clobazam, clonazepam, etosuximida, fenitoína, fenobarbital, primidona e valproato de sódio (ácido valpróico). Medicamentos mais novos incluem a lamotrigina, a oxcarbazepina, o topiramato e a vigabatrina ${ }^{(20)}$.

As DAEs de primeira linha, isto é, consideradas no início do tratamento, são as convencionais. $\mathrm{Na}$ epilepsia parcial ou focal, com ou sem generalização secundária, são indicadas a carbamazepina, fenitoína, valproato de sódio e fenobarbital. Nos casos de epilepsias de início generalizado: valproato de sódio, etosuximida (apenas eficaz em crises de ausências), carbamazepina, fenitoína e fenobarbital ${ }^{(20)}$.

Se as drogas de primeira escolha forem ineficazes ou intoleradas, geralmente, serão prescritos o clobazam, clonazepam, lamotrigina ou topiramato para as crises de ausência e mioclônicas e nas crises primariamente generalizadas tônico-clônicas, geralmente, serão prescritos o clobazam, o clonazepam, a lamotrigina, a gabapentina, o topiramato e a vigabatrina ${ }^{(20)}$.

As principais vantagens da substituição versus a combinação incluem facilidade para identificar a droga que causa efeito colateral e evitar os efeitos adversos prejudiciais decorrentes das interações medicamentosas. Além disso, a 
Carla Maria Maluf Ferrari

substituição da monoterapia também tem mostrado efeitos terapêuticos eficazes no controle das crises ${ }^{(20)}$

Quando não se consegue o controle satisfatório das crises epilépticas com monoterapia, utiliza-se associação de duas DAEs (politerapia). A combinação ideal das DAEs na politerapia deve ser conseguida com drogas que têm diferentes mecanismos de ação, índices terapêuticos maiores e menos efeitos colaterais em relação às demais, além de nenhuma ou pequena interação ${ }^{(25)}$.

Quando as medicações tradicionais falham na politerapia, denomina-se que o paciente é de difícil controle ou refratário. Nestas condições, pode-se, de acordo com a síndrome epiléptica, considerar o uso de politerapia com outras DAEs: clobazam, lamotrigina, topiramato e vigabatrina. Estas medicações são caras (com exceção do clobazam). As DAEs de nova geração são muito úteis, porém, para a maioria dos pacientes refratários às drogas tradicionais não são capazes de controlar as crises epilépticas $^{(2,24)}$.

$\mathrm{Na}$ Espanha, sessenta médicos especialistas em epilepsia participaram de uma pesquisa utilizando o método Delphi modificado, respondendo a duas rodadas de questionários. $\mathrm{O}$ objetivo da investigação foi estabelecer um consenso quanto ao início do tratamento e seleção da monoterapia inicial, considerando o tipo de epilepsia e a presença de comorbidades. Os principais achados da pesquisa revelaram consenso sobre o início imediato do tratamento, após a primeira crise nos casos em que forem observadas alterações eletrencefalográficas, imagem de lesão cerebral epileptogênica em exame de Ressonância Nuclear Magnética encefálica e nos doentes idosos. Nesse estudo, as drogas em que houve maior consenso quanto à indicação, foram o levetiracetam, lamotrigina, ácido valpróico e topiramato ${ }^{(26)}$. O levetiracetam é uma droga ainda não comercializada no Brasil.

$\mathrm{Na}$ epilepsia, o tratamento medicamentoso não é indicado no caso de dúvida de diagnóstico, se a crise puder ser evitada sem o medicamento e também se o paciente ou responsável não consentir no tratamento ${ }^{(2,15,27)}$.Por exemplo, pacientes com bom prognóstico, que apresentam crise febril não complicada, epilepsia parcial benigna idiopática muitas vezes não necessitam de tratamento medicamentoso ${ }^{(2)}$. 
Carla Maria Maluf Ferrari

A decisão de iniciar o tratamento medicamentoso requer uma avaliação individual cuidadosa em relação a riscos e benefícios, ou seja, os efeitos adversos às drogas, como toxicidade do sistema nervoso central e reações de hipersensibilidade devem ser consideradas frente ao potencial benéfico da medicação ${ }^{(2,3)}$.

De maneira geral, os efeitos colaterais inciais das DAEs incluem sonolência, lipotímia, piora das crises, problemas gastrointestinais e hepáticos, hipersensibilidade e rush cutâneo. Tardiamente com o uso prolongado, podem ocorrer alterações diretas no sistema nervoso central, como sedação, encefalopatias, depressão, mudanças de comportamento, episódios psicóticos e outros comprometimentos sistêmicos como, leucopenia, anemia aplástica, pancreatite, trombocitopenia, osteoporose, ganho ou perda excessiva de peso, etc. Certamente na vigência do agravo de algum desses sintomas a droga deverá ser suspensa e substituída ${ }^{(2)}$.

Evita-se a politerapia e os efeitos adversos das drogas com a introdução de doses baixas e aumento progressivo até a dose de manutenção do medicamento, sempre que não for necessário um aumento abrupto para o controle da crise ${ }^{(2)}$.

O tratamento cirúrgico é indicado quando se tem documentação sistemática e comprovada da intratabilidade, ou seja, toda vez que um paciente não apresentar controle aceitável das crises com o uso das DAEs ${ }^{(22,23)}$. Nesses casos, as drogas chegam a ser utilizadas nas doses máximas permitidas; no entanto, também se considera para reconhecer a intratabilidade que as DAES só devem ser mantidas no tratamento se apresentarem ausência ou presença mínima e aceitável de efeitos colaterais ${ }^{(23)}$.

Ao considerar a possibilidade da cirurgia como um tratamento para a epilepsia, o primeiro objetivo é que o paciente fique livre das crises epilépticas, porém este resultado cirúrgico nem sempre é um objetivo tangível, e em alguns casos, não ocorre a redução drástica da frequência das crises com o tratamento. No entanto, outros objetivos podem ser atingidos, tais como: recuperação mais rápida das crises, diminuição da frequência da depressão pos-ictal, crises menos severas, de tal forma que os medicamentos possam ser reduzidos e os efeitos colaterais minimizados ${ }^{(28)}$. 
Carla Maria Maluf Ferrari

Importantes aspectos devem ser considerados quando a opção do tratamento for o cirúrgico e esses incluem: o diagnóstico preciso de que as crises realmente são eventos de natureza epiléptica; a localização exata da região de início das crises; que a zona epileptogênica não inclui uma parte importante da córtex e que a remoção da área epileptogênica não trará como consequência déficits maiores do que os associados às próprias crises. Para indicação cirúrgica, consideram-se as avaliações por meio do Vídeoeletrencefalograma com avaliação ictal e interictal, exames de Ressonância Magnética, Tomografia por Emissão de Pósitrons (Positron Emission Tomography - PET Scan), Tomografia por Emissão de Fóton Único (Single Photon Emission Computed Tomography - SPECT Scan) teste neuropsicológicos e outros $^{(28)}$.

Para as crianças, que evoluem com crises epilépticas intratáveis e sem indicação cirúrgica, a dieta cetogênica pode ser uma opção terapêutica ${ }^{(29)}$.

Esta dieta é indicada sobretudo para crianças com mais de 1 ano de idade, que tenham epilepsia comprovadamente refratária a duas ou mais DAEs ou, então, para as que apresentam efeitos colaterais intoleráveis ou que tenham reações idiossincrásicas ao tratamento medicamentoso. Não obstante, ainda existem questões quanto quais pacientes são os mais beneficiados, qual o momento ideal para o início da dieta e sua máxima eficácia, quais as crises e síndromes epilépticas que respondem melhor a dieta cetogênica e qual a duração adequada do tratamento ${ }^{(23,30)}$.

Em 1921, a dieta cetogênica foi introduzida como tratamento por Wilder, que concebeu uma dieta com restrição de carboidratos, taxa minimamente adequada de proteínas e alto teor de gorduras, mantendo uma produção hepática contínua de corpos cetônicos, tanto no estado alimentado como em jejum, objetivando contribuir para o controle das crises ${ }^{(23,30)}$.

O mecanismo de ação mais aceito é de que o sistema nervoso central tem maior capacidade para extrair e oxidar os corpos cetônicos em crianças e a consequente cetose produzida no organismo provoca acidose, alterações no balanço eletrolítico e alterações na concentração de lipídios cerebrais. Estas adaptações metabólicas no cérebro, além do efeito sedativo do ácido acetoacético, diminuem a 
Carla Maria Maluf Ferrari

excitabilidade neuronal e elevam o limiar convulsivógeno decorrente do catabolismo cerebral de gorduras ${ }^{(23,30)}$.

A taxa de alimentos cetogênicos/anticetogênicos na dieta deve ser no mínimo 1,5:1 para elevar os níveis de corpos cetônicos no sangue e urina ${ }^{(22)}$. Nesse tratamento, devem ser consideradas algumas complicações decorrentes da dieta como: hipoglicemia, hiperlipidemia, hiperuricemia, diarreia , fome, constipação intestinal, desidratação, desmineralização óssea, litíase renal, acidose metabólica, infecções recorrentes e alterações do estado mental. O período de permanência na dieta e as proporções alimentares dependem, além da aceitação pela criança, do controle das crises $^{(23,30)}$.

O uso do estimulador de nervo vago foi aprovado em julho de 1997, como coadjuvante no tratamento da epilepsia para adultos e adolescentes, acima de 12 anos de idade ${ }^{(2)}$. Os candidatos ao implante do estimulador do nervo vago são os refratários ao tratamento com as DAEs e os que têm contraindicação ao tratamento cirúrgico. $\mathrm{O}$ estimulador no nervo vago pode atuar em crises focais e generalizadas. Estudos e estatísticas clínicas têm comprovado a redução das crises em 30\% dos pacientes em tratamento com o estimulador do nervo vago ${ }^{(22,31,32,33)}$.

O tratamento de estimulação do nervo vago consiste no uso de um gerador (tipo marca-passo) e fio bipolar com dois eletrodos para estimulação, que são enrolados no nervo vago. O gerador é implantado na fossa supraclavicular ou na região axilar por meio de uma cervicotomia esquerda. O mecanismo de ação, é provavelmente, em razão das alterações que provoca no sistema ativador reticular ascendente, nas conexões centrais do sistema autônomo límbico e nas projeções difusas noradrenérgicas, dessincronizando a atividade elétrica e impedindo a crise epiléptica. Outro provável mecanismo de ação é que o aumento do fluxo sanguíneo no tálamo durante a estimulação do nervo vago contribua para a redução da frequência das crises. Os efeitos colaterais mais comuns são tosse, dispneia , dispepsia, êmese e insônia que podem ser minimizados, iniciando a estimulação uma semana após o implante ${ }^{(22,31,32,33)}$.

Embora a cirurgia, a dieta cetogênica e a estimulação do nervo vago sejam utilizadas no tratamento da epilepsia, em decorrência dos riscos apresentados por 
Carla Maria Maluf Ferrari

essas diferentes modalidades terapêuticas, o controle completo das crises com as DAEs na ausência de efeitos colaterais ainda é a primeira opção para o tratamento da doença $^{(23)}$.

Segundo Garnett $(2000)^{(15)}$, um adequado tratamento para indivíduos com epilepsia deve prevenir a ocorrência das crises, não apresentar efeitos colaterais, melhorar a qualidade de vida dos pacientes, oferecer vantagens na relação custobenefício e garantir a satisfação do paciente. O mesmo autor cita que a melhora da qualidade de vida do paciente epiléptico com a terapêutica é resultante de manter o paciente livre de crises ou reduzir a frequência e/ou amenizar a gravidade das crises.

Para finalizar a abordagem sobre a modalidade de tratamento, vale ressaltar que o resultado terapêutico na epilepsia pode ser descrito pela condição de vida do indivíduo, após uma intervenção médica, e esta deve ser melhor do que se estivesse sem o tratamento. Na epilepsia, como em outras doenças o resultado desejável é a cura, eliminar, reduzir os sintomas ou postergar o curso da doença ${ }^{(2,15)}$.

\subsection{ADESÃO E COMPLEXIDADE TERAPÊUTICA}

$\mathrm{Na}$ epilepsia, o objetivo do tratamento medicamentoso é eliminar ou reduzir a frequência das crises, assim como sua gravidade e seu impacto no trabalho, nas relações familiares e sociais. Entretanto, uma vez que os pacientes fazem uso das DAEs, também é fundamental identificar fatores modificáveis que podem afetar o controle das crises, tais como: estresse, privação de sono e sobretudo a baixa adesão ao tratamento ${ }^{(34)}$.

Segundo a Organização Pan-Amaricana da Saúde (OPAS) ${ }^{(35)}$, a adesão ao tratamento é a medida, segundo a qual o comportamento de uma pessoa, como por exemplo, utilizar uma medicação, seguir uma dieta, e/ou adotar mudanças no hábito de vida está de acordo com as recomendações de um profissional de saúde. O conceito de adesão varia entre os autores, porém, de uma forma geral, é compreendido como o uso dos medicamentos prescritos ou outros procedimentos em, pelo menos, $80 \%$ de seu total, observando horários, doses e tempo de tratamento ${ }^{(35)}$. 
Os termos utilizados na língua inglesa adherence $e$ compliance têm significados diferentes. Compliance pode ser traduzido como obediência, "cumprimento de algo", pressupõe um papel passivo do paciente e adherence, em nossa língua, adesão ou aderência, é o termo utilizado para identificar uma escolha livre das pessoas de adotarem ou não certa recomendação ${ }^{(36)}$. Tendo em vista essas observações, optou-se na atual pesquisa pelo uso do termo adesão terapêutica.

A adesão deve ser compreendida como uma ação conjunta entre profissional e paciente: quando o paciente adere ao tratamento, ele não só obedece às orientações médicas, mas as compreende, concorda e segue a prescrição ${ }^{(36,37)}$.

Ao estudarem a terapêutica entre pacientes HIV positivo, Gagne e Godin $(2005)^{(38)}$ alertaram para a gravidade do problema da não adesão ao tratamento entre esses pacientes, assim como no tratamento de outras doenças crônicas como hipertensão, diabetes e asma.

Muitos são os fatores determinantes para a não adesão ao tratamento indicados na literatura: fatores sociais e econômicos, fatores relacionados à equipe e ao sistema de saúde, fatores relacionados à condição da doença, fatores relacionados ao tratamento ${ }^{(39,40,41,42)}$.

A falta de acesso ao medicamento é um dos fatores mais citados na literatura e relacionados com a não adesão terapêutica. O mercado farmacêutico está concentrado nos países economicamente mais ricos e voltado às classes sociais mais abastadas. Apesar das despesas com medicamentos representarem grande parte dos investimentos em Saúde Pública; em países como o Brasil, a dispensação gratuita não cobre a demanda ${ }^{(36)}$.

Alguns autores ${ }^{(43,44)}$ reiteram que os fatores que influenciam na adesão estão relacionados às atitudes do paciente diante das orientações fornecidas pela equipe da saúde e separam os fatores em técnicos (relacionados à terapêutica medicamentosa); biológicos; psicológicos; sociais e mistos.

Os fatores técnicos referem-se aos medicamentos, rotinas, administração, apresentação das drogas, quantidade diária consumida e dificuldade para a deglutição. 
Carla Maria Maluf Ferrari

Os fatores relacionados à terapêutica exercem papel decisivo no grau de adesão ao tratamento. A quantidade de medicamento e a posologia complexa influenciam negativamente no processo ${ }^{(45,46)}$.

Os fatores biológicos referem-se à farmacocinética das drogas; absorção, distribuição e eliminação do medicamento. Efeitos indesejáveis da medicação, ou seja, colaterais, tóxicos e idiossincrásicos tornam os pacientes receosos de manter o tratamento e provocam desconfiança em relação à capacidade da equipe médica. Pacientes com manifestações indesejáveis da droga tendem a diminuir a dose por conta própria ou abandonar o tratamento.

Os fatores psicológicos estão voltados às características afetivas e emocionais frente à epilepsia, incluindo a negação do diagnóstico, autoestima diminuída, descrédito e desânimo frente às orientações e vergonha das crises.

Os fatores sociais dizem respeito à interação do paciente com o meio e os valores sociais aceitos pelo indivíduo. Como exemplo, a dificuldade financeira para aquisição do medicamento, as fantasias relacionadas ao diagnóstico e aos medicamentos, as repercussões das drogas e da epilepsia sobre as atividades diárias, percepção desfavorável em relação ao custo-benefício do tratamento, impedimentos religiosos, familiares, no trabalho ou na escola para tomar a medicação. Além disso, alguns pacientes julgam o remédio desnecessário, não tomam a droga para ingestão de bebida alcoólica ou para verificar se estão curados e, ainda, substituem o medicamento seguindo conselho de terceiros ${ }^{(44)}$.

Por outro lado, o suporte social, atitudes positivas em relação à epilepsia e o medo de novas crises são importantes fatores relacionados à tomada correta da medicação. $\mathrm{O}$ apoio de familiares e amigos também é essencial para a autoconfiança do paciente; muitas vezes, essas pessoas oferecem incentivos, utilizam comunicação persuasiva, minimizam os pontos negativos e salientam os aspectos importantes da medicação e, assim, contribuem para melhor adesão ao tratamento e, na maioria dos casos, conseguem que o indivíduo tenha suas crises controladas ${ }^{(6)}$.

Mensurar a adesão é uma tarefa complexa e difícil ${ }^{(47)}$. Na ausência de um padrão ouro para avaliar a adesão, múltiplas medidas são utilizadas, como: contagem de pílulas, autorrelato do paciente, marcadores laboratoriais, acompanhamento direto 
Carla Maria Maluf Ferrari

da tomada do medicamento e outros. A contagem de comprimidos ou de refil pode superestimar a real adesão, pois os pacientes facilmente podem desprezar as doses em lugar de ingeri-las ${ }^{(38)}$. Existe a base de dados de centrais farmacêuticas informatizadas, porém o conhecimento é sobre a aquisição, o que não garante a tomada da medicação ${ }^{(45)}$. O registro em um diário também tem uma utilidade limitada na avaliação da adesão, pois a maioria dos pacientes não segue as instruções dadas ou preenche o diário pouco antes da visita ao médico ${ }^{(40)}$. Os autorrelatos dos pacientes ou cuidadores dificultam a quantificação, pois é uma avaliação subjetiva e a adesão pode ser superestimada ${ }^{(45)}$.

No estudo da adesão ao tratamento medicamentoso de indivíduos com epilepsia, a dosagem sérica das DAEs tem sido um parâmetro importante. $\mathrm{Na}$ Alemanha, estudo realizado com 52 pacientes do Centro de Epilepsia de Bethel evidenciou em seus resultados associação entre o baixo nível sérico da droga no período pós-ictal e baixa adesão terapêutica ${ }^{(46)}$. Handoko et al. $(2008)^{(34)}$, também demonstraram em estudo realizado em um hospital-escola no Sul da Holanda, clara associação entre a baixa concentração sérica da DAE e a ocorrência de crise

Segundo Ben-Menachem et al. (2010) ${ }^{(47)}$, a dosagem do nível sérico da droga ou concentração urinária são os métodos mais precisos para mensurar a adesão, mas também são invasivos e pouco práticos para grandes populações. $O$ acompanhamento direto da tomada do medicamento só é viável com dose única ou no tratamento entre os pacientes que estão hospitalizados, ou sob assistência contínua da enfermagem.

Questionários também são utilizados para avaliar a adesão ou não à medicação, e a praticidade desses instrumentos torna-os ferramentas comumente utilizadas para avaliação da adesão. Eles são relativamente baratos, convenientes e aplicáveis, tanto na clínica diária como nas investigações científicas ${ }^{(47,48)}$.

O Teste de Morisky ${ }^{(49)}$ é um desses questionários, que tem a finalidade de identificar o grau de adesão ao tratamento medicamentoso prescrito, assim como permite avaliar o comportamento do paciente em relação ao uso diário do medicamento. $\mathrm{O}$ teste consiste de quatro perguntas e permite avaliar se a não adesão é decorrente de um comportamento intencional ou não, apesar dos baixos valores 
Carla Maria Maluf Ferrari

referentes à sensibilidade, este teste já foi utilizado em vários estudos e também traduzido e aplicado no Brasil ${ }^{(50-55)}$.

Além disso, McAuley et al. (2008) ${ }^{(56)}$, avaliaram em pacientes com epilepsia a adesão terapêutica e o comportamento do autocuidado. Utilizaram nessa investigação o Teste de Morisky e a Epilepsy Self-Management Scale, composta por cinco subitens e um, entre eles, relacionado à medicação. Os resultados mostraram que os pacientes com alta adesão também obtiveram altos escores na subescala de autocuidado com a medicação, portanto, o Teste de Morisky apresentou convergência com outras medidas relacionadas à medicação quando aplicado em pacientes com epilepsia.

A importância da complexidade terapêutica na adesão ao tratamento é bem documentada na literatura internacional ${ }^{(2,9-12,57)}$; que vem sendo constatada não só em indivíduos recém diagnosticados, mas também naqueles em tratamento por longos períodos. Pesquisa realizada com 661 pacientes, com epilepsia e em tratamento há 10 anos, mostrou relação entre o esquecimento da tomada da medicação e a ocorrência de crises e também evidenciou que a grande complexidade terapêutica acarreta o esquecimento da tomada da medicação e em consequência aumenta a probabilidade de ocorrência das crises epilépticas ${ }^{(57)}$.

A complexidade medicamentosa consiste nas múltiplas características do regime prescrito, incluindo o número de diferentes medicações no esquema terapêutico, o número de unidades por dose, o número total de doses por dia e os cuidados na administração dos medicamentos, tais como: ingerir em jejum, tomar no momento das refeições, amassar o comprimido e outros ${ }^{(4)}$.

$\mathrm{Na}$ busca de instrumentos que avaliam a complexidade terapêutica de pacientes, encontrou-se o Medication Regimen Complexity Index ${ }^{(58)}$, um instrumento traduzido e validado para o português que mensura a complexidade medicamentosa do tratamento de diferentes doenças, porém não contempla as especificidades do paciente com epilepsia.

DiIorio et al. (2003) ${ }^{(11)}$ desenvolveram e validaram o Epilepsy Medication Complexity Index ${ }^{(11)}$, instrumento elaborado para medir especificamente a complexidade terapêutica entre pacientes adultos com epilepsia. É um instrumento 
Carla Maria Maluf Ferrari

que se originou baseado na modificação do Medication Complexity Tool. Originalmente, o Epilepsy Medication Complexity Index que foi desenvolvido nos Estados Unidos da América (EUA) demonstrou boa confiabilidade e validade, após análises psicométricas: confiabilidade entre avaliadores, teste-reteste, validade de critério e construto.

Recentemente, o Epilepsy Medication Complexity Index foi traduzido para a língua portuguesa e denominado Índice de Complexidade do Tratamento Medicamentoso em Epilepsia (ICTME). Os procedimentos para tradução e adaptação do instrumento foram baseados nas recomendações de Beaton, Bombardier,Guillemin ${ }^{(59)}$; tradução do instrumento para o português, tradução de volta para a língua de origem (back translation), avaliação da equivalência entre o instrumento original e a versão da back-translation e o pré-teste. Após esses procedimentos, foram analisados a a confiabildade e a validade da versão brasileira do ICTME. Para estimativa da confiabilidade interobservador, aplicou-se o coeficiente de correlação intraclasse e, para estimativa da validade, foi realizada a análise da associação da pontuação média do ICTME com as variáveis: número das DAEs, controle de crises, percepção do paciente em relação ao controle de crises e adesão terapêutica por meio do uso do Teste de Morisky. O coeficiente de correlação intraclasse variou de 0,721 a 0,999 . Houve associação significante entre a média do ICTME e as variáveis estudadas. Os resultados dessa investigação indicaram que a versão em português do instrumento é confiável e válida para aplicação clínica no Brasil $^{(60)}$.

O ICTME é um questionário dividido em quatro partes que abordam as informações gerais sobre a medicação, frequência de administração, instruções e ações especiais para tomar o medicamento ${ }^{(11)}$.

Neste questionário, as informações contidas são úteis para descrever questões relacionadas ao tratamento e à adesão de pessoas com epilepsia. De acordo com os autores, tomar a medicação prescrita requer que a pessoa tome o medicamento correto, no horário e dose corretos, e também que o paciente siga instruções específicas, desde o preparo da medicação até tomar o medicamento em jejum, nas refeições ou em dias alternados ${ }^{(11)}$. 
Carla Maria Maluf Ferrari

A não adesão ao tratamento medicamentoso está diretamente relacionada ao não controle das crises, perda de emprego, acidentes automobilísticos, enfim piora na qualidade de vida dos indivíduos com epilepsia ${ }^{(6)}$.

Assim como a adesão ao tratamento, a qualidade de vida é reconhecida como um importante indicador da qualidade do sistema de saúde e da habilidade do paciente adaptar-se à doença e tratamento.

\subsection{QUALIDADE DE VIDA}

No contexto da saúde, avaliações da qualidade de vida tornaram-se práticas frequentes e importantes para pesquisa, acompanhamento clínico, planejamento de ações e de políticas, alocação de recursos e avaliação de programas, sobretudo em países desenvolvidos. Qualidade de vida tem sido usada substituindo indicadores de saúde tradicionais, como taxas de morbidade e capacidade funcional em estudos clínicos, e é o principal indicador de pesquisas avaliativas de resultados de intervenções. A importância de seu emprego no campo da saúde reflete se no aumento exponencial de publicações na literatura científica ${ }^{(16)}$.

O grupo de qualidade de vida da Organização Mundial da Saúde (OMS) definiu qualidade de vida, como sendo a percepção da pessoa em relação à sua vida abrangendo cultura, expectativas, sistema de valores, padrões e preocupações. A qualidade de vida representa a competência humana de direcionar a vida para conquistas positivas e além da saúde inclui educação, acesso aos serviços de saúde, satisfação e condições dignas de trabalho ${ }^{(61)}$.

Os primeiros conceitos de qualidade de vida foram publicados na década de 1970, período em que era reconhecida, como uma vaga entidade sobre a qual muitos falavam, mas, na realidade não sabiam do que se tratava ${ }^{(16)}$. No início da década de 1990, estudiosos da área começaram a considerar a definição de qualidade de vida sob o aspecto da subjetividade, ou seja, a percepção da pessoa sobre seu estado de saúde e sobre os aspectos não médicos de seu contexto de vida; por isso, o indivíduo 
Carla Maria Maluf Ferrari

passou a avaliar sua situação pessoal, substituindo a atuação de um observador que, na maioria das avaliações, se tratava de um profissional da saúde ${ }^{(62)}$.

Fazer uso do termo qualidade de vida implica em um processo de avaliação de como se vive e qual o contexto em que se processa esse viver. Envolve um amplo encadeamento de ideias, afetado de uma maneira complexa pela saúde física do indivíduo, estado psicológico, nível de independência e relacionamentos sociais ${ }^{(61)}$.

Trata-se, portanto, de um conceito multidimensional que inclui muitos domínios, relacionados às funções físicas, psicológicas e sociais. Tendo em vista o caráter de multidimensionalidade do construto da qualidade de vida, seu conceito é composto de diferentes dimensões que se busca contemplar nos processos de avaliação $^{(62)}$.

Atualmente, existem duas tendências para conceituar qualidade de vida que estão projetadas nos instrumentos de avaliação utilizados para mensurar esse fenômeno: a primeira como um conceito genérico, observado no instrumento de avaliação da Organização Mundial da Saúde que avalia a qualidade de vida em uma perspectiva internacional e transcultural, incluindo pessoas saudáveis da população e não se restringindo às parcelas da população com problemas de saúde (World Health Organization Quality Of Life Assessment - WHOQOL-100). A segunda conceituação, está diretamente associada a grupos específicos com problemas de saúde ${ }^{(16)}$.

A expressão qualidade de vida relacionada à saúde é definida como o valor atribuído à vida, ponderado pelas deteriorações funcionais; as percepções e condições sociais que são induzidas pela doença, agravos, tratamentos e pela organização política e econômica do sistema assistencial ${ }^{(63,64)}$.

Os termos qualidade de vida e estado de saúde, muitas vezes, aparecem na literatura como sinônimos, porém os dois construtos são diferentes. Alguns pesquisadores interessados em desvendar esses conceitos investigaram a importância das três dimensões: saúde mental, funcionamento físico e funcionamento social na percepção da qualidade de vida e do estado de saúde de pacientes com enfermidades crônicas (câncer, hipertensão, HIV positivo e outras). A dimensão que mais influenciou o escore da qualidade de vida foi a da saúde mental/bem-estar 
Carla Maria Maluf Ferrari

psicológico. Resultado diferente foi observado em relação à percepção do estado de saúde em que a dimensão funcionamento físico destacou-se, incluindo variáveis como energia, fatiga e dor ${ }^{(16)}$.

Não obstante, a qualidade de vida relacionada à saúde e estado subjetivo de saúde são conceitos centrados na avaliação subjetiva do paciente e ligados necessariamente ao impacto do estado de saúde sobre a capacidade do indivíduo de viver plenamente ${ }^{(65)}$.

Souza $(2001)^{(66)}$ sintetiza vários aspectos relacionados à qualidade de vida nas seguintes afirmações: qualidade de vida é um termo subjetivo baseado na perspectiva de vida do indivíduo; o paciente é a pessoa que melhor pode definir sua própria qualidade de vida e relatar suas expectativas, satisfação e bem-estar. O termo qualidade de vida relacionado à saúde está diretamente associado às enfermidades ou às intervenções em saúde, e os instrumentos de mensuração dão ênfase aos sintomas, incapacidades ou limitações ocasionados pelas enfermidades.

Autores que avaliaram a qualidade de vida de indivíduos adultos com epilepsia, utilizando o SF-12 Health Survey obtiveram escore significativamente mais baixo nos não aderentes ao tratamento e ao utilizarem o questionário que avalia saúde e trabalho, Health Work Questionnaire, observaram que os não aderentes apresentavam maior esquecimento ou desistência de frequentar a escola ou trabalho em razão de problemas com a memória decorrente das crises, ou por enfrentarem situações constrangedoras pela ocorrência de crises epilépticas em frente a um colega de classe ou trabalho ${ }^{(7)}$.

$\mathrm{Na}$ epilepsia, a não adesão ao tratamento medicamentoso está diretamente relacionada ao não controle das crises, piora na qualidade de vida, diminuição da produtividade e perda do emprego devido às crises. Pacientes não aderentes têm maior probabilidade de serem demitidos do trabalho, de abandonar o emprego ou a escola e ainda de serem acometidos por depressão, quando comparados aos aderentes $^{(7)}$.

Quantificar e monitorar os aspectos físicos, psicológicos, emocionais, sociais educacionais e vocacionais do indivíduo com epilepsia são possíveis pelos instrumentos de avaliação da qualidade de vida, elaborados especificamente para 
Carla Maria Maluf Ferrari

essas pessoas. Estes instrumentos podem ajudar o profissional a conhecer o impacto da doença na qualidade de vida e também compreender a repercussão das crises no trabalho, escola, relacionamento familiar, atividades sociais e autoestima ${ }^{(67)}$.

Em outros países, existem vários instrumentos desenvolvidos que avaliam a qualidade de vida de indivíduos com epilepsia: o Quality of Life in Epilepsy Inventory-89 (QOLIE-89), o Liverpool Assessment Battery, o Epilepsy-Surgery Inventory (ESI-55), o Washington Psychosocial Inventory, o Epilepsy Foundation of America's (EFA) Concerns Index e o Quality of Life in Epilepsy Inventory-31 (QOLIE-31). Os domínios abordados nesses instrumentos são o funcionamento físico, psicológico (saúde mental), social, conquistas pessoais, estigma e o impacto da doença para o paciente com epilepsia ${ }^{(67)}$.

O Questionário QOLIE-31 é um instrumento derivado do QOLIE-89, que foi desenvolvido nos Estados Unidos da América publicado em $1993^{(68)}$, objetivando medir a qualidade de vida relacionada à saúde das pessoas com epilepsia. Os itens que compõem a forma abreviada QOLIE-31 foram empiricamente selecionados do QOLIE-89 com base nas questões mais relevantes às pessoas com epilepsia ${ }^{(69,70)}$.

O QOLIE-31 foi traduzido e adaptado para nossa cultura ${ }^{(71,72)}$. A confiabilidade mensurada pela análise da consistência interna variou de 0,67 a 0,93 , foi alta em todos os domínios com exceção do escore total $(0,67)$; no teste-reteste e na confiabilidade interobservador os coeficientes de correlação foram acima 0,90 . Os resultados apontaram para boa confiabilidade no uso do instrumento ${ }^{(72)}$.

A validade de construto do questionário foi estimada por meio da análise da associação entre os domínios do QOLIE-31 e os instrumentos: Perfil de Saúde de Nottingham, desenvolvidos para avaliar qualidade de vida em pacientes com doenças crônicas, Anti-epileptic Adverse Events Profile, escala utilizada para mensurar os efeitos adversos apresentados pelos pacientes medicados com DAEs e Inventário de Depressão de Beck. Para validação do QOLIE-31, foi também analisada a associação entre os domínios do questionário e os resultados de avaliação neuropsicológica ${ }^{(72)}$.

$\mathrm{Na}$ validade do construto, associações foram observadas na maioria das hipóteses testadas; portanto, os resultados da investigação também indicaram boa validade da versão em Português para o Brasil do QOLI-31 ${ }^{(72)}$. 
Segundo Silva et al. (2006) ${ }^{(71)}$, o QOLIE-31 é o questionário mais usado mundialmente em indivíduos com epilepsia, por ser breve e de fácil avaliação. Vários países já o traduziram e adaptaram a seu idioma e cultura. Além da língua portuguesa, a tradução também está disponível nas línguas africana, árabe, dinamarquesa, russa, polonesa, norueguesa, sueca, neerlandesa, finlandêsa, belga, hebraíca, inglesa (Austrália, Reino Unido e USA) ${ }^{(71)}$, alemã ${ }^{(73)}$, japonesa ${ }^{(74)}$, espanhola ${ }^{(75)}$, francesa (Canadá e França) ${ }^{(76)}$, italiana ${ }^{(77)}$ e checa ${ }^{(78)}$.

De acordo com o que foi exposto e baseado nos conceitos apresentados, foram elaborados os objetivos deste estudo que pretendeu, por meio do uso de instrumentos e métodos adequados, elucidar, em nosso meio, aspectos relacionados à complexidade terapêutica, à adesão e à qualidade de vida de pacientes com epilepsia. 


$$
1
$$




\section{OBJETIVOS}

\subsection{GERAL}

Descrever a adesão ao tratamento de indivíduos com epilepsia e a qualidade de vida, evidenciando associações com as características do paciente, doença, terapêutica e suporte social.

\subsection{ESPECÍFICOS}

1. Explicitar a complexidade do tratamento medicamentoso de pacientes epilépticos, segundo o ICTME.

2. Descrever a adesão do paciente ao tratamento de epilepsia, segundo o Teste de Morisky.

3. Relatar a qualidade de vida dos pacientes por meio da utilização do questionário QOLIE-31.

4. Identificar os fatores associados à não adesão terapêutica.

5. Identificar os fatores relacionados à qualidade de vida. 


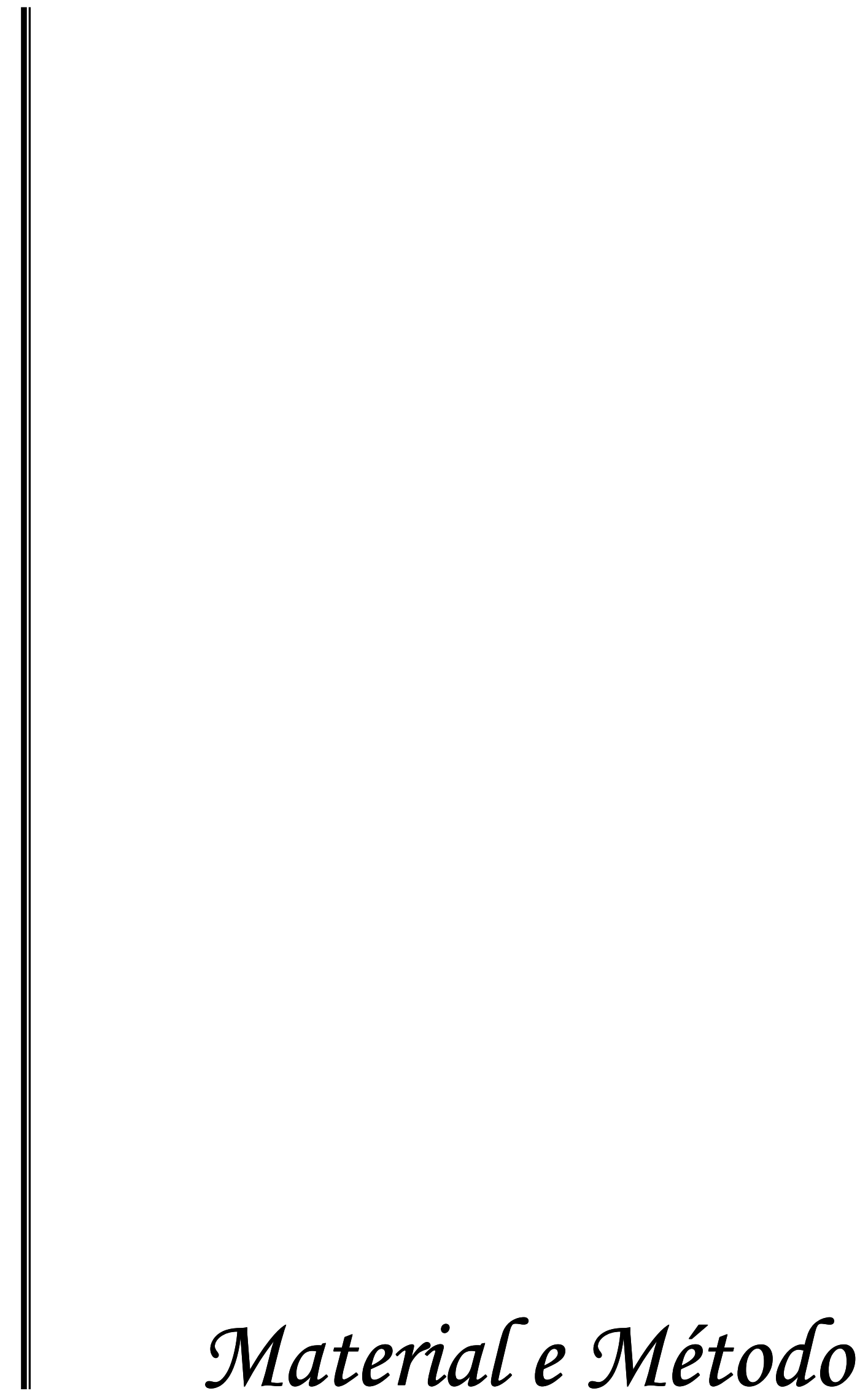




\section{MATERIAL E MÉTODO}

Estudo prospectivo, transversal, com análise descritiva e correlacional, objetivando conhecer a complexidade terapêutica, a adesão ao tratamento e a qualidade de vida de indivíduos com epilepsia, além de identificar fatores relacionados a esses dois últimos parâmetros.

\subsection{LOCAL DO ESTUDO}

O estudo foi realizado no Ambulatório de epilepsia de adultos da divisão de clínica neurológica do Hospital das Clínicas da Faculdade de Medicina da Universidade de São Paulo (HCFMUSP), referência no tratamento da epilepsia, localizado na região centro oeste do Município de São Paulo.

O serviço atende pacientes encaminhados de qualquer região do Brasil e também de São Paulo. Às segundas-feiras à tarde, ocorrem as atividades da Liga de Epilepsia, com atendimento por alunos da Faculdade de Medicina da Universidade de São Paulo e respectivos preceptores; e às sextas-feiras, os atendimentos são realizados por residentes e pelo médico responsável pelo ambulatório. As características dos dois atendimentos diferem à medida que os pacientes agendados às sextas-feiras apresentam maior complexidade da doença. $\mathrm{Na}$ liga, estão cadastrados 240 pacientes e ocorre uma média de 15 atendimentos semanais e, às sextas-feiras estão cadastrados 3.000 pacientes, $1.500 \mathrm{em}$ atendimento ativo, sendo cerca de $60-80$ pacientes/ semana.

\subsection{CASUÍSTICA}

A casuística constituiu-se de indivíduos com epilepsia, que atenderam aos seguintes critérios de elegibilidade: ter idade igual ou superior a 18 anos, ser alfabetizado, independente nas atividades da vida diária, sem deficiência mental ou 
alteração psíquica ativa diagnosticada no período da entrevista e aceitar participar do estudo, assinando o Termo de Consentimento Livre e Esclarecido (TCLE), apresentado no Apêndice A.

Os critérios de elegibilidade foram estabelecidos, tendo em vista os instrumentos utilizados na coleta de dados. Estes requeriam que os participantes tivessem capacidade instrucional e cognitiva para compreender e responder às questões, além disso, para aplicação do QOLIE-31 era também necessário o acompanhamento da leitura do questionário pelo paciente.

A amostragem foi não aleatória e todos os pacientes que atenderam aos critérios de elegibilidade e compareceram ao ambulatório de epilepsia, após o início da coleta de dados foram incluídos na casuística, até que o número estimado da amostra fosse atingido.

Para o cálculo do tamanho da amostra, foi consultado especialista na área e foi considerada a hipótese principal que tem como foco as análises de adesão ao tratamento. Para um tamanho de amostra mais conservador, foi estipulado que a proporção esperada (p) de pacientes com alta adesão ao tratamento é de $50 \%$. Com base nesse pressuposto, estimou-se uma amostra de 385 pacientes, para um nível de confiança de $95 \%$ e margem de erro arbitrada de $0,05^{(79)}$.

\subsection{VARIÁVEIS DO ESTUDO}

Nas análises de relações entre variáveis, estas foram consideradas dependentes e independentes e categorizadas de forma dicotômica nos casos de variáveis nominais.

\subsubsection{Variáveis dependentes:}

Adesão terapêutica: para avaliação da adesão terapêutica, foi aplicado o Teste de Morisky (Apêndice B). As respostas foram avaliadas utilizando-se uma forma de 
medida ordinal que considera pacientes com alta adesão os que respondem negativamente as quatro questões, adesão média, quando a resposta afirmativa é observada em uma ou duas questões e adesão baixa se mais de duas respostas afirmativas foram apresentadas pelos pacientes. Para análise de associação, essas categorias foram reunidas de forma dicotômica e os pacientes foram agrupados em alta perante média/baixa adesão.

Qualidade de Vida Relacionada à Saúde: variável numérica contínua, foi avaliada por meio do questionário QOLIE-31 traduzido e validado para a língua portuguêsa ${ }^{(71,72) \text {, }}$ (Apêndice $\mathrm{C}$ ). O escore total do instrumento foi o parâmetro para as análises de associação entre qualidade de vida relacionada à saúde e as variáveis independentes deste estudo.

\subsubsection{Variáveis independentes}

\subsubsection{Variáveis sóciodemográficas}

Idade: variável numérica contínua considerada em anos e referida pelo paciente no dia da entrevista.

Sexo: categoria nominal dicotômica

Vínculo conjugal: categoria nominal que classificou os pacientes em dois grupos: dos casados, que viviam em companhia de cônjuge ou companheiro e dos não casados, grupo que incluiu os solteiros, separados e viúvos.

Raça: para categorização dos participantes da pesquisa, segundo esta variável foi utilizada a informação do paciente, não se considerando a observação do entrevistador. Para análise de associação, as categorias foram reunidas em brancos/ amarelos e pardos/negros.

Religião: variável categórica nominal considerada a informada pelo paciente e categorizada nas análises de associação em dois grupos; dos que referiram alguma religião e dos que informaram nenhuma religião. 
Escolaridade: variável categórica nominal registrada, conforme a série que o indivíduo informou ter estudado. Nas análises de relação entre as variáveis, os respondentes foram incluídos em duas categorias ensino Fundamental I e II incompleto ou completo e escolaridade maior que Fundamental.

Situação ocupacional: para categorização desta variável, os pacientes foram agrupados em inseridos no mercado de trabalho (empregado e autônomo), e os que não estavam inseridos no mercado de trabalho (auxílio-doença, aposentado, desempregado, nunca trabalhou, estudante e do lar)

Renda per capita: para categorização dos participantes da pesquisa, segundo esta variável, foi utilizada a informação do paciente quanto à renda familiar e calculada a renda per capita pela divisão desse valor pelo número de dependentes dessa renda.

\subsubsection{Variáveis relacionadas à doença}

Diagnóstico médico: variável categórica nominal. Informação registrada, após consulta no prontuário médico, sendo considerada a classificação proposta pela International League Against Epilepsy no ano de $1989^{(19)}$.

Tempo que conhece o diagnóstico da doença: variável numérica contínua medida em anos, referente há quanto tempo sabe que tem epilepsia.

Tempo de tratamento: variável quantitativa, medida em anos que expressa o tempo de tratamento para a epilepsia considerando-se a data do primeiro esquema terapêutico, mesmo que tenha ocorrido interrupção.

Frequência das crises nos últimos 30 dias: informação obtida com o paciente e acompanhante, referente a quantas crises apresentou no último mês. Nas análises de associação dois grupos foram considerados; os participantes que apresentaram crises nos últimos 30 dias e os que não apresentaram.

Percepção sobre o controle das crises com o tratamento: as respostas da entrevista categorizaram os sujeitos em controlados, não controlados e nem sempre 
Carla Maria Maluf Ferrari

controlados. Nas análises de associação, o grupo dos nem sempre controlados foram reunidos aos dos não controlados.

Controle das crises: variável dicotômica em que pacientes que não apresentaram crises nos últimos 6 meses, antes da entrevista foram considerados controlados e os demais, não controladas.

\subsubsection{Variável relacionada ao apoio familiar}

Apoio familiar: variável categórica nominal que classificou o apoio familiar ou de amigos em: contínuo quando a resposta à pergunta 4.1 do Apêndice D foi sim, e sempre à pergunta 4.2; intermitente, quando as respostas a essas perguntas foram sim e quase sempre, respectivamente; raro, quando a resposta foi afirmativa na questão 4.1, porém raramente na pergunta 4.2. O apoio familiar e social foi considerado ausente nos casos de respostas negativas no item 4.1 do questionário (Apêndice D). Na análise de associação, essa variável foi categorizada em dois grupos sempre/quase sempre e raramente/não tem apoio.

\subsubsection{Variáveis relacionadas à terapêutica medicamentosa}

Número das DAEs: nas análises de associação, essa variável reuniu os participantes em dois grupos; os em uso de monoterapia e politerapia.

Complexidade terapêutica: a pontuação total do ICTME (Apêndice E) foi utilizada nas análises deste estudo. Pacientes que necessitam de várias medicações, portanto, com mais de um medicamento prescrito em seu regime terapêutico, tiveram seu escore total calculado pela soma da pontuação de todas as drogas prescritas, obtendo-se assim um único escore que indicou a complexidade de seu tratamento.

Adesão terapêutica: nas análises de associação relacionadas à qualidade de vida também foi incluída, como variável independente, a adesão terapêutica mensurada pelo o Teste de Morisky (Apêndice B). 
Carla Maria Maluf Ferrari

4.3.2.5 Variáveis relacionadas ao Sistema de Saúde:

Forma de aquisição das DAEs: as respostas referentes a essa variável foram agrupadas em serviço público e privado.

Procedimento quando falta medicação: os procedimentos foram categorizados em fica sem tomar a medicação, compra a medicação e outro. Nas análises de associação, reuniram-se as duas últimas categorias.

Frequência das consultas médicas: variável numérica contínua, mensurada em dias. Expressa o período entre as consultas médicas no ambulatório de epilepsia.

Facilidade de agendamento da consulta médica: em relação a essa variável, os participantes foram categorizados em dois grupos; os que consideraram ser fácil o agendamento de consultas médicas no ambulatório e os demais que responderam que não ou nem sempre é fácil.

Consulta extra: variável nominal classificada, conforme a resposta do entrevistado em relação à disponibilidade do serviço para consulta médica extra. $\mathrm{Na}$ análise de associação foram considerados dois grupos; os que responderam que sempre tem vaga/na maioria das vezes tem vaga/nunca precisou e dos que informaram que, de vez em quando tem vaga/nunca tem vaga.

Qualidade do atendimento médico: A classificação foi realizada, conforme as respostas dos entrevistados e categorizada em muito bom /bom e ruim/não opinaram.

Percepção do estado de saúde, após início do tratamento no ambulatório: variável nominal, categorizada para análise de associação em dois grupos; dos que se sentem melhor (muito melhor/melhor) e dos que não percebem melhora (um pouco melhor/não melhorou nada/não sabe).

\subsection{INSTRUMENTOS DE COLETA DE DADOS}

Durante a coleta de dados, foram aplicados os cinco instrumentos descritos a seguir: 
Carla Maria Maluf Ferrari

\section{1) Termo de Consentimento Livre e Esclarecido ( Apêndice A)}

Utilizado para obter o consentimento do paciente de participação na pesquisa. Compreende os dados sobre a pesquisa, informações sobre o responsável pelo estudo e sobre o pesquisador, também oferece garantias de sigilo dos dados individuais e de ausência de prejuízos em consequência da desistência ou não participação na pesquisa.

\section{2) Formulário para entrevista.(Apêndice D)}

Impresso elaborado pela autora para coleta dos dados de caracterização da amostra em relação à quase totalidade das variáveis independentes. Utilizado para direcionar a coleta de informações na entrevista com os pacientes.

\section{3)ICTME (Apêndice E),}

Versão traduzida do Epilepsy Medication Complexity Índex que foi aplicado segundo instruções dos autores do instrumento original. As instruções sobre o uso do instrumento estão apresentadas no Apêndice F.

4) Teste de Morisky (Apêndice B).

Instrumento aplicado em forma de entrevista para avaliação da adesão terapêutica. É constituído por quatro questões que se respondidas de forma afirmativa indicam um comportamento de não adesão ao tratamento. No Apêndice F, apresentam-se as instruções que foram seguidas em sua aplicação.

\section{5) QOLIE-31 (Apêndice C).}

Instrumento aplicado em forma de entrevista para avaliação da qualidade de vida dos indivíduos com epilepsia. Trata-se de um instrumento traduzido e validado para a cultura brasileira que foi aplicado, conforme as instruções apresentadas no Apêndice F. O questionário contém 31 questões, distribuídas em sete domínios: preocupação com as crises; qualidade de vida em geral; bem-estar emocional, energia e cansaço; função cognitiva, efeito medicamentoso e funcionamento social. 
Carla Maria Maluf Ferrari

As respostas inicialmente recebem um escore que varia de um a seis, posteriormente, utilizando-se a Tabela de Correção para os escores do QOLIE-31 (Anexo A), são atribuídos valores de zero a cem a essas pontuações obtendo-se os escores de cada domínio. Aplicando-se a Formula para Cálculo do Escore Geral do QOLIE-31, apresentada no Anexo A, tem-se o escore total do QOLIE-31.

Todos os instrumentos utilizados na coleta de dados apresentaram local próprio para identificação do paciente e entrevistador. Estes registros permitiram reconhecer os instrumentos aplicados em um único paciente e resgatar dados do prontuário sempre que necessário.

\subsection{OPERACIONALIZAÇÃO DA COLETA DE DADOS}

Após a aprovação da pesquisa pela Comissão de Ética para Análise de Projetos de Pesquisa da Diretoria Clinica do HCFMUSP sob o protocolo de pesquisa de $n^{0}$ 0210/09 (Anexo B), iniciou-se a coleta de dados em junho/2009. Esta foi realizada no ambulatório de epilepsia de adultos da divisão de Clínica Neurológica do HCFMUSP, todas as segundas-feiras e sextas-feiras à tarde, no período da coleta de dados. Este período foi encerrado em fevereiro de 2010, quando foi alcançado o número de pacientes estimado para o tamanho da amostra $(\mathrm{n}=385)$. Os dados referentes aos pacientes foram obtidos por meio de entrevistas e consultas aos prontuários.

Nos dias de atendimento no ambulatório e liga de epilepsia, os pacientes eram abordados na sala de espera das consultas médicas com a finalidade de identificar se atendiam os critérios de inclusão da investigação. Nesta fase, também houve a colaboração da equipe médica na indicação dos pacientes elegíveis para o estudo.

Os pacientes selecionados foram esclarecidos sobre sua participação na pesquisa que foi opcional, sem remuneração e respeitando o sigilo das informações individuais. O paciente também foi informado sobre a possibilidade de desistir a qualquer momento da pesquisa. Perante tais esclarecimentos, aqueles que concordaram participar assinaram o TCLE (Apêndice A). 
Carla Maria Maluf Ferrari

Após o consentimento do paciente, foi realizada a entrevista quando foram completados os seguintes instrumentos: Formulário para entrevista (Apêndice D); ICTME (Apêndice E); Teste de Morisky (Apêndice B) e QOLIE-31 (Apêndice C). Para aplicação do ICTME, foi usada uma folha do instrumento para cada medicamento prescrito e cada item do ICTME foi discutido com o paciente para seu preenchimento. A aplicação do questionário QOLIE-31 foi assistida, isto é, o entrevistador realizou em voz alta a leitura pausada do instrumento que foi acompanhada continuamente pelo respondente que apontou a alternativa selecionada. O ICTME, o teste de Morisky e o QOLIE-31 foram aplicados seguindo as instruções específicas do Apêndice F.

Em razão da dinâmica do ambulatório e liga de epilepsia, o acesso ao prontuário para coleta de informações referentes ao diagnóstico médico só foi possível, após as consultas; em consequência, foram excluídos e substituídos na amostra os pacientes com diagnóstico de crise não epiléptica psicogênica e/ ou com distúrbio psíquico ativo diagnosticado.

A coleta de dados foi feita pela pesquisadora, com quatro coletadoras: duas enfermeiras e duas graduandas do $7^{\circ}$ semestre do Curso de Enfermagem. Todas as coletadoras foram submetidas a treinamento realizado pela pesquisadora e aplicaram os instrumentos durante toda coleta de dados sob sua supervisão e consulta às instruções específicas descritas no Apêndice F.

\subsection{TRATAMENTO ESTATÍSTICO}

Os dados deste estudo foram submetidos a provas estatísticas, conforme orientação do especialista na área com o uso do software SPSS-18 ${ }^{\circledR}$.

Estatísticas descritivas foram realizadas para todas as variáveis, visando à caracterização geral da amostra do estudo e descrição da complexidade do tratamento medicamentoso, adesão ao tratamento e qualidade de vida dos pacientes.

Em uma primeira etapa, foram realizados testes de associação entre a variável adesão (sim/não) e as variáveis independentes qualitativas com o teste do Qui- 
Carla Maria Maluf Ferrari

Quadrado. Quando o teste do Qui-Quadrado não pode ser aplicado por conta de mais de $20 \%$ das caselas apresentarem valores esperados menores do que cinco, foi utilizado o teste da Razão de Verossimilhança.

A comparação das médias entre os grupos dos pacientes com adesão ou não, foi feita com o Teste-t de Student, quando a variável apresentou distribuição normal (verificada pelo teste de Kolmogorov-Smirnov) e homogeneidade das variâncias; caso contrário, utilizou-se o teste alternativo não paramétrico de Mann-Whitney.

A média do escore total do QOLE-31 também foi comparada com o Teste-t de Student nas variáveis qualitativas que apresentaram normalidade e homogeneidade das variâncias. Para variável diagnóstico médico, foi empregada a Análise de Variância com um fator. Para verificar a correlação entre as variáveis quantitativas e o escore total do QOLIE-31, foi usado o teste de correlação de Pearson (quando ambas as variáveis apresentaram distribuição normal) ou o teste alternativo não paramétrico de Spearman.

A regressão logística múltipla foi utilizada para identificar os fatores associados com não adesão terapêutica. Foi realizada modelagem múltipla com todas as variáveis que apresentaram $p<0,20$. Para construção desse modelo de regressão logística, foi usado o método stepwise backward onde as variáveis que apresentaram valor de $\mathrm{p}<0,20$ na análise de associação foram incluídas no início da modelagem e retiradas, seguindo a ordem de maior para menor significância. A adequação do modelo foi avaliada pela curva Receiver-Operating Characteristics (ROC).

Para o escore total do QOLIE-31 foi ajustado um modelo de regressão linear com o processo de modelagem stepwise backward. O modelo inicial foi feito com as variáveis que apresentaram $\mathrm{p}<0,20$ nas análises de comparação das médias e de correlação. O valor de "p" foi o parâmetro para retirada da variável do modelo, em uma sequência do maior para o menor. As variáveis independentes permaneceram no modelo final se $\mathrm{p} \leq 0,05$.

O diagnóstico de multicolinearidade do modelo foi realizado por meio do Fator de Inflação de Variância (FIV) e teste Tolerance, sendo valores acima de 10 no FIV e abaixo de 0,10 no teste Tolerance, considerados indicativos de problemas de multicolinearidade. 
A análise de confiabilidade do QOLIE-31 foi feita por meio do alfa de Cronbach $^{(80)}$.

Para todos os testes de hipóteses, foi utilizado o nível de 5\% de significância.

\subsection{ASPECTOS ÉTICOS}

O projeto foi avaliado e aprovado pela Comissão de Ética para Análise de Projetos de Pesquisa - CAPPesq, nº 0210/09 (Anexo B ).

Os entrevistados foram previamente informados e esclarecidos sobre o objetivo do estudo e que não haveria prejuízo em relação à assistência que recebem no ambulatório, caso optassem pela não participação . Foi solicitado para que lesem e assinassem o TCLE (Apêndice A), durante esse procedimento receberam uma cópia do termo e a garantia de que seria mantido o sigilo de sua identidade. 


$$
\text { | }
$$




\section{RESULTADOS}

\subsection{CARACTERIZAÇÃO DA AMOSTRA ATENDIDA NO AMBULATÓRIO E LIGA DE EPILEPSIA.}

A casuística do estudo compôs-se de 385 pacientes com diagnóstico de epilepsia que foram atendidos no ambulatório ou liga no período de julho de 2009 a fevereiro de 2010. Nesse período foram atendidos no ambulatório 331 pacientes e na liga de epilepsia, 54 indivíduos que atenderam aos critérios de elegibilidade e participaram do estudo.

Tabela 1 - Distribuição dos pacientes ( $\mathrm{n}=385)$, segundo a idade, sexo, vínculo conjugal, raça e religião. São Paulo, 2009-2010.

\begin{tabular}{lcc}
\hline IDADE & $\mathbf{n}^{\mathbf{0}}$ & $\mathbf{\%}$ \\
\hline$\geq 18<30$ & 101 & 26,2 \\
$\geq 30<42$ & 116 & 30,1 \\
$\geq 42<60$ & 142 & 36,9 \\
$>60$ & 26 & 6,8 \\
& Média: 39,7 & \\
& Desvio padrão: 12,6 & \\
& IC 95\%: $38,4-40,9$ & \\
& Min - Max: $18,0-76,0$ & 53,5 \\
\hline SEXO & & 46,5 \\
\hline Feminino & 206 & 45,5 \\
Masculino & 179 & 31,9 \\
VÍNCULO CONJUGAL & & 22,6 \\
\hline Casado & 175 & \\
Solteiro & 123 & 60,8 \\
Viúvo/separado & 87 & 38,2 \\
\hline RAÇA & & 1,0 \\
\hline Branca & 234 & 31,4 \\
Preta/parda & 147 & 3,9 \\
Amarela & 4 & \\
\hline RELIGIÃO & & \\
\hline Católica & 198 & \\
Protestante/evangélica & 121 & \\
Espírita & 23 & \\
Outras & 15 & \\
Nenhuma & & \\
\hline
\end{tabular}


Carla Maria Maluf Ferrari

Nos dados da Tabela 1, observa-se que a idade variou de 18 a 76 anos, a média foi de 39,7 anos (dp 12,6 anos). A maioria dos indivíduos era do sexo feminino, $53,5 \%$.

Quanto ao vínculo conjugal, 45,5\% viviam em companhia de cônjuge ou companheiro e $54,5 \%$ eram solteiros $(31,9 \%)$ e viúvos ou separados $(22,6 \%)$. Houve predomínio de indivíduos da raça branca $(60,8 \%)$ e 92,7\% declararam ter alguma religião. $\mathrm{Na}$ categoria outras religiões (3,9\%), foram incluídos os pacientes, messiânicos, budistas e testemunha de Jeová.

Tabela 2 - Distribuição dos pacientes $(n=385)$, segundo a escolaridade e situação ocupacional. São Paulo, 2009-2010.

\begin{tabular}{lrr}
\hline ESCOLARIDADE & $\mathrm{n}^{\circ}$ & $\%$ \\
\hline Fundamental I incompleto & 27 & 7,0 \\
Fundamental I completo & 47 & 12,2 \\
Fundamental II incompleto & 34 & 8,8 \\
Fundamental II completo & 35 & 9,1 \\
Médio incompleto & 24 & 6,2 \\
Médio completo & 155 & 40,3 \\
Superior incompleto & 17 & 4,4 \\
Superior completo & 40 & 10,4 \\
Pós-graduação incompleto & 1 & 0,3 \\
Curso técnico & 5 & 1,3 \\
\hline SITUAÇÃO OCUPACIONAL & & \\
\hline Empregado & 121 & 31,4 \\
Autônomo & 25 & 6,5 \\
Auxílio-doença & 31 & 8,1 \\
Aposentado & 60 & 15,6 \\
Desempregado & 102 & 26,5 \\
Nunca trabalhou & 9 & 2,3 \\
Estudante & 9 & 2,3 \\
Do lar & 28 & 7,3 \\
\hline
\end{tabular}

Quanto à escolaridade observa-se nos dados da Tabela 2, que 40,3\% dos participantes apresentaram 11 anos completos de estudo, correspondente ao nível Médio completo. $\mathrm{Na}$ amostra, não foram incluídos os analfabetos, pelo critério de 
Carla Maria Maluf Ferrari

inclusão do estudo, mesmo assim, 37,1\% dos participantes não freqüentaram o Ensino Médio e cursaram somente o nível Fundamental completo ou incompleto.

Ainda, nos dados da Tabela 2, observa-se em relação à situação ocupacional que $23,7 \%$ eram aposentados ou recebiam auxílio (15,6\% aposentados e 8,1\% recebiam auxílio-doença); 28,8\% eram desempregados ou nunca trabalharam, 9,6 \% eram estudantes ou realizavam serviços domésticos.

Tabela 3 - Distribuição dos pacientes segundo informação sobre a renda per capita (R\$). São Paulo, 2009-2010.

\begin{tabular}{lrc}
\hline Renda per capita (R\$) & $\mathbf{n}^{\mathbf{0}}$ & $\mathbf{\%}$ \\
\hline$\leq 250,00$ & 80 & 28,1 \\
$\geq 251,00 \leq 500,00$ & 98 & 34,4 \\
$\geq 501,00 \leq 750,00$ & 50 & 17,5 \\
$\geq 751,00 \leq 1000,00$ & 27 & 9,5 \\
$\geq 1001,00 \leq 1500,00$ & 14 & 4,9 \\
$>1500,00$ & 16 & 5,6 \\
\hline Sub-total & $\mathbf{2 8 5}$ & $\mathbf{7 4 , 1}$ \\
\hline Não sabem informar & 91 & 23,6 \\
Recusou informação & 9 & 2,3 \\
\hline Total & $\mathbf{3 8 5}$ & $\mathbf{1 0 0 , 0}$ \\
\hline
\end{tabular}

Nos dados da Tabela 3 , nota-se que só $74,1 \%$ dos participantes da pesquisa informaram a renda per capita. Entre eles, $62,5 \%$ apresentavam renda inferior a um salário mínimo, renda $\leq$ a $R \$ 500,00$ e renda per capita acima de $\mathrm{R} \$ 1.500,00$ foi informada por $5,6 \%$ dos participantes desta investigação. A renda per capita média foi de $\mathrm{R} \$ 627,25$; desvio padrão $\mathrm{R} \$ 851,33$ e a variação de $\mathrm{R} \$ 85,00$ a $\mathrm{R} \$ 8.000,00$. 
Carla Maria Maluf Ferrari

Tabela 4 - Distribuição dos pacientes $(n=385)$, segundo o diagnóstico médico, tempo que conhece o diagnóstico, tempo de tratamento e número de DAEs prescritas. São Paulo, 2009-2010.

\begin{tabular}{lrc}
\hline Diagnóstico Médico & $\mathbf{n}^{\mathbf{0}}$ & $\mathbf{\%}$ \\
\hline Focal sintomática & 306 & 79,5 \\
Focal criptogênica & 34 & 8,8 \\
Generalizada idiopática & 38 & 9,9 \\
Generalizada criptogênica & 7 & 1,8 \\
\hline Tempo que conhece o diagnóstico (anos) & & \\
\hline$\leq 5$ & 38 & 9,9 \\
$\geq 6 \leq 10$ & 52 & 13,5 \\
$\geq 11 \leq 20$ & 101 & 26,2 \\
$\geq 21 \leq 30$ & 91 & 23,6 \\
$\geq 31 \leq 40$ & 68 & 17,7 \\
$\geq 41$ & 35 & 9,1
\end{tabular}

Média: 22,4

Desvio padrão: 13,53

Mín - Max: 0,2 - 64

\begin{tabular}{lrr}
\hline Tempo de tratamento (anos) & & \\
\hline$\leq 5$ & 44 & 11,4 \\
$\geq 6 \leq 10$ & 55 & 14,3 \\
$\geq 11 \leq 20$ & 105 & 27,3 \\
$\geq 21 \leq 30$ & 83 & 21,6 \\
$\geq 31 \leq 40$ & 71 & 18,4 \\
$\geq 41$ & 27 & 7,0 \\
Total & 385 & 100,0
\end{tabular}

Média: 21,5

Desvio padrão: 13,2

Mín - Máx: 0,2 - 60

\begin{tabular}{lrr}
\hline Número de DAEs & & \\
\hline 1 & 111 & 28,9 \\
2 & 139 & 36,1 \\
3 & 109 & 28,3 \\
4 & 24 & 6,2 \\
5 & 2 & 0,5 \\
\hline
\end{tabular}

$\mathrm{Na}$ Tabela 4 observa-se que $79,5 \%$ dos participantes deste estudo apresentavam epilepsia focal sintomática, entre eles, $20 \%$ tinham epilepsia de lobo temporal e $34,5 \%$ esclerose mesial temporal. A média de tempo que conhece a 
Carla Maria Maluf Ferrari

doença foi de 22,4 anos, próximo ao tempo médio de tratamento que foi de 21,5 anos. Ainda na mesma tabela, observa-se que 28,9\% faziam uso de apenas uma DAE (monoterapia) para o controle das crises e 71,1\% faziam uso de duas a cinco medicações diferentes (politerapia).

Gráfico 1 - Porcentagem de pacientes, segundo prescrição dos diferentes tipos de DAEs. São Paulo, 2009-2010.

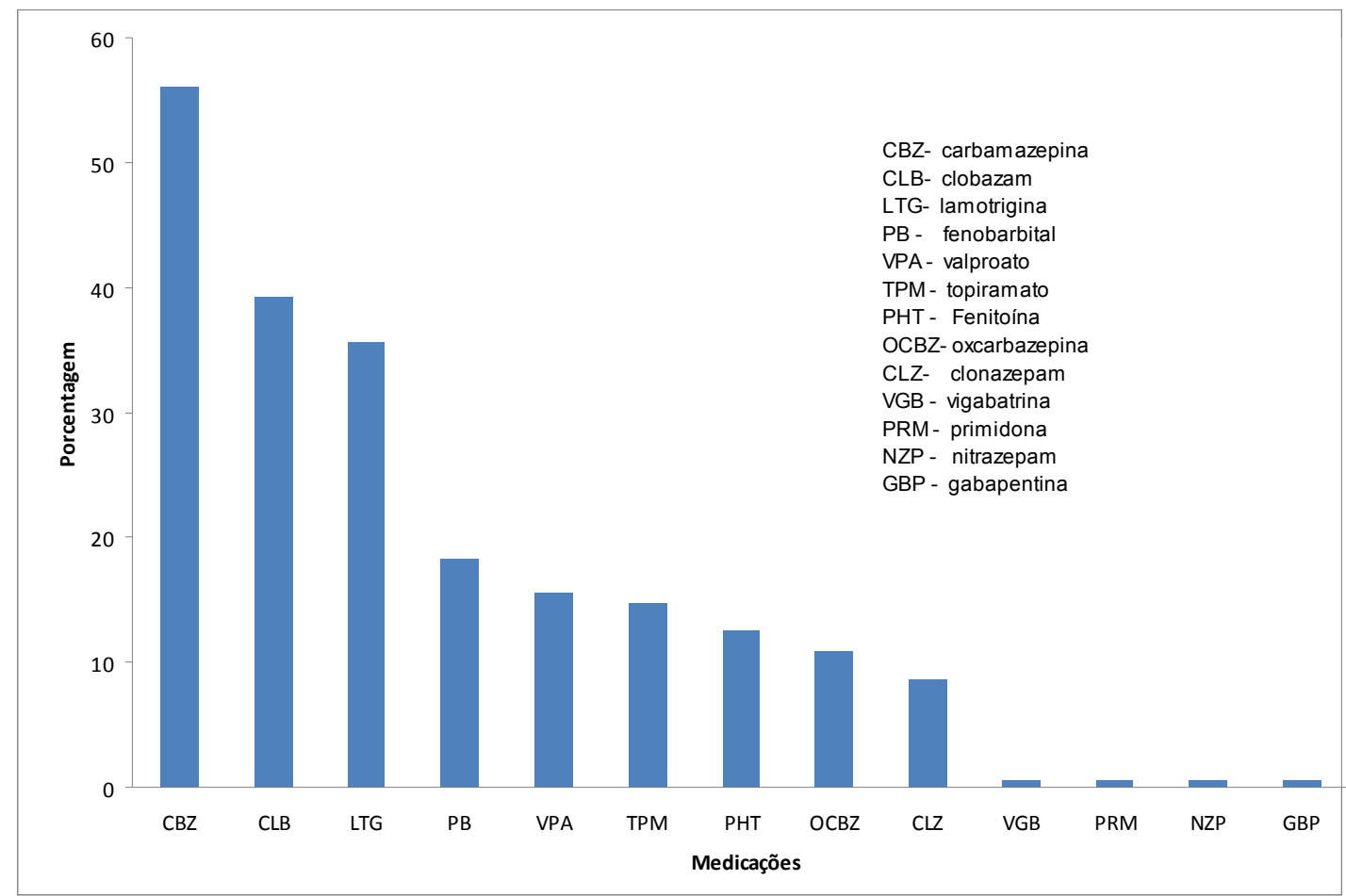

Pelos dados do gráfico 1, observa-se que a maioria dos pacientes fazia uso da carbamazepina (55,8\%), 38,7\% do clobazam e 35,3\% da lamotrigina. 
Carla Maria Maluf Ferrari

Tabela 5 - Distribuição dos pacientes ( $\mathrm{n}=385)$, segundo a frequência das crises nos últimos 30 dias, controle de crise, percepção quanto ao controle das crises e apoio de familiares ou de amigos. São Paulo, 2009-2010.

\begin{tabular}{lcc}
\hline Frequência das Crises (30 dias) & $\mathbf{n}^{\mathbf{0}}$ & $\mathbf{\%}$ \\
\hline Sem crise & 155 & 40,3 \\
$\geq 1 \leq 2$ & 109 & 28,3 \\
$\geq 3 \leq 4$ & 48 & 12,5 \\
$\geq 5 \leq 10$ & 39 & 10,1 \\
$>10$ & 34 & 8,8 \\
\hline Controle de crise & & \\
\hline Controlada & 81 & 21,0 \\
Não controlada & 304 & 79,0 \\
\hline Percepção quanto ao controle das crises & & 59,0 \\
\hline Controlada & 227 & 26,5 \\
Nem sempre controlada & 102 & 14,5 \\
Não controlada & 56 & \\
\hline Apoio de familiares ou amigos & & 63,6 \\
\hline Sempre & 245 & 9,4 \\
Quase sempre & 36 & 3,1 \\
Raramente & 12 & 23,9 \\
Não tem apoio & 92 & \\
\hline
\end{tabular}

Nos dados da Tabela 5, observa-se que 40,3\% dos entrevistados não apresentaram crise nos últimos 30 dias; $28,3 \%$ tiveram uma ou duas crises; $12,5 \%$, três ou quatro crises e 18,9\% cinco ou mais crises no mês. Nos últimos 6 meses $79,0 \%$ dos pacientes tiveram crises e, portanto, suas crises não eram controladas. Quanto a percepção do paciente em relação ao controle das crises, 14,5\% afirmaram que suas crises não estavam controladas; $26,5 \%$ consideraram as crises nem sempre controladas (menos frequentes ou menos graves) e 59,0\%, consideram suas crises controladas. A maioria $(73,0 \%)$ dos participantes deste estudo tinha apoio de familiares ou amigos sempre $(63,6 \%)$ ou quase sempre $(9,4 \%)$. 
Carla Maria Maluf Ferrari

Tabela 6 - Distribuição dos pacientes $(n=385)$, segundo informação sobre a facilidade de agendamento de consulta médica periódica e extra frequência das consultas (dias), qualidade do atendimento médico e percepção de seu estado de saúde, após início do tratamento ambulatorial. São Paulo, 2009-2010.

\begin{tabular}{|c|c|c|}
\hline Facilidade de agendamento da consulta médica & $\mathrm{n}^{\mathbf{0}}$ & $\%$ \\
\hline Sim & 234 & 60,8 \\
\hline Às vezes & 39 & 10,1 \\
\hline Não & 112 & 29,1 \\
\hline \multicolumn{3}{|l|}{ Consulta extra } \\
\hline Sempre tem vaga & 232 & 60,3 \\
\hline Na maioria das vezes tem vaga & 13 & 3,4 \\
\hline De vez em quando tem vaga & 23 & 6,0 \\
\hline Nunca tem vaga & 16 & 4,1 \\
\hline Não precisou & 101 & 26,2 \\
\hline \multicolumn{3}{|l|}{ Frequência das consultas (dias) } \\
\hline $15-30$ dias & 43 & 11,2 \\
\hline $60-90$ dias & 109 & 28,3 \\
\hline $120-180$ dias & 190 & 49,4 \\
\hline $210-270$ dias & 19 & 4,9 \\
\hline \multirow[t]{5}{*}{ 300- 360 dias } & 24 & 6,2 \\
\hline & Média: 141,7 & \\
\hline & Desvio padrão: 81,4 & \\
\hline & Mediana: 150 & \\
\hline & Min - Max: $15-360$ & \\
\hline \multicolumn{3}{|l|}{ Atendimento médico } \\
\hline Muito Bom & 182 & 47,3 \\
\hline Bom & 177 & 46,0 \\
\hline Ruim & 7 & 1,8 \\
\hline Não opinaram & 19 & 4,9 \\
\hline \multicolumn{3}{|l|}{$\begin{array}{l}\text { Percepção do estado de saúde após início do } \\
\text { tratamento ambulatorial }\end{array}$} \\
\hline Muito melhor & 154 & 40,0 \\
\hline Melhor & 166 & 43,1 \\
\hline Um pouco melhor & 42 & 10,9 \\
\hline Não melhorou nada & 15 & 3,9 \\
\hline Não sabe & 8 & 2,1 \\
\hline
\end{tabular}

A maioria dos pacientes $(60,8 \%)$ considerou ser fácil o agendamento das consultas, após a primeira consulta e que sempre há vagas para consulta extra 
Carla Maria Maluf Ferrari

(60,3\%). A média de intervalo entre as consultas foi de 141,7 dias, desvio padrão de 81,4 dias, variando entre 15 e 360 dias; 49,4\% compareciam às consultas a cada 120/180 dias (intervalo de consultas entre $4-6$ meses). A grande maioria dos pacientes $(93,3 \%)$ considerou o atendimento médico entre muito bom ou bom e $83,1 \%$ atribuíram melhora ou muita melhora em seu estado de saúde, após terem iniciado o tratamento no ambulatório.

Tabela 7 - Distribuição dos pacientes $(n=385)$ segundo forma de aquisição das DAEs e procedimento quando falta a medicação. São Paulo, 2009-2010.

\begin{tabular}{lrc}
\hline Forma de aquisição das DAEs & \multicolumn{1}{c}{$\mathbf{n}^{\mathbf{0}}$} & $\mathbf{\%}$ \\
\hline Serviço público/consegue todos & 262 & 68,1 \\
Serviço público/ consegue parte & 104 & 27,0 \\
Serviço público/ não consegue & 4 & 1,0 \\
Serviço privado/ consegue todos & 13 & 3,4 \\
Serviço privado/ consegue parte & 2 & 0,5 \\
\hline Procedimento quando falta a medicação & & \\
\hline Compra & 251 & 65,2 \\
Fica sem tomar & 69 & 17,9 \\
Outro & 65 & 16,9 \\
\hline
\end{tabular}

Nos dados da Tabela 7, observa-se que 71,5\% dos pacientes recebem do serviço público ou privado todos os medicamentos prescritos e $27,5 \%$ recebem desses serviços parte dos medicamentos. Quando não conseguem receber a medicação nos serviços que estão habituados, 65,2\% dos pacientes compra os medicamentos, $17,9 \%$ fica sem tomar e $16,9 \%$ busca adquirir o medicamento na empresa onde trabalha, igreja e nas Unidades Básicas de Saúde da grande São Paulo. 


\subsection{COMPLEXIDADE TERAPÊUTICA, ADESÃO AO TRATAMENTO MEDICAMENTOSO E QUALIDADE DE VIDA DOS PACIENTES COM EPILEPSIA.}

Tabela 8 - Distribuição dos pacientes segundo a complexidade do tratamento medicamentoso, mensurada pelo ICTME. São Paulo, 2009 - 2010.

\begin{tabular}{lcc}
\hline ICTME & $\mathbf{n}^{\mathbf{0}}$ & $\mathbf{\%}$ \\
\hline$\geq 2 \leq 14$ & 218 & 56,6 \\
$\geq 15 \leq 29$ & 141 & 36,6 \\
$\geq 30 \leq 44$ & 26 & 6,8 \\
\hline Total & 385 & 100,0 \\
\hline \multicolumn{4}{c}{ Média: 14,7} \\
& Desvio padrão: 8,0 & \\
& Min - Max: $2,0-44,0$ & \\
\hline
\end{tabular}

Nos dados da Tabela 8, a complexidade do tratamento está descrita, segundo o ICTME. A pontuação no índice variou de 2,0 a 44,0 pontos, com média de 14,7 pontos e desvio padrão de 8,0 .

Tabela 9 - Estatística descritiva da complexidade terapêutica pelo ICTME, segundo a quantidade de DAEs prescritas aos pacientes (n=385). São Paulo, 2009-2010.

\begin{tabular}{lrrrc}
\hline \multicolumn{5}{c}{ ICTME } \\
\hline Número de DAEs & $\mathbf{n}^{\mathbf{0}}$ & Média (dp) & IC 95\% & Mín - Máx \\
\hline $\mathbf{1}$ & 111 & $7,3(2,74)$ & $6,8-7,8$ & $2-14$ \\
$\mathbf{2}$ & 139 & $13,6(4,69)$ & $12,8-14,4$ & $4-32$ \\
$\mathbf{3}$ & 109 & $19,8(5,61)$ & $18,7-20,8$ & $9-33$ \\
$\mathbf{4}$ & 24 & $31,3(7,08)$ & $28,3-34,2$ & $11-44$ \\
$\mathbf{5}$ & 2 & $29,5(2,12)$ & $10,4-48,6$ & $28-31$ \\
\hline
\end{tabular}

Nos dados da Tabela 9, observa-se que à medida que ocorreu o aumento do número de DAEs prescritas, houve aumento da pontuação média do ICTME. Não obstante, pelos valores mínimos - máximos, pode-se observar que alguns pacientes com uso de DAE única apresentaram escore do ICTME similar aos que faziam uso de três ou quatro DAEs. A complexidade terapêutica média e máxima dos pacientes que receberam cinco DAEs, foi inferior daqueles com quatro drogas prescritas. 
Carla Maria Maluf Ferrari

Tabela 10 - Distribuição dos pacientes com epilepsia quanto à adesão ao tratamento medicamentoso, segundo o Teste de Morisky. São Paulo, 2009-2010.

\begin{tabular}{|c|c|c|}
\hline Morisky & $\mathrm{n}^{0}$ & $\%$ \\
\hline Alta & 130 & 33,8 \\
\hline Média & 233 & 60,5 \\
\hline Baixa & 22 & 5,7 \\
\hline Total & 385 & 100,0 \\
\hline
\end{tabular}

$\mathrm{Na}$ descrição da adesão segundo o Teste de Morisky, nos dados da Tabela 10 , observa-se que $66,2 \%$ dos indivíduos com epilepsia apresentam média/baixa adesão ao tratamento medicamentoso; no entanto a baixa adesão foi identificada em somente $5,7 \%$ dos pacientes.

Gráfico 2 - Porcentual de respostas afirmativas às questões do Teste de Morisky. São Paulo, 2009-2010.

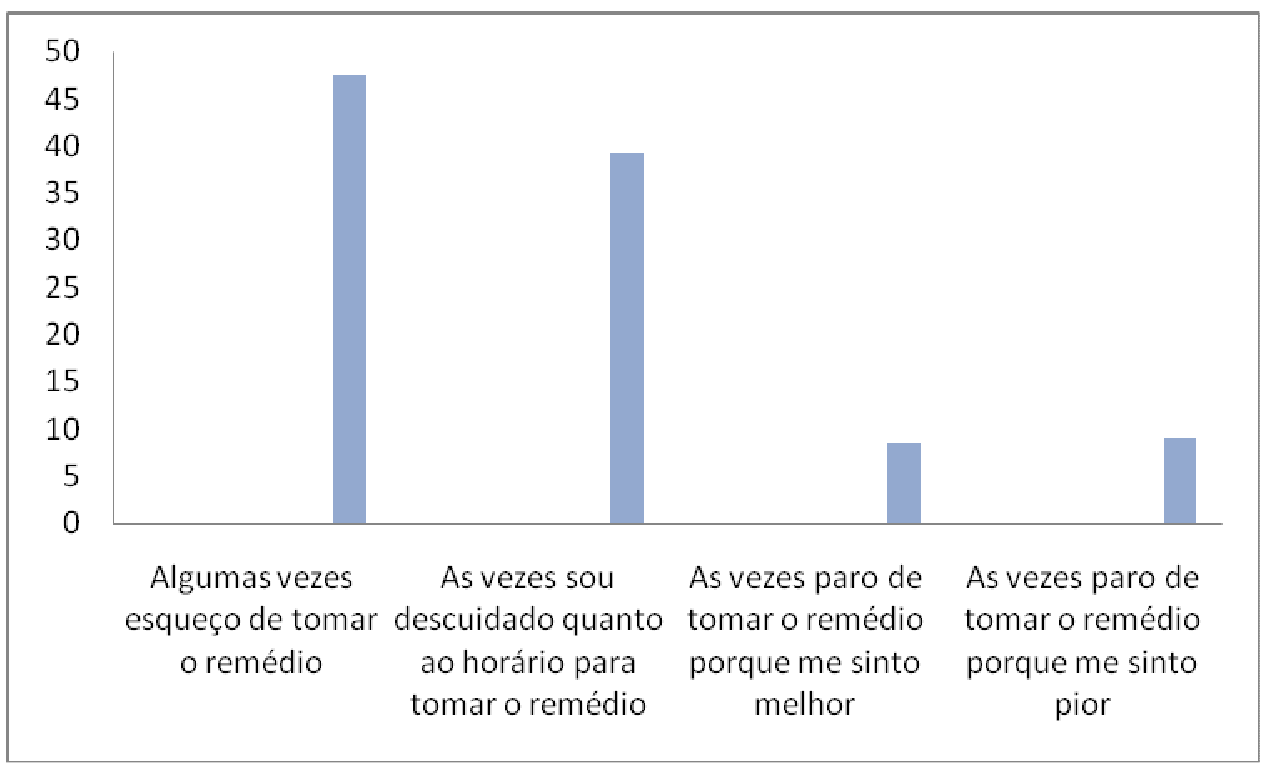

Pelos dados do Gráfico 2, observa-se que a resposta afirmativa mais frequente do questionário relacionou-se ao esquecimento de tomar a medicação em 47,5\% dos participantes, seguida pelo descuido em relação ao horário em tomar o medicamento $(39,2 \%)$; parar de tomar o remédio, porque se sente pior $(9,0 \%)$ e parar de tomar o remédio porque se sente melhor $(8,5 \%)$. 
Carla Maria Maluf Ferrari

Tabela 11 - Estatística descritiva da pontuação total de cada domínio e questão 31 do QOLIE-31. São Paulo, 2009-2010.

\begin{tabular}{lcccc}
\hline Domínios & Média (DP) & IC 95\% & Mediana & Mínimo - Máximo \\
\hline Preocupação com as crises & $53,2(31,38)$ & $50,1-56,4$ & 60,0 & $0,0-100,0$ \\
Qualidade de vida geral & $65,2(18,62)$ & $63,3-67,1$ & 65,0 & $0,0-100,0$ \\
Bem-estar emocional & $62,9(22,86)$ & $60,0-65,2$ & 68,0 & $0,0-100,0$ \\
Energia e fatiga & $64,9(20,9)$ & $62,8-67,0$ & 65,0 & $5,0-100,0$ \\
Aspecto cognitivo & $63,2(26,16)$ & $60,6-65,9$ & 66,1 & $0,0-100,0$ \\
Efeito da medicação & $61,3(32,61)$ & $58,0-64,5$ & 66,7 & $0,0-100,0$ \\
Aspecto social & $69,8(25,74)$ & $67,2-72,3$ & 75,0 & $0,0-100,0$ \\
Pontuação Total & $64,2(18,19)$ & $62,4-66,0$ & 65,9 & $12,6-99,4$ \\
Questão 31 & $67,7(22,00)$ & $65,5-69,9$ & 70,0 & $0,0-100,0$ \\
\hline
\end{tabular}

Pelas medidas descritivas relacionadas aos domínios do QOLIE-31, apresentadas nos dados da Tabela 11, pode-se afirmar que o valor médio mais baixo, 53,2, foi observado no domínio preocupação com as crises, seguido do domínio relacionado ao efeito da medicação $(61,3)$. O domínio que alcançou maior pontuação média foi o aspecto social $(69,8)$. O alfa de Cronbach da pontuação total do QOLIE31 nesta investigação foi de 0,775 .

\subsection{FATORES ASSOCIADOS A NÃO-ADESÃO AO TRATAMENTO MEDICAMENTOSO}

Nos dados das Tabelas 12 a 16 são apresentadas as comparações realizadas entre os grupos de alta e média/ baixa adesão, tendo em vista as variáveis independentes desta investigação. 
Carla Maria Maluf Ferrari

Tabela 12 - Comparação entre os grupos de alta e media/baixa adesão em relação ao sexo, ao vínculo conjugal, à raça, à religião, à escolaridade e à situação ocupacional. São Paulo, 2009-2010.

\begin{tabular}{|c|c|c|c|}
\hline \multicolumn{4}{|c|}{ ADESÃO TERAPÊUTICA } \\
\hline Características & Alta & Média/baixa & $\mathbf{P}^{\S}$ \\
\hline \multicolumn{4}{|l|}{ Sexo } \\
\hline Masculino & $51(39,2 \%)$ & $128(50,2 \%)$ & \multirow{2}{*}{0,053} \\
\hline Feminino & $79(60,8 \%)$ & $127(49,8 \%)$ & \\
\hline \multicolumn{4}{|l|}{ Vínculo conjugal } \\
\hline Casados & $61(46,9 \%)$ & $114(44,7 \%)$ & \multirow{2}{*}{0,760} \\
\hline Não casados & $69(53,1 \%)$ & $141(55,3 \%)$ & \\
\hline \multicolumn{4}{|l|}{ Raça } \\
\hline Branca/amarela & $87(66,9 \%)$ & $151(59,2 \%)$ & \multirow{2}{*}{0,173} \\
\hline Negra/parda & $43(33,1 \%)$ & $104(40,8 \%)$ & \\
\hline \multicolumn{4}{|l|}{ Religião } \\
\hline Alguma & $124(95,4 \%)$ & $233(91,4 \%)$ & \multirow{2}{*}{0,220} \\
\hline Nenhuma & $6 \quad(4,6 \%)$ & $22 \quad(8,6 \%)$ & \\
\hline \multicolumn{4}{|l|}{ Escolaridade } \\
\hline Fundamental incompleto ou completo & $53(40,7 \%)$ & $90(35,3 \%)$ & \multirow{2}{*}{0,347} \\
\hline$>$ Fundamental & $77(59,3 \%)$ & $165(64,7 \%)$ & \\
\hline \multicolumn{4}{|l|}{ Situação ocupacional } \\
\hline Inserido no mercado de trabalho & $47(36,2 \%)$ & $99(38,8 \%)$ & \multirow{2}{*}{0,690} \\
\hline Não inserido no mercado de trabalho & $83(63,8 \%)$ & $156(61,2 \%)$ & \\
\hline
\end{tabular}

$\S$ Teste qui-quadrado de Pearson

Nos dados da Tabela 12, observa-se que as vaiáveis: sexo, vínculo conjugal, raça, religião, escolaridade e situação ocupacional não apresentaram associação estatisticamente significante com a adesão terapêutica. Das variáveis independentes da Tabela 12, foram selecionadas para análise de regressão logística múltipla o sexo e a raça $(p<0,20)$. 
Carla Maria Maluf Ferrari

Tabela 13 - Comparação entre os grupos de alta e média/baixa adesão em relação ao diagnóstico médico, à presença de crise nos últimos 30 dias, ao controle de crises, à percepção do paciente quanto ao controle de crises e ao número de DAEs. São Paulo, 2009-2010.

\begin{tabular}{|c|c|c|c|}
\hline \multicolumn{4}{|c|}{ ADESÃO TERAPÊUTICA } \\
\hline Características & Alta & Média/baixa & $\mathbf{P}^{\varepsilon}$ \\
\hline \multicolumn{4}{|l|}{ Diagnóstico Médico } \\
\hline Focal sintomática & $96(73,8 \%)$ & $210(82,3 \%)$ & \multirow{4}{*}{$0,205^{\varepsilon}$} \\
\hline Focal Criptogênica & $16(12,3 \%)$ & $18(7,1 \%)$ & \\
\hline Generalizada Idiopática & $16(12,3 \%)$ & $22(8,6 \%)$ & \\
\hline Generalizada Criptogênica & $2(1,6 \%)$ & $5(2,0 \%)$ & \\
\hline \multicolumn{4}{|l|}{ Presença de crise (30 dias) } \\
\hline Sem crise & $65(50 \%)$ & $90(35,3 \%)$ & \multirow{2}{*}{$0,008^{\S}$} \\
\hline Com crise & $65(50 \%)$ & $165(64,7 \%)$ & \\
\hline \multicolumn{4}{|l|}{ Controle de crises } \\
\hline Controlada & $40(30,8 \%)$ & $41(16,1 \%)$ & \multirow{2}{*}{$0,001^{\S}$} \\
\hline Não controlada & $90(69,2 \%)$ & $214(83,9 \%)$ & \\
\hline \multicolumn{4}{|c|}{ Percepção do controle de crise } \\
\hline Controlada & $83(63,8 \%)$ & $144(56,5 \%)$ & \multirow{2}{*}{$0,200^{\S}$} \\
\hline Não controlada & $47(36,2 \%)$ & $111(43,5 \%)$ & \\
\hline \multicolumn{4}{|l|}{ Número de DAEs } \\
\hline Monoterapia & $50(38,5 \%)$ & $61(23,9 \%)$ & \multirow{2}{*}{0,004} \\
\hline Politerapia & $80(61,5 \%)$ & $194(76,1 \%)$ & \\
\hline
\end{tabular}

$\S$ Teste Qui-quadrado de Pearson; $\varepsilon$ Razão de verossimilhança.

Nos dados da Tabela 13, observa-se que a adesão ao tratamento esteve significativamente associada à presença de crise nos últimos 30 dias antes da entrevista, ao controle das crises e ao número das DAEs prescritas ao paciente. $\mathrm{O}$ grupo com média/baixa adesão alcançou proporcionalmente maior frequência de indivíduos com presença de crise nos últimos 30 dias $(64,7 \%)$, com crises não controladas $(83,9 \%)$ e em uso de politerapia $(76,1 \%)$ perante o grupo de alta adesão que apresentou percentuais de $50,0 \%, 69,2 \%$ e $61,5 \%$, respectivamente.

Das características apresentadas nos dados da Tabela 13, foram selecionadas as que foram significativamente associadas à adesão, as demais apresentaram valor de $p \geq 0,20$. 
Carla Maria Maluf Ferrari

Tabela 14 - Comparação entre os grupos de alta e média/baixa adesão em relação ao apoio de familiares ou amigos, à facilidade de agendamento de consulta médica periódica e extra, à qualidade do atendimento médico e à percepção do estado de saúde, após início do tratamento ambulatorial. São Paulo, 2009-2010.

\begin{tabular}{|c|c|c|c|}
\hline \multicolumn{4}{|c|}{ ADESÃO TERAPÊUTICA } \\
\hline Características & Alta & Média/baixa & $\mathbf{P}^{\S}$ \\
\hline \multicolumn{4}{|c|}{ Apoio de familiares ou amigos } \\
\hline Recebe apoio & $93(71,5 \%)$ & $188(73,7 \%)$ & \multirow{2}{*}{$0,737^{\S}$} \\
\hline Não recebe apoio & $37(28,5 \%)$ & $67(26,3 \%)$ & \\
\hline \multicolumn{4}{|c|}{ Facilidade de agendamento de consulta médica } \\
\hline Sim & $79(60,8 \%)$ & $155(60,8 \%)$ & \multirow{2}{*}{$1,000^{\S}$} \\
\hline As vezes/não & $51(39,2 \%)$ & $100(39,2 \%)$ & \\
\hline \multicolumn{4}{|l|}{ Consulta extra } \\
\hline Sempre tem vaga & $116(89,2 \%)$ & $230(90,2 \%)$ & \multirow{2}{*}{0,906} \\
\hline Não tem vaga & $14(10,8 \%)$ & $25 \quad(9,8 \%)$ & \\
\hline \multicolumn{4}{|l|}{ Atendimento Médico } \\
\hline Muito bom/bom & $122(93,8 \%)$ & $237(92,9 \%)$ & \multirow{2}{*}{$0,905^{\varsigma}$} \\
\hline Ruim/não opinaram & $8(6,2 \%)$ & $18(7,1 \%)$ & \\
\hline \multicolumn{4}{|c|}{$\begin{array}{l}\text { Percepção do estado de saúde, após início do } \\
\text { tratamento ambulatorial }\end{array}$} \\
\hline Está melhor & $112(35 \%)$ & $18(27,7 \%)$ & \multirow{2}{*}{$0,321^{\S}$} \\
\hline Não percebe melhora & $208(65 \%)$ & $47(72,3 \%)$ & \\
\hline
\end{tabular}

Tabela 15 - Comparação entre os grupos de alta e média/baixa adesão em relação à forma de aquisição das DAEs e ao procedimento quando falta a medicação. São Paulo, 2009-2010.

\begin{tabular}{lrrr}
\hline \multicolumn{4}{c}{ ADESÃO TERAPÊUTICA } \\
\hline Características & Alta & Média/baixa & P $^{\S}$ \\
\hline Forma de aquisição do medicamento & & & \\
\hline Serviço público & $124(95,4 \%)$ & $246(96,5 \%)$ & $0,809^{\S}$ \\
Serviço privado & $6(4,6 \%)$ & $9(3,5 \%)$ & \\
\hline Procedimento quando falta a medicação & & & \\
\hline Compra & $109(83,9 \%)$ & $207(81,2 \%)$ & $0,613^{\S}$ \\
Fica sem tomar & $21(16,1 \%)$ & $48(18,8 \%)$ & \\
\hline
\end{tabular}

$\S$ Teste de associação Qui-quadrado de Pearson.

Todas as variáveis apresentadas nos dados das Tabelas 14 e 15 não mostraram correlação estatisticamente significativa com a adesão ao tratamento. 
Carla Maria Maluf Ferrari

Destas variáveis, nenhuma foi selecionada para análise múltipla, visto que não apresentaram $\mathrm{p}<0,20$.

Tabela 16 - Comparação entre os grupos de alta e média/baixa adesão em relação à idade, à renda per capita, ao tempo que conhece o diagnóstico, ao tempo de tratamento, à frequência das consultas e à pontuação do ICTME. São Paulo, 2009-2010.

\begin{tabular}{|c|c|c|c|}
\hline \multicolumn{4}{|c|}{ ADESÃO TERAPÊUTICA } \\
\hline Características & Alta & Média/baixa & $\mathbf{p}$ \\
\hline \multicolumn{4}{|l|}{ Idade } \\
\hline Média (dp) & $42,4(12,98)$ & $38,2(12,10)$ & \multirow{4}{*}{$0,001^{\&}$} \\
\hline Mediana & 45,0 & 38,0 & \\
\hline IC 95\% média & $40,2-44,7$ & $36,7-39,7$ & \\
\hline Min-Max & $18,0-76,0$ & $18,0-76,0$ & \\
\hline \multicolumn{4}{|c|}{ Renda per capita (R\$) } \\
\hline Média (dp) & $618,75(905,20)$ & $631,04(828,50)$ & \multirow{4}{*}{$0,976^{\&}$} \\
\hline Mediana & 400,00 & 460,00 & \\
\hline IC 95\% média & $427,00-810,50$ & $514,60-747,50$ & \\
\hline Min-Max & $85,00-7.500,00$ & $93,00-8.000,00$ & \\
\hline \multicolumn{4}{|c|}{ Tempo que conhece o diagnóstico } \\
\hline Média (dp) & $23,4(14,71)$ & $22,0(12,80)$ & \multirow{4}{*}{$0,205^{\lambda}$} \\
\hline Mediana & 20,0 & 21,0 & \\
\hline IC 95\% média & $20,8-25,9$ & $20,4-23,6$ & \\
\hline Min-Max & $0,16-60,0$ & $0,5-64,0$ & \\
\hline \multicolumn{4}{|c|}{ Tempo de tratamento } \\
\hline Média (dp) & $22,0(13,89)$ & $21,2(12,80)$ & \multirow{4}{*}{$0,710^{\&}$} \\
\hline Mediana & 20,0 & 20,0 & \\
\hline IC 95\% média & $19,6-24,4$ & $19,6-22,8$ & \\
\hline Min-Max & $0,16-60,0$ & $0,5-60,0$ & \\
\hline \multicolumn{4}{|c|}{ Frequência das consultas } \\
\hline Média (dp) & $153,3(91,47)$ & $135,8(74,67)$ & \multirow{4}{*}{$0,135^{\&}$} \\
\hline Mediana & 180,0 & 120,0 & \\
\hline IC 95\% média & $137,5-169,2$ & $126,6-145,0$ & \\
\hline Min-Max & $15,0-360,0$ & $30,0-360,0$ & \\
\hline \multicolumn{4}{|l|}{ ICTME } \\
\hline Média (dp) & $12,3(6,36)$ & $16,1(8,45)$ & \multirow{4}{*}{$<0,000^{\&}$} \\
\hline Mediana & 11,0 & 15,0 & \\
\hline IC 95\% média & $11,2-13,4$ & $15,0-17,1$ & \\
\hline Min-Max & $2,0-33,0$ & $3,0-44,0$ & \\
\hline
\end{tabular}

$\&$ Teste de Mann-Whitney; $\lambda$ teste-t 
Carla Maria Maluf Ferrari

A média de idade do grupo de média/baixa adesão foi inferior ao grupo de alta adesão. A complexidade terapêutica mensurada pelo ICTME foi em média superior no grupo com indicação de menor adesão ao tratamento. Das variáveis apresentadas nos dados da Tabela 16, foram selecionadas a idade, a frequência das consultas, e o ICTME para análise múltipla.

Tabela 17 - Modelo de regressão logística múltipla para estimativa de associação com a não adesão. São Paulo, 2009-2010.

\begin{tabular}{lcccc}
\hline Características & B & P (modelo) & $\operatorname{Exp(B)}$ & IC 95\% EXP(B) \\
\hline Sexo (feminino) & $-0,48$ & 0,037 & 0,62 & $0,39-0,97$ \\
Controle de crise (controladas) & $-0,56$ & 0,041 & 0,57 & $0,33-0,98$ \\
ICTME & 0,61 & 0,000 & 1,06 & $1,03-1,10$ \\
Idade & $-0,27$ & 0,003 & 0,97 & $0,96-0,99$ \\
\hline
\end{tabular}

Nos dados da Tabela 17, está representado o modelo final de regressão logística resultante da análise conjunta dos fatores associados ou selecionados nas análises anteriores $(p<0,20)$. Os resultados mostraram que quatro variáveis destacaram-se e apresentaram associação estatisticamente significativa no final da modelagem: sexo, controle de crises, complexidade terapêutica e idade. Indivíduos do sexo feminino e que apresentavam controle das crises mostraram menor probabilidade de não adesão terapêutica perante aqueles do sexo masculino e sem controle das crises (coeficientes negativos). A não adesão foi menos frequente nos mais velhos, e o aumento de 1 ano na idade diminui a probabilidade de não adesão em 3\%, Exp (B) de 0,97. A não adesão foi mais frequente nos indivíduos que tinham regimes terapêuticos mais complexos, e a probabilidade da não adesão ocorrer foi $6 \%$ maior a cada aumento de um ponto no escore do IMTCE. No modelo final, em nenhuma das variáveis o intervalo de confiança cruzou a linha de não efeito, ou seja, o IC 95\% $\operatorname{Exp(B)~não~incluiu~o~valor~1,0.~}$

A curva ROC mostrou area sob a curva de 0,69 (IC 95\%: 0,64 - 0,75) e $p=0,000$. A indicação correta de adesão e não adesão no modelo foi de $68,3 \%$. A porcentagem de classificação correta para não adesão foi de $91,8 \%$ e para adesão $22,3 \%$. 


\subsection{FATORES RELACIONADOS À QUALIDADE DE VIDA}

Nos dados das Tabelas 18 a 22, são observadas as análises de associação entre as médias do escore total do QOLIE-31 e as variáveis independentes desta investigação.

Tabela 18 - Comparação entre as médias do escore total do QOLIE-31 em relação ao sexo, ao vínculo conjugal, à raça, à religião, à escolaridade e à situação ocupacional. São Paulo, 2009-2010.

\begin{tabular}{|c|c|c|c|c|}
\hline \multicolumn{5}{|c|}{ QOLIE-31 } \\
\hline Características & Média(dp) & IC $95 \%$ & Min-Máx & $\mathbf{p}^{\lambda}$ \\
\hline \multicolumn{5}{|l|}{ Sexo } \\
\hline Masculino & $66,3(17,69)$ & $63,7-68,9$ & $12,6-97,0$ & \multirow{2}{*}{$\mathbf{0 , 0 3 0 ^ { \lambda }}$} \\
\hline Feminino & $62,3(18,44)$ & $59,8-64,8$ & $15,1-99,4$ & \\
\hline \multicolumn{5}{|l|}{ Vínculo conjugal } \\
\hline Casados & $64,8(19,3)$ & $62,1-67,9$ & $18,4-99,4$ & \multirow{2}{*}{$0,435^{\lambda}$} \\
\hline Não casados & $63,5(17,2)$ & $61,2-65,8$ & $12,6-97,1$ & \\
\hline \multicolumn{5}{|l|}{ Raça } \\
\hline Branca/amarela & $66,2(17,1)$ & $64,0-68,4$ & $20,2-99,4$ & \multirow{2}{*}{$\mathbf{0 , 0 0 6}{ }^{\lambda}$} \\
\hline Negra/parda & $60,9(19,4)$ & $57,8-64,1$ & $12,6-96,6$ & \\
\hline \multicolumn{5}{|l|}{ Religião } \\
\hline Alguma & $64,2(18,4)$ & $62,2-66,1$ & $12,6-99,4$ & \multirow{2}{*}{$0,964^{\lambda}$} \\
\hline Nenhuma & $64,3(15,4)$ & $58,3-70,3$ & $20,1-93,0$ & \\
\hline \multicolumn{5}{|l|}{ Escolaridade } \\
\hline $\begin{array}{l}\text { Fundamental Incompleto ou } \\
\text { completo }\end{array}$ & $64,8(18,5)$ & $61,8-68,0$ & $61,8-68,0$ & \multirow[t]{2}{*}{$0,585^{\lambda}$} \\
\hline$>$ Fundamental & $63,8(18,0)$ & $61,5-66,1$ & $61,5-66,1$ & \\
\hline \multicolumn{5}{|l|}{ Situação ocupacional } \\
\hline Inserido no mercado de trabalho & $68,2(16,7)$ & $65,4-71,0$ & $17,4-99,4$ & \multirow{2}{*}{$0,001^{\lambda}$} \\
\hline Não inserido no mercado de trabalho & $61,7(18,6)$ & $59,3-64,1$ & $12,6-96,6$ & \\
\hline
\end{tabular}

${ }^{\lambda}$ Teste-t

Nos dados da Tabela 18, observa-se que houve diferença estatisticamente significativa entre as médias do escore total do QOLIE-31 nas variáveis sexo $(\mathrm{p}=0,030)$, raça $(\mathrm{p}=0,006)$ e situação ocupacional $(\mathrm{p}=0,001)$. Indivíduos do sexo masculino, da raça branca/amarela e inseridos no mercado de trabalho apresentaram maiores médias no escore total do QOLIE-31. 
Carla Maria Maluf Ferrari

Das características apresentadas na Tabela 18, foram selecionadas para análise múltipla: o sexo, a raça e a situação ocupacional.

Tabela 19 - Comparação entre as médias do escore total do QOLIE-31 em relação ao diagnóstico médico, à presença de crise, ao controle de crises, à percepção do paciente quanto ao controle de crises, ao número das DAEs e à adesão ao tratamento (Teste de Morisky). São Paulo, 2009-2010.

\begin{tabular}{|c|c|c|c|c|}
\hline \multirow[b]{2}{*}{ Características } & \multicolumn{4}{|c|}{ QOLIE-31 } \\
\hline & Média(dp) & IC $95 \%$ & Min-máx & $\mathbf{P}$ \\
\hline \multicolumn{5}{|l|}{ Diagnóstico Médico } \\
\hline Focal sintomática & $63,8(18,1)$ & $61,7-65,8$ & $18,4-99,4$ & \multirow{4}{*}{$0,728^{\mu}$} \\
\hline Focal Criptogênica & $65,4(19,6)$ & $58,5-72,2$ & $12,6-91,0$ & \\
\hline Generalizada Idiopática & $66,9(19,4)$ & $60,5-73,2$ & $15,2-93,0$ & \\
\hline Generalizada Criptogênica & $61,3(9,3)$ & $52,7-70,0$ & $45,7-75,1$ & \\
\hline \multicolumn{5}{|l|}{ Presença de crise (30 dias) } \\
\hline Sem crise & $70,3(15,7)$ & $67,8-72,8$ & $17,4-99,4$ & \multirow{2}{*}{$0.000^{\lambda}$} \\
\hline Com crise & $60,1(18,6)$ & $57,6-62,4$ & $12,6-97,0$ & \\
\hline \multicolumn{5}{|l|}{ Controle de crises } \\
\hline Controlada & $71,1(15,0)$ & $67,8-74,4$ & $18,8-94,6$ & \multirow{2}{*}{$\mathbf{0 , 0 0 0 ^ { \lambda }}$} \\
\hline Não controlada & $62,3(18,5)$ & $60,2-64,4$ & $12,6-99,4$ & \\
\hline \multicolumn{5}{|c|}{ Percepção do controle de crises } \\
\hline Controlada & $70,0(15,6)$ & $68,0-71,0$ & $17,5-99,4$ & \multirow{2}{*}{$\mathbf{0}, 000^{\lambda}$} \\
\hline Não controlada & $55,8(18,4)$ & $52,9-58,7$ & $12,6-93,0$ & \\
\hline \multicolumn{5}{|l|}{ Número de DAEs } \\
\hline Monoterapia & $68,7(16,7)$ & $65,4-71,8$ & $17,4-99,4$ & \multirow{2}{*}{$0,002^{\lambda}$} \\
\hline Politerapia & $62,3(18,4)$ & $60,1-64,5$ & $12,6-97,0$ & \\
\hline \multicolumn{5}{|l|}{ Adesão (Morisky) } \\
\hline Alta & $69,2(16,8)$ & $66,3-62,1$ & $15,2-99,4$ & \multirow{2}{*}{$0,000^{\lambda}$} \\
\hline Média/baixa & $61,6(18,4)$ & $59,3-58,1$ & $12,6-97,0$ & \\
\hline
\end{tabular}

$\mu$ ANOVA- $\lambda$ Teste-t

Nos dados da Tabela 19, são notadas diferenças estatisticamente significativas entre as médias da pontuação do escore total do QOLIE-31 nas variáveis presença de crise nos últimos 30 dias, controle de crises, percepção do controle de crises, número das DAEs e adesão ao tratamento. Indivíduos que não apresentaram crise epiléptica nos últimos 30 dias, estavam com as crises controladas, tinham percepção de que suas crises estavam sob controle, faziam uso de monoterapia e eram aderentes ao tratamento obtiveram maior média no escore total 
Carla Maria Maluf Ferrari

do QOLIE-31, exceto o diagnóstico médico, as demais variáveis foram selecionadas para análise múltipla.

Tabela 20 - Comparação entre as médias do escore total do QOLIE-31 em relação ao apoio de familiares ou amigos, facilidade de agendamento de consulta médica periódica e extra, qualidade do atendimento médico e percepção do estado de saúde, após início do tratamento ambulatorial. São Paulo, 2009-2010.

\begin{tabular}{|c|c|c|c|c|}
\hline \multirow[b]{2}{*}{ Características } & \multicolumn{4}{|c|}{ QOLIE-31 } \\
\hline & Média(dp) & IC $95 \%$ & Min-Máx & $\mathbf{P}$ \\
\hline \multicolumn{5}{|c|}{ Apoio de familiares ou amigos } \\
\hline Recebe apoio & $63,0(18,8)$ & $60,7-65,2$ & $12,6-99,4$ & \multirow{2}{*}{$\mathbf{0 , 0 3 2 ^ { \lambda }}$} \\
\hline Não recebe apoio & $67,4(15,9)$ & $64,3-70,5$ & $18,8-94,6$ & \\
\hline \multicolumn{5}{|c|}{$\begin{array}{l}\text { Facilidade quanto ao agendamento da } \\
\text { consulta médica }\end{array}$} \\
\hline Sim & $64,8(18,3)$ & $62,3-67,2$ & $12,6-99,4$ & \multirow{2}{*}{$0,361^{\lambda}$} \\
\hline Não & $63,1(18,0)$ & $60,2-66,0$ & $15,1-92,7$ & \\
\hline \multicolumn{5}{|l|}{ Consulta extra } \\
\hline Sempre tem vaga & $64,6(18,4)$ & $62,2-66,5$ & $12,6-99,4$ & \multirow{2}{*}{$0,208^{\lambda}$} \\
\hline Não tem vaga & $60,7(16,1)$ & $55,5-66,0$ & $25,7-91,0$ & \\
\hline \multicolumn{5}{|l|}{ Atendimento médico } \\
\hline Muito bom/bom & $64,5(18,2)$ & $62,6-66,4$ & $15,2-99,4$ & \multirow{2}{*}{$0,227^{\lambda}$} \\
\hline Ruim/não opinaram & $60,0(17,7)$ & $52,8-67,2$ & $12,6-87,5$ & \\
\hline \multicolumn{5}{|c|}{$\begin{array}{l}\text { Percepção do estado de saúde, após } \\
\text { início do tratamento ambulatorial }\end{array}$} \\
\hline Está melhor & $66,0(17,7)$ & $64,1-68,0$ & $12,6-99,4$ & \multirow{2}{*}{$\mathbf{0 , 0 0 0}{ }^{\lambda}$} \\
\hline Não percebe melhora & $55,0(17,7)$ & $50,6-59,4$ & $15,2-88,4$ & \\
\hline
\end{tabular}

${ }^{\lambda}$ Teste-t

Nos dados da Tabela 20, observa-se que as variáveis apoio de familiares ou amigos e percepção do estado de saúde, após início do tratamento ambulatorial apresentaram associação estatisticamente significativa com o QOLIE-31, e os indivíduos que recebiam apoio de familiares ou amigos mostraram menor média de escore em relação aos que consideraram receber pouco ou nenhum apoio. Os indivíduos que perceberam melhora no estado de saúde após tratamento ambulatorial apresentaram maior média de escore no QOLIE-31. 
As características da Tabela 20 selecionadas para análise de regressão múltipla foram: apoio de familiares ou amigos e percepção do estado de saúde, após início do tratamento ambulatorial.

Tabela 21 - Comparação entre as médias do escore total do QOLIE-31 em relação à forma de aquisição das DAEs e procedimento quando falta a medicação. São Paulo, 2009-2010.

\begin{tabular}{lcccc}
\hline Características & \multicolumn{4}{c}{ QOLIE-31 } \\
\hline & Média(dp) & IC 95\% & Min-Máx & p \\
\hline Forma de aquisição das DAEs & & & & \\
Serviço público & $63,8(18,3)$ & $61,9-65,7$ & $12,6-99,4$ & $0,057^{\lambda}$ \\
Serviço privado & $72,9(11,0)$ & $66,8: 69,0$ & $53,9-90,3$ & \\
\hline Procedimento quando falta a & & & & \\
medicação & & & & \\
\hline Compra & $65,1-18,4$ & $63,1-67,2$ & $12,6-99,4$ & $0,411^{\lambda}$ \\
Fica sem tomar & $59,8-16,8$ & $55,8-63,9$ & $18,8-88,2$ & \\
\hline
\end{tabular}

${ }^{\lambda}$ Teste-t

Não houve diferença estatisticamente significativa entre as médias do escore do QOLIE-31, em relação às variáveis independentes apresentadas nos dados da Tabela 21; no entanto, a variável forma de aquisição das DAEs foi selecionada para análise múltipla $(\mathrm{p}<0,20)$. 
Carla Maria Maluf Ferrari

Tabela 22 - Correlação entre as médias do escore total do QOLIE-31 e idade, renda per capita, tempo que conhece o diagnóstico, tempo de tratamento, frequência de consultas e ICTME. São Paulo 2009-2010.

\begin{tabular}{|c|c|c|c|c|c|c|}
\hline \multirow[b]{2}{*}{ Característica } & \multirow[b]{2}{*}{$\mathbf{N}^{\mathbf{O}}$} & \multicolumn{5}{|c|}{ QOLIE-31 } \\
\hline & & media (dp) & IC 95\% & min-máx & $\mathbf{r}$ & $\mathbf{p}$ \\
\hline \multicolumn{7}{|l|}{ Idade } \\
\hline$<30$ & 111 & $64,1(16,30)$ & $61,0-67,2$ & $18,8-88,4$ & \multirow{4}{*}{$0,069^{\theta}$} & \multirow{4}{*}{0,178} \\
\hline$\geq 31 \leq 45$ & 155 & $62,4(20,15)$ & $59,2-65,2$ & $12,6-97,0$ & & \\
\hline$\geq 46 \leq 60$ & 97 & $66,3(17,23)$ & $62,8-69,7$ & $23,3-99,4$ & & \\
\hline$>60$ & 22 & $68,0(16,25)$ & $60,8-75,2$ & $37,8-90,3$ & & \\
\hline \multicolumn{7}{|l|}{ Renda per capita } \\
\hline$\leq \mathrm{R} \$ 250,00$ & 80 & $59,7(21,55)$ & $54,9-64,5$ & $17,5-99,4$ & \multirow{6}{*}{$0,188^{\theta}$} & \multirow{6}{*}{$\mathbf{0 , 0 2 5}$} \\
\hline$\geq \mathrm{R} \$ 251,00 \leq \mathrm{R} \$ 500,00$ & 98 & $63,6(17,70)$ & $60,0-67,1$ & $12,6-90,9$ & & \\
\hline$\geq \mathrm{R} \$ 501,00 \leq \mathrm{R} \$ 750,00$ & 50 & $65,7(18,51)$ & $60,4-70,9$ & $21,2-94,6$ & & \\
\hline$\geq \mathrm{R} \$ 751,00 \leq \mathrm{R} \$ 1000,00$ & 27 & $70,4(10,65)$ & $66,2-74,6$ & $50,4-89,6$ & & \\
\hline$\geq \mathrm{R} \$ 1,001,00 \leq \mathrm{R} \$ 1500,00$ & 14 & $70,3(15,09)$ & $61,5-79,0$ & $42,3-88,0$ & & \\
\hline$>1500,00$ & 16 & $72,2(14,63)$ & $64,4-80,0$ & $41,3-91,0$ & & \\
\hline \multicolumn{7}{|l|}{$\begin{array}{l}\text { Tempo que conhece o } \\
\text { diagnóstico (anos) }\end{array}$} \\
\hline$\leq 5$ & 38 & $63,2(19,24)$ & $57,2-69,9$ & $18,8-89,7$ & \multirow{6}{*}{$0,136^{\mathfrak{f}}$} & \multirow{6}{*}{$\mathbf{0 , 0 0 7}$} \\
\hline$\geq 6 \leq 10$ & 52 & $58,7(18,03)$ & $53,7-63,7$ & $12,6-93,0$ & & \\
\hline$\geq 11 \leq 20$ & 101 & $63,2(19,08)$ & $59,5-67,0$ & $15,2-92,7$ & & \\
\hline$\geq 21 \leq 30$ & 91 & $64,8(18,13)$ & $61,1-68,6$ & $22,3-97,0$ & & \\
\hline$\geq 31 \leq 40$ & 68 & $66,5(16,22)$ & $62,6-70,4$ & $20,1-99,4$ & & \\
\hline$>41$ & 35 & $69,6(17,22)$ & $63,6-75,5$ & $32,1-92,7$ & & \\
\hline \multicolumn{7}{|l|}{ Tempo de tratamento } \\
\hline$\leq 5$ & 44 & $62,4(19,31)$ & $56,5-68,3$ & $18,8-89,7$ & \multirow{6}{*}{$0,115^{\theta}$} & \multirow{6}{*}{0,024} \\
\hline$\geq 6 \leq 10$ & 55 & $58,3(18,66)$ & $53,3-63,4$ & $12,6-93,0$ & & \\
\hline$\geq 11 \leq 20$ & 105 & $64,2(18,70)$ & $60,6-67,8$ & $15,2-92,7$ & & \\
\hline$\geq 21 \leq 30$ & 83 & $65,7(17,93)$ & $61,8-69,7$ & $22,3-97,0$ & & \\
\hline$\geq 31 \leq 40$ & 71 & $66,3(16,10)$ & $62,4-70,1$ & $20,1-99,4$ & & \\
\hline$>41$ & 27 & $68,5(17,87)$ & $61,5-75,6$ & $32,1-92,7$ & & \\
\hline \multicolumn{7}{|l|}{ Frequência de consultas } \\
\hline 15 a 30 & 43 & $59,1(19,44)$ & $53,1-65,1$ & $17,5-89,6$ & \multirow{5}{*}{$0,215^{\theta}$} & \multirow{5}{*}{$\mathbf{0 , 0 0 0}$} \\
\hline 60 a 90 & 109 & $59,9(19,40)$ & $56,3-63,6$ & $12,6-96,6$ & & \\
\hline 120 a 180 & 190 & $66,5(16,66)$ & $64,1-68,9$ & $18,4-99,4$ & & \\
\hline 210 a 270 & 19 & $65,1(19,46)$ & $55,8-74,5$ & $32,1-97,0$ & & \\
\hline 300 a 360 & 24 & $73,3(14,94)$ & $67,0-79,7$ & $31,9-94,6$ & & \\
\hline \multicolumn{7}{|l|}{ ICTME } \\
\hline$\leq 14$ & 218 & $66,4(18,10)$ & $64,0-68,8$ & $15,2-99,4$ & \multirow{3}{*}{$-0,171^{\theta}$} & \multirow{3}{*}{0,001} \\
\hline$\geq 15 \leq 29$ & 141 & $61,2(18,33)$ & $58,1-64,2$ & $12,696,6$ & & \\
\hline$>29$ & 26 & $61,8(16,04)$ & $55,3-68,3$ & $26,8-91,0$ & & \\
\hline
\end{tabular}

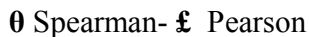


Carla Maria Maluf Ferrari

Nos dados da Tabela 22, nota-se correlação significante entre o escore total do QOLI-31 e a renda per capita, tempo que conhece o diagnóstico, tempo de tratamento, frequência de consultas e complexidade terapêutica. Indivíduos com maior renda per capita apresentaram maiores médias dos escores no QOLIE-31, assim como os que conheciam o diagnóstico há mais tempo, e os que tomavam a medicação há mais de dez anos. Também foi observado maior média das pontuações no QOLIE-31 entre os indivíduos com maiores intervalos entre as consultas médicas e com as menores pontuações no ICTME. Todas as variáveis apresentadas na Tabela 22 foram selecionadas para a análise múltipla.

Tabela 23 - Regressão linear para o escore total do QOLIE-31. São Paulo, 2009 -2010.

\begin{tabular}{lccccc}
\hline \multicolumn{1}{c}{ Características } & B & $\begin{array}{c}\text { Erro } \\
\text { Padrão (B) }\end{array}$ & $\begin{array}{c}\text { P } \\
\text { (modelo) }\end{array}$ & \multicolumn{2}{c}{$\begin{array}{c}\text { Estatística de } \\
\text { Multicolinearidade }\end{array}$} \\
\cline { 5 - 7 } & & & & Tolerance & FIV \\
\hline Raça branca/amarela & 6,86 & 2,82 & 0,016 & 0,96 & 1,04 \\
\hline Inseridos no mercado de trabalho & 7,03 & 3,00 & 0,021 & 0,98 & 1,02 \\
\hline Percepção de crises controladas & 16,40 & 2,79 & 0,000 & 0,98 & 1,02 \\
\hline Recebe apoio de familiares ou amigos & $-9,47$ & 3,08 & 0,003 & 0,98 & 1,02 \\
\hline
\end{tabular}

A construção do modelo de regressão linear para a variável resposta qualidade de vida foi iniciada com a inclusão de todas as variáveis que apresentaram $p<0,20$. Houve indicação da presença de multicolinearidade para tempo de diagnóstico e tempo de tratamento. A constatação foi feita por meio do FIV que indicou valores de 47,3 e 46,8 para tempo de doença e tratamento, respectivamente. $\mathrm{O}$ índice de Tolerance de ambas variáveis foi 0,021. Em consequência foram realizadas duas modelagens, uma sem o tempo de diagnóstico e outra retirando o tempo de tratamento. À medida que o resultado final dos dois modelos foi similar, o modelo final apresentado nos dados da Tabela 23 representa o resultado da modelagem iniciada com o tempo de diagnóstico ou tempo de tratamento. $\mathrm{O} \mathrm{R}^{2}$ ajustado foi 0,33, indicando que o modelo explica 33\% da variância do QOLIE-31.

Os coeficientes apresentados modelo final (Coluna B da Tabela 23) mostram que indivíduos das raças branca e amarela, inseridos no mercado de trabalho e com a percepção que suas crises estavam controladas, tiveram pontuações mais elevadas 
Carla Maria Maluf Ferrari

no QOLIE -31 em relação aos que não apresentavam essas características (coeficientes positivos). Por outro lado, os que recebiam apoio de familiares ou amigos apresentaram menores escores nesse questionário em relação aos demais. Quanto aos valores dos coeficientes, a percepção que as crises encontravam-se controladas destacou-se pelo seu maior valor $(16,40)$ e menor erro-padrão $(2,79)$. 


$$
1
$$




\section{DISCUSSÃO}

A epilepsia é um distúrbio neurológico que afeta quase 50 milhões de pessoas em todo o mundo, das quais cinco milhões vivem na América Latina e Caribe ${ }^{(81)}$.

De acordo com o Ministério da Saúde, ocupava o $30^{\circ}$ lugar entre as causas de hospitalização e foi responsável por mais de 40 mil internações por ano no início da década de 1990 (cerca de 0,54 / mil habitantes) ${ }^{(81)}$.

Segundo pesquisa no DATASUS, no Brasil, em 2009, o número de internações por epilepsia foi de 46.610; no entanto, a população brasileira nesses últimos 20 anos aumentou cerca de $40 \%$, podendo-se considerar que a incidência de internações por essa causa diminuíram, provavelmente pelos avanços do tratamento desses pacientes ${ }^{(82)}$.

No atual estudo, o perfil sociodemográfico dos participantes mostrou que $53,5 \%$ eram do sexo feminino, idade média de 39,7 anos, $60,8 \%$ da raça branca e $92,7 \%$ tinham uma religião, na maioria dos casos, a católica.

Alguns estudos internacionais relatam incidência da epilepsia ligeiramente mais elevada entre indivíduos do sexo masculino ${ }^{(83,84)}$. Em estudo de base populacional da Dinamarca, entre pessoas com idade de zero a 80 anos, revelou incidência da epilepsia ligeiramente maior em homens do que em mulheres, com exceção das pessoas entre 10 a 20 anos $^{(84)}$. Outros estudos apresentam em seus resultados freqüência mais elevada em mulheres, $53,5 \%$ a $62,1 \%$ dos indivíduos adultos com epilepsia ${ }^{(85-87)}$.

Pardos e pretos são cerca de metade da população brasileira; no entanto, São Paulo é um dos estados da federação com menor proporção de negros, 30,9\%, segundo a Pesquisa Nacional por Amostra de Domicílios do ano de 2005. Nessa pesquisa, o Município de São Paulo apresenta proporções de 67,5\% para pessoas brancas, amarelas, indígenas ou sem declaração de raça e de 30,3\% para pardos e pretos. Em conseqüência, a proporção de 60,8\% de indivíduos da raça branca, conforme esta pesquisa parece refletir a distribuição de raças no Município e não uma tendência específica da doença ${ }^{(88)}$. 
Ter uma religião foi uma característica muito frequente dos entrevistados nesta pesquisa $(92,7 \%)$. A associação dos aspectos religiosos às práticas de saúde possui raízes histórico-culturais muito antigas presentes nos mitos gregos, rituais indígenas e nas inscrições bíblicas e influenciam a cultura ocidental nos tempos atuais $^{(89) .}$ As crenças predominam na história da epilepsia. Na Roma antiga os indivíduos com epilepsia eram evitados por medo de contágio. Na Idade Média foram perseguidas como bruxos. Além disso, alguns autores consideram que a religiosidade, pode ser um traço de personalidade em algumas formas da doença ${ }^{(90)}$.

Quanto às demais características sociodemográficas, a maioria dos indivíduos não vivia com cônjuge ou companheiro (54,5\%), nem estava inserida no mercado de trabalho $(62,1 \%)$, tinha renda per capita inferior a um salário mínimo $(62,5 \%)$ e também, foi baixo o percentual dos que cursaram o nível superior $(15,1 \%)$. O impacto da epilepsia pode ser observado em diferentes atividades da vida diária, que incluem, educação, casamento, formação da família e trabalho ${ }^{(91,92)}$.

Estudo desenvolvido na Coreia do $\mathrm{Sul}^{(93)}$, comparando indivíduos maiores de 18 anos com e sem epilepsia, mostrou que os grupos diferiram significativamente no nível de escolaridade, estado civil e condição profissional $(\mathrm{P}=0,000)$. Entre os indivíduos com epilepsia, foi encontrada uma alta proporção de divorciados e solteiros, além disso, menos da metade dos entrevistados completou o ensino médio e cursou a universidade ${ }^{(93)}$. Quanto à situação ocupacional, estudo recente japonês apontou valor similar de indivíduos empregados (39,5\%), se comparados a 37,9\% na casuística da atual pesquisa ${ }^{(74)}$.

Em relação às características clínicas da doença, predominou o diagnóstico de epilepsia focal sintomática e entre esta a epilepsia de lobo temporal, que é provavelmente a área mais epileptogênica e a região mais comum das síndromes focais sintomáticas que, estão associadas à refratariedade ${ }^{(94,95)}$.

A ausência de crises epilépticas nos últimos 6 meses que antecederam a entrevista foi observada em $21 \%$ dos participantes deste estudo, só 40,3\% dos pacientes permaneceram sem crises no último mês, ainda que 59\% deles considerassem que suas crises estivessem controladas. 
Estudo realizado em Taiwan com 357 pacientes com epilepsia identificou que $51,8 \%$ dos participantes não tinham tido crise, há pelo menos, 1 ano ${ }^{(96)}$. A ausência de crises no período de 1 e 3 meses foi de $23 \%$ e $46 \%$, respectivamente, entre participantes de um estudo europeu, restando $31 \%$ de pacientes com uma ou mais crises dentro de 1 mês ${ }^{(97)}$. Outros estudos apresentam percentuais de 26,3\% de indivíduos com crises no último mês ${ }^{(98)}$ e $30 \%$ nos últimos 3 meses que antecederam à pesquisa ${ }^{(7)}$. Os resultados das investigações indicam maior controle das crises quando comparados com os da presente pesquisa.

Além de maior frequência das crises perante dados da literatura, os participantes da atual investigação apresentaram também alto percentual de tratamento com polterapia, $71,1 \%$, tendo em vista os estudos que apontaram cerca de $45 \%$ dos indivíduos com epilepsia tratados com mais de uma $\operatorname{droga}^{(34,99)}$

Indivíduos com epilepsia refratária fazem uso de maior número de fármacos, sendo assim são vários os indícios de refratariedade ao tratamento na casuística analisada; a inserção em ambulatório de referência no tratamento da epilepsia, a elevada frequência de pacientes com epilepsia focal sintomática de lobo temporal, o percentual de indivíduos com crises não controladas e em uso de politerapia.

O tempo médio de doença informado pelos participantes foi de 22,4 anos e o de tratamento 21,5 anos. A epilepsia é uma doença crônica que, geralmente, se manifesta nos primeiros anos de vida e em muitos casos exige tratamento e cuidados para seu controle durante toda a vida. A epilepsia de lobo temporal, frequente neste estudo, é descrita na literatura com início das crises no final da infância ou na adolescência $^{(100)}$.

A carbamazepina, o clobazam, e a lamotrigina foram as medicações mais prescritas para os pacientes (Gráfico 1). A carbamazepina é um fármaco de primeira escolha no tratamento das crises parciais em adultos, nas epilepsias localizadas e, em algumas formas de epilepsias generalizadas ${ }^{(2,21)}$. Os benzodiazepínicos, entre eles, o clobazam, representam um grupo das DAEs frequentemente prescritas. A lamotrigina introduzida nos Estados Unidos da América, em 1994, também comercializada no Brasil é indicada em tratamentos com monoterapia, pelo seu amplo espectro de 
Carla Maria Maluf Ferrari

eficácia e tolerabilidade nos pacientes que não obtiveram o controle de suas crises ou apresentaram efeitos colaterais indesejados com o uso de outra DAE ${ }^{(101)}$.

Outras características consideradas neste estudo estavam relacionadas ao apoio recebido pelo paciente de familiares ou amigos e serviços de saúde. Pela análise dos resultados, observou-se que a maioria sempre ou quase sempre recebia apoio de familiares ou amigos $(73,0 \%)$ e estava satisfeita com o serviço prestado no ambulatório por médicos $(93,0 \%)$ e enfermeiros $(78,6 \%$ dos que conheciam esse profissional).

A satisfação quanto à assistência recebida do(a) enfermeiro(a) também foi interrogada, porém uma parcela muito pequena $(13,6 \%)$ dos entrevistados conhecia esse profissional e tinha condições de opinar sobre seu atendimento. O serviço prestado no ambulatório, local deste estudo, é centrado no atendimento da equipe médica, sendo a participação dos demais profissionais restrita a situações específicas. Em consequência, a previsão dos profissionais de enfermagem para o setor é bem aquém do necessário, para que ocorra um atendimento sistematizado a todos os atendidos no serviço.

Ainda em relação à satisfação do paciente com o atendimento recebido, a maioria, aproximadamente, $61 \%$ dos participantes, considerou fácil marcar consultas periódicas e extras no serviço, além de informar melhora ou muita melhora em seu estado de saúde, após início do tratamento ambulatorial (93,3\%).

A satisfação do paciente é considerada parte importante da avaliação do serviço de saúde. Indivíduos com epilepsia atribuem grande importância à ter uma equipe multiprofissional acessível, comunicativa e experiente para fornecer informações adequadas sobre sua doença ${ }^{(102)}$.

Neste estudo, para adquirir as DAEs, 68,1\% dos participantes informaram utilizar o serviço público onde conseguem todos os medicamentos prescritos Os serviços públicos de assistência são integrados ao Sistema Único de Saúde (SUS) que, além de outras ações, fornece os medicamentos aos pacientes, utilizando protocolos clínicos e diretrizes preestabelecidas ${ }^{(103)}$. 
Carla Maria Maluf Ferrari

No protocolo clínico e nas diretrizes terapêuticas para epilepsia do Ministério da Saúde, o princípio da previsão de dispensação dos medicamentos é estabelecido, no entanto, mais de $30 \%$ dos participantes do estudo não conseguiam adquirir todas as DAEs nesses serviços e buscavam outros meios para conseguir seu medicamento ou ficavam sem tomar.

A complexidade do tratamento medicamentoso mensurada pelo ICTME variou de 2 a 44 pontos, com média de 14,7 pontos e desvio padrão de 8,0. A maioria dos pacientes teve pontuação de 2 a 14 pontos $(56,6 \%)$ e para pacientes em monoterapia, 29,0\% da amostra, esta foi a variação dos valores do índice (2 a 14 pontos). A média dos valores do ICTME para o grupo que recebia uma única droga, foi de 7,3 .

Em estudo realizado por Yeager et al $(2006)^{(4)}$ com 314 pacientes adultos, usando o ICTME, a média desse índice foi de 6,0 pontos por medicamento, com variação de 1 a 20 pontos, e 56\% dos participantes tomavam mais de uma DAE para o tratamento da epilepsia. Na validação da versão inglesa do ICTME, os escores do instrumento variaram de 1 a 15 para cada medicamento e, em média, os participantes tomavam duas DAEs ${ }^{(11)}$.

Embora os resultados desta investigação não permitam comparação direta com os estudos internacionais, vale o comentário de dois aspectos: na avaliação da complexidade terapêutica de droga única, os valores do ICTME alcançaram até 20 pontos e houve indícios de que a complexidade terapêutica da casuística do atual estudo era mais elevada em relação ao grupo avaliado por Yeager et al (2006) ${ }^{(4)}$, resultado provavelmente relacionado com a refratariedade ao tratamento.

No Brasil, resultados sobre a complexidade terapêutica foram observados com o uso do Medication Regimen Complexity Índex ${ }^{(58)}$, instrumento genérico que apresenta três seções: dosagem do medicamento, frequência e orientações adicionais. Este índice foi traduzido e validado em nossa cultura e, nesse processo, os autores brasileiros analisaram os prontuários de 105 pacientes com diabetes tipo 2. Para este estudo, o uso de medicamentos de cada paciente foi analisado em sua totalidade, incluindo as medicações prescritas para outras doenças, os medicamentos prescritos para quadros agudos e os indicados quando necessário. Os resultados mostraram 
Carla Maria Maluf Ferrari

média de 4,5 medicamentos por paciente, complexidade do regime terapêutico de 15,7 pontos em média, valor máximo de 45,5 para 12 medicamentos e mínimo de 4 pontos para um medicamento ${ }^{(58)}$.

O Medication Regimen Complexity Índex foi aplicado em estudo internacional de pacientes com doença pulmonar obstrutiva crônica ${ }^{(104)}$. Nos resultados, foram observadas pontuações de 25,5; 30; 32 e 41 para quatro pacientes que tomavam oito medicações; por outro lado, escores de 23,5; 26,5 e 36,5 foram identificados em três pacientes que faziam uso de nove drogas. De forma similar na atual investigação, indivíduos que recebiam quatro DAEs tiveram maior pontuação média no ICTME do que os com cinco medicações em seu regime terapêutico.

No geral, as maiores médias de pontuação no ICTME foram observadas em indivíduos que recebiam maior número das DAEs, entretanto, também foi percebido que indivíduos com uma única droga tiveram indicação de complexidade terapêutica igual ou superior àqueles com prescrição de até quatro drogas (Tabela 9). Estes resultados indicam que além do número de drogas, outras características do regime terapêutico são de grande importância em sua complexidade.

O ICTME apresenta quatro seções que se referem às informações gerais sobre o medicamento; frequência da administração; instruções especiais e ações para administração. A seção informações gerais sobre a medicação, não pontua no índice, mas identifica o nome genérico do medicamento; quantidade em relação ao número total de medicamentos prescritos; número de comprimidos tomados por dia e a dosagem. A seção frequência que toma a medicação refere-se à quantidade de vezes e/ou horários das medicações, são apresentados 16 horários diferentes correspondentes aos períodos tradicionalmente prescritos. $\mathrm{Na}$ seção instruções especiais, são consideradas aquelas que são frequentemente solicitadas ao paciente epiléptico, tais como: diferentes doses da mesma medicação no mesmo dia ou em dias alternados, entre outras. Na seção ações para administração estão listadas 13 ações diferentes, por ex: tomar a medicação com a comida, dividir o comprimido ao meio; misturar com a comida. A pontuação total do instrumento pode ter grande variação, mesmo quando se considera um único medicamento, visto que vários itens 
Carla Maria Maluf Ferrari

podem ser checados na mesma seção e outros novos itens podem ser descritos e pontuados.

Autores anteriormente citados que aplicaram o $\operatorname{ICTME}^{(4)}$, constataram que as ações de administração da medicação contribuíram com o maior número de pontos no escore total da complexidade terapêutica.

A maior complexidade do esquema terapêutico requer muitos cuidados e diferentes em razão da quantidade de drogas, número de comprimidos/ horários, dose, e outras condições para a tomada do medicamento ${ }^{(4,11)}$.

Vários autores ${ }^{(9,10,57,58)}$ afirmam que o aumento do número de comprimidos torna o esquema terapêutico mais complexo e aumenta a falha no tratamento ${ }^{(105)}$. A alta complexidade do tratamento com as DAEs pode causar grande impacto negativo na adesão ao tratamento entre indivíduos com epilepsia ${ }^{(4,11,106)}$, assim como em outras doenças crônicas ${ }^{(58,104,107)}$.

Nesta pesquisa, a mensuração da adesão por meio do teste de Morisky evidenciou que 33,8\% dos indivíduos com epilepsia apresentaram alta adesão ao tratamento, $66,2 \%$ média/baixa adesão (60,5\% média e 5,7\% baixa adesão).

Estudos internacionais que avaliaram a adesão ao tratamento de pacientes epilépticos com o teste de Morisky, mostraram percentuais bastante próximos de não adesão terapêutica $58 \%$ e $59 \%{ }^{(1,99)}$. Em estudo americano realizado com uma amostra de 50 pacientes, idade entre 20 a 70 anos, 50\% do sexo feminino, $92 \%$ da raça branca, $53 \%$ com crises nos últimos 30 dias, $48 \%$ em uso de duas ou mais DAEs, o percentual de média/baixa adesão foi de $58 \%{ }^{(99)}$. Em investigação realizada com 54 indivíduos adultos no Reino Unido, esse valor alcançou $59 \%{ }^{(1)}$. Os valores observados em nossa meio foram, portanto, mais altos, porém próximos aos desses países.

Frequência similar de não adesão, 68,5\%, foi observada em grupo de pacientes brasileiros com epilepsia mioclônica juvenil em seguimento ambulatorial. Nesse estudo, a partir de informações da literatura, os autores elaboraram o instrumento de mensuração de adesão utilizada ${ }^{(108)}$. 
Carla Maria Maluf Ferrari

Estudos nacionais não têm avaliado adesão terapêutica com o teste de Morisky em grupos de pacientes com epilepsia; entretanto, são várias as pesquisas brasileiras que analisaram a adesão em pacientes com doenças crônicas, utilizando esse teste como instrumento de avaliação.

Os porcentuais de não adesão nesses estudos variaram de $28 \%$ a $85,8 \%{ }^{(109,110,111)}$. O mais baixo percentual de não adesão foi observado entre 61 pacientes adultos em terapia antineoplásica oral $(28 \%)^{(109)}$. Grupos de pacientes com doenças crônicas com percentuais de não adesão mais próxima, porém inferiores à atual investigação, foram observados em pacientes de doença de Crohn, 50,0\% ${ }^{(103)} \mathrm{e}$ $64 \%{ }^{(112)}$, com pancreatite, $54 \%{ }^{(103)}$, para indivíduos diabéticos, $54,4 \%{ }^{(113)}$ para diagnóstico de retocolite ulcerativa, 63,35\% ${ }^{(103)}$ e $63,4 \%$ para afecções crônicas digestivas ${ }^{(103)}$. Para grupos de pacientes com diagnóstico de hipertensão arterial a ocorrência de não adesão foi mais elevada, estudos mostraram percentuais de $77 \%$ (110) e $85,8 \%{ }^{(111)}$.

Nesta pesquisa, as respostas mais frequentes no teste de Morisky que se relacionaram com a não adesão, foram o esquecimento da tomada do medicamento e o descuido para tomar a medicação, observadas em 47,5\% e 39,2\% dos casos respectivamente (Gráfico 2).

Cramer et al (2002) ${ }^{(57)}$ avaliaram 661 indivíduos adultos com epilepsia em relação à baixa adesão ao tratamento e a presença de crises, após o esquecimento da tomada do medicamento, por meio de um questionário com dez questões que abordava a medicação, a dose, o esquecimento e a presença de crise. O resultado mostrou que $66 \%$ dos entrevistados faziam uso de mais de quatro comprimidos/dia, $71 \%$ referiram esquecimento em tomar a DAE, apenas 32\% informaram a equipe quanto ao esquecimento da tomada do medicamento e $45 \%$ referiram apresentar crise, após a não tomada da medicação.

A adesão em pacientes epilépticos mensurada por meio do autorelato do paciente, quanto a ter falhado ou interrompido a medicação há 1 semana, há 1 mês e há 3 meses da data da entrevista, classificou $29 \%$ dos pacientes como não aderentes e $72 \%$ informaram que o esquecimento foi o principal fator ${ }^{(7)}$. 
Carla Maria Maluf Ferrari

Além desses estudos internacionais que evidenciaram o esquecimento como fator importante na não adesão em pacientes epilépticos, algumas das pesquisas brasileiras que avaliaram a adesão terapêutica com o teste de Morisky, também analisaram essa associação e mostraram que em outras doenças crônicas, além da epilepsia, o esquecimento e o descuido quanto à tomada do medicamento são fatores associados à adesão.

Em acompanhamento do tratamento com hipoglicemiante oral em unidades básicas de saúde de Sobral-Ceará, 66\% dos diabéticos informaram que se esquece de tomar a medicação e 54,5\% que foram descuidados quanto ao horário de ingestão da tomada do fármaco ${ }^{(113)}$.

O estudo nacional que obteve maior percentual de não adesão ao tratamento mensurada pelo teste de Morisky, 85,8\%, mostrou que $89 \%$ dos participantes relataram descuido quanto ao horário da medicação; a outra resposta mais frequente apontou o esquecimento com frequência de $58,3 \%^{(111)}$.

Este estudo revelou associação entre não adesão ao tratamento e as variáveis, presença de crise nos últimos 30 dias, controle de crises, número das DAEs, idade e complexidade terapêutica. O sexo, embora tenha apresentado na análise univariada fraca evidência de associação com não adesão, $p=0,053$, na análise de regressão logística alcançou significância estatística e manteve-se no modelo final, assim como as variáveis, controle de crises, idade e complexidade terapêutica mensurada pelo ICTME.

No norte de Taiwan, estudo de adesão ao tratamento com 357 indivíduos adultos com epilepsia, abordando variáveis demográficas, relacionadas aos sintomas da doença, ao autocuidado e à relação médico paciente, mostrou que as mulheres eram mais aderentes ao tratamento medicamentoso em relação ao sexo masculino, $58,9 \%$ perante $41,1 \%$ dos homens, alcançando significância estatística na comparação dos grupos $(\mathrm{p}<0,01)^{(97)}$.

Pierin et al (2001) $)^{(114)}$ estudaram 205 pessoas adultas com hipertensão em tratamento ambulatorial obtiveram como principal resultado que homens, jovens e não brancos desconhecem aspectos importantes da doença e que maiores níveis tensionais relacionam-se às variáveis biológicas e sociais desfavoráveis. Ressaltaram 
Carla Maria Maluf Ferrari

ainda que os homens tendem a ser menos aderentes ao tratamento medicamentoso em relação às mulheres, possivelmente decorrente de aspectos culturais e sociais relacionados a este gênero que se considera em uma posição de comando e dominação.

Segundo Gomes e Nascimento $(2006)^{(115)}$, na literatura internacional algumas considerações são feitas, quando se buscam aspectos da relação "homem e saúde" e, entre elas, está a indicação de que os homens, em geral, padecem mais de condições severas e crônicas de saúde do que as mulheres.

Estudo qualitativo sobre as concepções masculinas e femininas em relação à saúde mostrou que as mulheres assumem em maior grau atitudes preventivas, apresentam melhor enfrentamento ao diagnóstico e adesão ao tratamento. Os aspectos destacados em relação à concepção dos homens foram: a prioridade que atribuem ao trabalho, fato que faz com que posterguem ao máximo a ajuda médica diante do risco de desemprego; a dificuldade de acesso aos serviços; a falta de unidades específicas para a saúde do homem e a crença de que o cuidar representa uma tarefa feminina ${ }^{(116)}$

A idade foi outra variável demográfica que se manteve no modelo final. A não adesão foi mais freqüente nos mais jovens; no modelo de regressão houve indicação que o aumento de um 1 ano na idade diminuiu em $3 \%$ a probabilidade de não adesão.

Colombrini et al. (2006) $)^{(117)}$ em estudo de revisão da literatura sobre adesão à terapia para HIV positivo, obtiveram como resultado que a adesão aumenta com a idade, exceto acima dos 75 anos. No atual estudo a idade dos participantes variou de 18 a 76 anos, portanto indivíduos maiores de 75 anos tiveram pouca expressão nos resultados (três indivíduos).

A análise dos fatores de risco para não adesão ao tratamento entre indivíduos acima de 18 anos com doença de Chron evidenciou os jovens e não-brancos como os pacientes de maior risco de não adesão ${ }^{(112)}$.

O número das DAEs e a complexidade terapêutica mensurada ICTME também estiveram significativamente associados a não adesão terapêutica, e a 
Carla Maria Maluf Ferrari

complexidade terapêutica foi a única variável que permaneceu no modelo de regressão com um coeficiente positivo, aumentando a probabilidade de não adesão em $6 \%$ a cada aumento de um ponto no escore do ICTME.

A adesão entre indivíduos com epilepsia diminui, à medida que aumenta o número de doses da medicação tomada ao dia e a variedade de fármacos do esquema terapêutico $^{(57)}$.

Tanto na epilepsia como em outras doenças crônicas, como a hipertensão e a AIDS, a complexidade terapêutica é fator associado à tomada do medicamento, ou seja, onforme aumenta a complexidade do regime terapêtico, diminui a compreensão do paciente referente à posologia das medicações podendo acarretar em falha ao seguir o esquema terapêutico ${ }^{(4,56,104,107,118)}$. Consequentemente, a complexidade terapêutica também interfere no controle dos sintomas das doenças.

Entre indivíduos com epilepsia, o não controle das crises é o principal fator associado à alta morbidade e mortalidade. As crises epilépticas não controladas estão associadas a lesões físicas como traumatismos cranianos, fraturas, queimaduras, além de problemas psicossociais como depressão e ansiedade, redução da qualidade de vida e também morte súbita. Existem muitos fatores relacionados à epilepsia e ao tratamento que contribuem para o não controle das crises, a etiologia e tipo de crise as comorbidades e a não adesão ao tratamento ${ }^{(119)}$.

As variáveis, frequência de crises nos últimos 30 dias e o controle das crises apresentaram relação com a não adesão, no entanto somente esta última permaneceu no modelo final de regressão. Neste estudo, pacientes com controle de crises apresentaram mais baixa probabilidade de não adesão, havendo assim um impacto negativo da presença de controle de crises na não adesão (coeficiente negativo).

A comparação de dois grupos de indivíduos com epilepsia, aderentes (298) e não aderentes ao tratamento (110), também mostrou associação da não-adesão ao não controle das crises. Nesse mesmo estudo, observou-se que indivíduos sem controle das crises tiveram alteração da dose da medicação (70\%), acréscimo de uma nova droga $(56 \%)$ ou mudança de medicamento $(61 \%)$, intervenções que podem resultar em aumento da complexidade do regime terapêutico dos pacientes ${ }^{(7)}$. 
Carla Maria Maluf Ferrari

A baixa adesão entre indivíduos com epilepsia é um dos fatores fortemente associados ao não controle das crises epilépticas, assim como em outras doenças crônicas o controle das manifestações clínicas relaciona-se com a adesão ${ }^{(1)}$.

$\mathrm{Na}$ investigação da adesão por meio do teste de Morisky em uma amostra de 301 indivíduos com diabetes tipo 2 a análise de associação entre a adesão ao tratamento e o resultado da dosagem sérica da hemoglobina glicosilada demonstrou que à medida que aumentou a adesão, diminuiu o nível sérico da hemoglobina glicosilada. Os resultados, desse estudo também evidenciaram impacto clínico da adesão na diminuição dos riscos de complicações vasculares ${ }^{(120)}$.

Estudo retrospectivo de coorte que avaliou a não adesão entre 11.532 indivíduos adultos com diabetes mostrou que indivíduos jovens eram menos aderentes tinham menos comorbidade, porém durante o seguimento os não aderentes tinham elevação da hemoglobina glicosilada, dos níveis pressóricos, dos níveis de lipoproteína de baixa intensidade, além de maior risco de hospitalização e morte ${ }^{(121)}$.

A não adesão ao tratamento reduz os benefícios que podem ser adquiridos com a medicação e pode ser um fator importante do não controle das crises ${ }^{(1)}$.

O não controle das crises pode ser considerado consequência e não estímulo à não adesão; no entanto, na literatura encontram-se também evidências de que há impacto positivo na adesão quando ocorre a presença de crises, após falha de ingestão da dose da medicação ${ }^{(96)}$.

A qualidade de vida em indivíduos com epilepsia tem sido mensurada para avaliar aspectos da doença, os efeitos do tratamento com a DAE, a gravidade das crises e também os resultados de tratamentos cirúrgicos. ${ }^{(122)}$.

Nesta pesquisa, o valor total médio do QOLIE-31 foi de 67,7 pontos. Estudos internacionais que avaliaram a qualidade de vida de indivíduos com epilepsia com esse instrumento mostraram pontuação média do escore total de 49,5 a 65,9 pontos ${ }^{(92,}$ 77,78) . No estudo africano realizado em Togo e Benin as médias do escore total do QOLIE-31 foram de $49,5^{(92)}$ e 52,1 pontos ${ }^{(92)}$, respectivamente. Na Espanha a média do escore total foi de $61,77^{(75)}$; na Itália 63,9 $\operatorname{pontos}^{(77)}$ e na República Checa 65,6 pontos $^{(78)}$. Publicação brasileira ${ }^{(123)}$ que utilizou o QOLIE-31 em pacientes com 
Carla Maria Maluf Ferrari

epilepsia mioclônica juvenil, apresentou pontuação total de 62,1 , portanto, nesse estudo, assim como nos estudos europeus valores inferiores, porém próximos aos obtidos na atual pesquisa foram observados.

Quanto aos domínios do questionário, na pesquisa atual as menores médias foram nos domínios preocupação com as crises $(53,2)$, seguidas do efeito da medicação $(61,3)$ e a maior média $(69,8)$ relacionou-se ao aspecto social. Na análise de qualidade de vida em um grupo de pacientes com epilepsia mioclônica juvenil, da cidade de São Paulo, assim como no atual estudo, os menores valores médios foram observados nos domínios preocupação com a crise (33 pontos) e efeito da medicação (51 pontos). A maior média entre os domínios também foi observada em relação aos aspectos sociais (79 pontos).

A mensuração da qualidade de vida de 19 pacientes epilépticos em Alagoas mostrou as menores médias para preocupação com a crise (40,4 pontos) e aspecto cognitivo (58,2 pontos) sendo o maior valor referente ao domínio efeito de medicação $(74,8)^{(123)}$.

No processo de validação do QOLIE-31 para a nossa cultura, a menor média relacionou-se ao aspecto social $(33,1)$, seguida do aspecto cognitivo $(38,9)$, a mais elevada foi no domínio qualidade de vida geral $(68,9 \text { pontos })^{(72)}$.

Diferenças e semelhanças foram observadas nas pontuações dos domínios do QOLIE-31 na comparação desses estudos nacionais, no entanto, as diferenças regionais das condições sociais e culturais, assim como de critérios de inclusão na amostra dos estudos podem estar relacionadas com essa observação. Os critérios de elegibilidade da atual investigação incluíram ser alfabetizado, independente nas atividades de vida diária, sem deficiência mental ou alteração psíquica ativa diagnosticada no período da entrevista. Os demais estudos também tiveram critérios específicos, tais como, tipo de epilepsia, período do início das crises e tempo de tratamento no serviço, entre outros.

No estudo de Togo e Benin ${ }^{(92)}$ as menores médias foram no domínio de preocupação com as crises 27,9 e 30,4, respectivamente; seguidas de 45,4 e 39,01 no domínio energia e fatiga, e as maiores médias relacionaram-se ao domínio efeito das medicações $(89,6$ e 82,4). Segundo os autores, os indivíduos com epilepsia dessas 
Carla Maria Maluf Ferrari

regiões estão em desvantagem em comparação com a população de outros países e as razões para esse fato estão associadas às representações sócioculturais e crenças relacionadas à epilepsia, além do não controle das crises, deficiência no tratamento, dificuldade de ajustamento e altos níveis de estresse que se refletem negativamente nas relações conjugais, no acesso às escolas, no trabalho qualificado e na superação do estigma da doença ${ }^{(92)}$.

A epilepsia é uma condição crônica que acarreta mudanças de hábitos com impacto na qualidade de vida dos indivíduos e muitos fatores podem estar associados às suas repercussões. Vários estudos em países desenvolvidos como em desenvolvimento vêm indicando que a qualidade de vida relacionada a saúde, entre indivíduos com epilepsia é significativamente pior quando comparadas com a população em geral e a outras doenças crônicas ${ }^{(124)}$.

$\mathrm{Na}$ análise univariada, o escore total do QOLIE-31 apresentou associação significativa com o sexo, raça, situação ocupacional, renda per capita, presença de crises nos últimos 30 dias, controle de crises, percepção do controle de crises, número de DAEs, adesão terapêutica, apoio de familiares e amigos, além da percepção do estado de saúde após início do tratamento no ambulatório, tempo que conhece o diagnóstico, tempo de tratamento, frequência de consultas e complexidade terapêutica. Dessas variáveis permaneceram no modelo final de regressão linear as variáveis, raça, situação ocupacional, percepção do controle de crise e apoio de familiares e amigos, variáveis que apresentaram maior impacto na pontuação do QOLIE-31.

No modelo final, a raça foi significativamente associada à qualidade de vida. Indivíduos da raça branca/amarela tiveram maior probabilidade de apresentar melhor qualidade de vida, portanto, maior pontuação total do QOLIE-31em relação a negros e $\operatorname{pardos}(p=0,016)$.

Os brasileiros afro-descendentes constituem a segunda maior nação negra do mundo, ficando atrás somente da Nigéria. A raça tem importância significativa na estruturação das desigualdades sociais e econômicas no Brasil.

Em estudo sobre as desigualdades raciais no Brasil, constatou-se que nascer da cor negra ou parda aumenta significativamente a condição de ser pobre, e o fato 
Carla Maria Maluf Ferrari

está associado à desigualdade da distribuição dos recursos financeiros, redução de oportunidades de boa educação entre as crianças e jovens de 5 a 14 anos, o alto número dessa faixa etária inserida no mercado de trabalho, a maior precariedade de ofertas de emprego e condições habitacionais entre os negros do que entre os brancos (125)

Em revisão sistemática de literatura sobre diferenças raciais e étnicas entre indivíduos com epilepsia, pesquisadores ${ }^{(126)}$ analisaram 58 artigos publicados entre 1977 e 2005. Os resultados mostraram que os gastos com o tratamento da epilepsia entre os indivíduos brancos foi maior do que com os da raça negra. Os negros procuraram mais o atendimento de emergência em relação aos brancos, também foi observada menor freqüência do uso de terapias mais avançadas nesse grupo étnico, como por exemplo, as intervenções cirúrgicas. Os autores consideraram que tais fatos poderiam estar associados à não compreensão ou falta de conhecimento dos indivíduos da raça negra em relação à doença e terapias específicas ${ }^{(126,127)}$.

Em estudo sobre raça e desigualdade entre mulheres de 15 a 49 anos vivendo em uma cidade no Sul do Brasil, observou-se que as mulheres negras e pardas apresentaram menor escolaridade, renda familiar, piores condições de moradia do que as mulheres brancas. Além disso, usavam menos métodos contraceptivos, tinham mais filhos e apresentaram maior perda fetal do que as mulheres brancas. Os resultados evidenciaram associação entre cor da pele e condições sócioeconômicas das mulheres; conforme a cor da pele era mais escura piores eram suas condições ${ }^{(128)}$.

Paschal et al. (2005) ${ }^{(129)}$ em estudo sobre estigma e acessos ao cuidado de saúde entre mulheres afro-americanas com epilepsia indicou quatro principais obstáculos para o tratamento entre essas pessoas: recursos financeiros limitados, falta de conhecimento da doença, deficiente comunicação médico-paciente e falta de apoio social.

Baca et al (2009) ${ }^{(130)}$ em estudo sobre as diferenças raciais e expectativas dos pacientes, antes da cirurgia de epilepsia mostrou que entre os indivíduos não brancos era maior a expectativa relacionada a melhores condições de emprego, educação e melhora na cognição em relação aos brancos e, possívelmente, esses resultados 
Carla Maria Maluf Ferrari

refletiram diferenças gerais no status socioeconômico dos entrevistados. A maior expectativa para o emprego entre os não-brancos em comparação com os brancos pode ser em razão das taxas de desemprego mais elevada entre eles na amostra estudada (64\% de negros desempregados em comparação com 45\% dos brancos).

A situação profissional também se manteve no modelo final associada à qualidade de vida. A condição de estar inserido no mercado de trabalho aumentou a probabilidade dos indivíduos terem melhor qualidade de vida $(\mathrm{p}=0,021)$. Indivíduos inseridos no mercado de trabalho apresentaram em média maior pontuação no QOLIE-31.

Os problemas dos indivíduos com epilepsia no mercado de trabalho envolvem situações interligadas referentes à epilepsia, ao indivíduo, aos conceitos da sociedade e ao mercado que tem se tornado cada vez mais competitivo e colocado as pessoas com algum tipo de comprometimento em posição de desvantagem para a ocupação de uma vaga, mesmo que sejam capacitadas para tal ${ }^{(131,132)}$

Outro aspecto é o significado que um indivíduo dá para ter um emprego. Percepções da autoestima, as atitudes familiares e preocupações sobre a segurança no local de trabalho e sua percepção quanto ao risco de prejuízo para si e os outros também são fatores determinantes da situação de trabalho das pessoas com epilepsia $^{(133)}$

A taxa de desemprego dos indivíduos com epilepsia é de duas a quatro vezes maior que a da população geral e $40 \%$ dos trabalhadores com epilepsia estão subempregados. Esses indivíduos revelam dificuldades para encontrar e manter um emprego ${ }^{(133)}$. As taxas de desemprego são mais elevadas entre os que apresentam crises frequentes, e estas podem afetar negativamente o trabalho ${ }^{(134)}$.

A crise epiléptica torna o paciente dependente de terceiros, muitas vezes, é incapaz de gerenciar sua vida, pois a imprevisibilidade das crises diminui a autoconfiança, a autonomia e a sensação de liberdade, dificultando o relacionamento consigo mesmo e sociedade ${ }^{(131)}$. 
Trabalhar e ganhar são sinais de integração e aceitação na sociedade e ser empregado é parte fundamental da qualidade de vida. O emprego vai além de seu valor econômico, contribui para o status pessoal, identidade e autoestima ${ }^{(133)}$.

No resultado final da regressão linear, a percepção do controle das crises foi a variável que mais se destacou na associação com qualidade de vida. Indivíduos que informaram a percepção de controle das crises tiveram em média maior pontuação no QOLIE-31.

Em estudos internacionais sobre epilepsia, a percepção do paciente em relação à gravidade e controle das crises é um preditor de qualidade de vida relevante, até mais importante do que a frequência das crises ${ }^{(135,136)}$. Além disso, na literatura científica há indicação de que a diminuição da freqüência das crises causa um impacto positivo na qualidade de vida dos pacientes ${ }^{(137,138)}$.

Em estudo sobre a qualidade de vida entre 103 indivíduos adultos com epilepsia, maioria do sexo feminino, sem crises há 1 ano e em monoterapia, a média do escore total do QOLIE-31 foi de 76,26 pontos, e no domínio preocupação com as crises a pontuação média foi de 71,7 pontos. Na comparação com outros estudos, os autores atribuíram esse escore mais elevado ao controle das crises, a altos níveis de autoestima e aspectos psicossociais, a baixos níveis de ansiedade e estresse, assim como ao melhor ajuste em relação à doença ${ }^{(139)}$.

O diagnóstico de uma doença crônica limitante pode modificar a autopercepção, os valores da vida social, econômica e planos futuros. A percepção de bem estar de uma pessoa com doença crônica sofre mais influência dos mecanismos de auto-avaliação do que do próprio estado físico ${ }^{(13)}$.

Recentemente, Kubota e Awaya $(2010)^{(74)}$ realizaram um estudo com 599 indivíduos com epilepsia, maiores de 16 anos, sobre fatores que influenciam a qualidade de vida usando a versão japonesa do QOLIE-31. Obtiveram como resultado vários fatores com substancial influência na melhor qualidade de vida dos pacientes: controle de crises (ausência há 2 anos ou mais), crise "muito leve", ausência de lesões e quedas em consequência das crises, ausência de alteração cognitiva ictal, confusão pós-ictal com rápida recuparação, uso de monoterapia, bom resultado após o tratamento cirúrgico e ausência de comorbidades, tal como 
Carla Maria Maluf Ferrari

depressão. Além dessas variáveis, a inserção do mercado de trabalho também se destacou nas análises.

A relação da frequência e gravidade das crises e qualidade de vida é bem documentada na literatura ${ }^{(140,141)}$

Em estudo com uma amostra de mais de 5.000 indivíduos com epilepsia vivendo em 15 países da Europa, sobre a qualidade de vida dessa população, o controle e a redução das lesões pós-ictais (queimaduras, lesões cranianas, dentárias e outras) foram considerados aspectos importantes para reduzir o estigma, as incapacidades e melhorar a qualidade de vida dessas pessoas ${ }^{(142)}$.

Neste estudo, a presença de apoio recebido de familiares e amigos apresentou indicação de impacto negativo na qualidade de vida dos participantes. O grupo que reportou receber apoio de familiares ou amigos teve em média mais baixos escores no QOLIE-31 que os demais.

O apoio social tem sido definido como o empenho, carinho, conselhos e a ajuda nos relacionamentos pessoais. O conforto físico e emocional, quando demonstrado positivamente por parceiro íntimo ou por familiares e amigos próximos, contribui como "válvula de escape" em relação ao impacto negativo de eventos estressantes em condições crônicas de saúde. O apoio social envolve: apoio emocional (expressão de afeto, empatia e incentivo à expressão de sentimentos); suporte informacional (aconselhamento e orientação na resolução de problemas); suporte instrumental (o fornecimento de recursos tangíveis ou apoio financeiro e ajuda prática com atividades de vida diária); avaliação (comparação positiva com os demais); convívio social (participação em atividades de lazer e/ou recreativas) e apoio afetivo (expressões de amor e carinho). A doença crônica exige reajustes diários a situações que possam interferir nas atividades do dia a dia. Tanto os efeitos positivos de apoio ou os negativos da falta de apoio podem influenciar diretamente a saúde ${ }^{(143)}$.

A qualidade de vida pode ser influenciada por consequências sociais da epilepsia, que podem incluir discriminação na oferta de empregos, participação reduzida nas atividades comunitárias, estigma e problemas nas relações familiares. 
Carla Maria Maluf Ferrari

As reações familiares negativas podem ser prejudiciais para a qualidade de vida de adultos com epilepsia ${ }^{(144)}$.

Os resultados da atual investigação contrapõem-se a essas indicações da literatura, visto que foi observada melhor qualidade de vida entre os que referiram não ter apoio de seus familiares. A intensidade de apoio de familiares e amigos pode também ser vinculada a situações de fragilidades físicas e sociais dos pacientes com maior gravidade da doença. Em conseqüência, a gravidade das manifestações da doença pode ter prejudicado a qualidade de vida dos pacientes e também desencadeado apoio mais expressivo de familiares e amigos do paciente.

Por outro lado, a epilepsia pode causar altos níveis de dificuldades psicossociais entre os membros da família, estigmatização, estresse, problemas psiquiátricos, dificuldades conjugais, baixa autoestima e restrição nas atividades sociais. A superproteção e restrição das atividades também estão associados à má adaptação do indivíduo à doença e interferir em sua qualidade de vida ${ }^{(145)}$.

Em estudo prospectivo sobre emoções expressas por familiares em relação aos indivíduos com epilepsia, observou-se por meio da aplicação de um questionário específico (Expressed Emotion - EE) que o perfil emocional da amostra familiar estudada (19 esposas, 17 mães e 7 pais) foi de baixa empatia em relação ao paciente. Cerca de um quinto dos entrevistados apresentou indicação de hostilidade em sua avaliação, porém, as mães apresentaram níveis significativamente superiores de envolvimento emocional em comparação aos pais e cônjuges. A superproteção também foi negativa, pois muitas vezes, privou os pacientes das experiências de vida normal da sua idade ${ }^{(146)}$.

Mudanças no comportamento familiar podem melhorar a qualidade de vida do paciente. Quando o suporte é percebido positivamente os pacientes sentem-se encorajados em enfrentar melhor a doença e manter suas relações pessoais ${ }^{(145,146)}$.

O aconselhamento familiar em relação as expressões de apoio é útil, pois padrões de crítica e hostilidade estão correlacionados com maiores níveis de ansiedade e depressão do paciente, estes sintomas aumentam as limitações impostas pela doença. As intervenções terapêuticas também devem envolver a família 
Carla Maria Maluf Ferrari

permitindo uma reorganização das atitudes emocionais que possam ter um efeito desfavorável sobre o curso clínico da doença e adaptação do paciente a ela ${ }^{(146)}$.

No geral, os resultados deste estudo mostraram a frequência de não adesão e escores totais de qualidade de vida próximos aos observados em pacientes epilépticos de casuísticas de estudos em países desenvolvidos. A epilepsia é uma condição estigmatizaste por excelência, e isso inevitavelmente afeta a qualidade de vida. Vários são os impactos da epilepsia nas atividades de vida diária incluindo restrições na educação, emprego e independência decorrentes sobretudo da presença das crises e dos efeitos colaterais das medicações. A baixa adesão é uma das principais causas das complicações da doença e suas conseqüentes repercussões econômicas, sociais e pessoais.

Não obstante, a adesão não permaneceu no modelo final para variável resposta qualidade de vida e as variáveis sociodemográficas, raça e situação ocupacional tiveram maior destaque assim como o apoio de familiares e amigos e a percepção do controle das crises. Provavelmente essas variáveis têm mais direta relação com a qualidade de vida, visto que a adesão é importante, mas não garante o controle das crises e em conseqüência só terá o impacto positivo esperado se os desdobramentos da presença da crise forem evitados.

A percepção do controle da crise foi a variável que se destacou em relação as demais na análise dos coeficientes da regressão, provavelmente pela aproximação dos conceitos crise e doença no cotidiano do indivíduo epiléptico. A crise é a manifestação clínica que quando ausente diminui o impacto negativo da doença na vida dos pacientes epilépticos.

A expectativa que o paciente fique livre das crises epilépticas, é um objetivo dos profissionais de saúde, nem sempre facilmente tangível, portanto é importante que os profissionais ampliem seu foco além das manifestações clínicas da doença e valorizem seu apoio para os pacientes tanto para superar as dificuldades decorrentes da epilepsia como para otimizar o tratamento, além disso, semelhante a várias outras doenças cronicas, enfermeiros devem estar envolvidos no tratamento da epilepsia.

Para finalizar os comentários dos resultados, algumas limitações desta pesquisa merecem destaque: na avaliação da adesão, foi utilizado um instrumento 
que facilitou a comparação com outros grupos de pacientes com doenças crônicas, porém, genérico; os critérios de elegibilidade, necessários para aplicação dos instrumentos, restringem os resultados a grupos que atendem aos mesmos critérios, além disso, o estudo incluiu indivíduos com diferentes diagnóstico de epilepsia, portanto, com distintas manifestações clínicas da doença e diferentes respostas ao tratamento. 


$$
\mid
$$




\section{CONCLUSÕES}

O estudo de 385 indivíduos com epilepsia em tratamento ambulatorial no HCFMUSP, com idade média de 39,7 anos $(\mathrm{dp}=12,6)$, a maioria do sexo feminino (53,5\%), com diagnóstico de epilepsia focal sintomática $(79,5 \%)$, em uso de politerapia $(71,1 \%)$, apresentando crises nos últimos seis meses que precederam a investigação (79\%) e tempo médio de tratamento de 21,5 anos $(\mathrm{dp}=13,2)$ permitiu as conclusões descritas a seguir.

A complexidade terapêutica do tratamento medicamentoso para epilepsia mensurada pelo ICTME variou de 2,0 a 44 pontos, média de 14,7 e desvio padrão de 8,0. A média do ICTME para indivíduos em monoterapia foi de 7,3 $(\mathrm{dp}=2,74)$, para aqueles que recebiam duas DAEs foi de 13,6 $(\mathrm{dp}=4,69)$, para os com três drogas 19,8 $(\mathrm{dp}=5,61)$, para quatro e cinco DAEs os valores médios foram 31,3 $(\mathrm{dp}=7,08)$ e 29,5 $(\mathrm{dp}=2,12)$, respectivamente.

A adesão ao tratamento segundo o teste de Morisky foi alta para 33,8\% dos participantes deste estudo, média para $60,5 \%$ e baixa para $5,7 \%$; indivíduos não aderentes, média e baixa adesão, totalizaram $66,2 \%$ dos pacientes.

O escore total do QOLIE-31, instrumento específico para avaliar qualidade de vida em indivíduos com epilepsia, foi de 64,2, desvio padrão de 18,19. Entre os domínios do QOLIE-31 os valores médios mais baixos foram 53,2 ( $\mathrm{dp}=31,38)$, no domínio preocupação com as crises, seguido de $61,3(\mathrm{dp}=32,61)$ no domínio efeito da medicação. O mais alto valor médio foi $69,8(\mathrm{dp}=25,74)$ no domínio aspecto social.

As variáveis que apresentaram associação estatisticamente significante $(\mathrm{p}<0,05)$ com a adesão terapêutica foram: idade, presença de crise nos últimos 30 dias, controle de crises, número de DAEs e complexidade terapêutica, segundo ICTME.

O resultado da regressão logística multivariada para não adesão ao tratamento medicamentoso evidenciou as variáveis, idade, sexo, complexidade terapêutica e controle de crises. Indivíduos do sexo feminino e que apresentavam controle das 
crises tiveram menor probabilidade de não adesão terapêutica perante aos do sexo masculino e sem controle das crises. A não adesão foi menos freqüente nos mais velhos e o aumento de um ano na idade diminui a probabilidade de não adesão em $3 \%$. A probabilidade de não adesão ocorrer foi $6 \%$ maior a cada aumento de um ponto no ICTME.

$\mathrm{Na}$ análise dos fatores relacionados à qualidade de vida alcançaram associação estatisticamente significante as variáveis: sexo, raça, situação ocupacional, renda per capita, presença de crise nos últimos 30 dias, controle de crise, percepção do controle de crise, número de DAEs, adesão terapêutica mensurada pelo teste de Morisky, apoio de familiar ou amigos, percepção do estado de saúde após início do tratamento no ambulatório, tempo que conhece o diagnóstico de epilepsia, tempo de medicação, frequência de consultas e complexidade terapêutica.

A análise conjunta das diversas características evidenciou que as variáveis que melhor explicam a variação do QOLIE-31 foram raça, situação ocupacional, percepção do controle de crises e apoio de familiares ou amigos. Indivíduos da raça branca e amarela, inseridos no mercado de trabalho e que tinham percepção que suas crises estavam controladas tiveram pontuações mais elevadas em relação aos que não apresentavam essas características. Por outro lado, aqueles que recebiam apoio de familiares ou amigos apresentaram menores escores nesse questionário em relação aos demais. 


$$
1
$$




\section{REFERÊNCIAS}

1. Jones RM, Butler JA, Thomas VA, Peveler RC, Prevett M. Adherence to treatment in patients with epilepsy: associations with seizure control and illness beliefs. Seizure. 2006;15: 504-508.

2. Elger CE, Schmidt D. Modern management of epilepsy: a pratical approach. Epilepsy Behav. 2008; 12: $501-539$.

3. Valente K. Epilepsia.Laboratório de Neurociências do Instituto de Psiquiatria da faculdade de Medicina da Universidade de São Paulo. Disponível em http:// www.neurociencias.org.br.Acesso em 02/07/210.

4. Yeager KA, DiIorio C, Shafer PO, Mc Carty F, Letz R, Henry T, et al. The complexity of treatments for persons with epilepsy. Epilepsy Behav. 2005; 7:679-686

5. Santa Helena ET. Adesão ao tratamento farmacológico de pacientes com hipertensão arterial em unidades de saúde da família, Blumenau, SC. [tese]. São Paulo (SP): Faculdade de Medicina da Universidade de São Paulo; 2007.

6. Dilorio C, Shafer PO, Letz R, Henry TR, Schomer DL, Yeager K et al. Project EASE: a study to test a psychosocial model of epilepsy medication management. Epilepsy Behav. 2004;5: 926-936.

7. Hovinga CA, Asato MR, Manjunath R, Wheless JW, Phelps SJ, Sheth RD, et al. Association of non-adherence to antiepileptic drugs and seizures, quality of life, and productivity: survey of patients with epilepsy and physicians. Epilepsy Behav. 2008; 13: 316-322.

8. Karceski S, Morrell M, Carpenter D. The expert consensus guidelines series: treatment of epilepsy. Epilepsy Behav.2000; 2 Supl 6: A1-A50.

9. Hinkin CH, Castellon SA, Durvasula TRS, Hardy DJ, Lam MN, Mason KI,et al. Medication adherence among HIV+ adults: effects of cognitive dysfunction and regimen complexity. Neurol. 2002;59:1955-50.

10. Rubin RR. Adherence to pharmacologic therapy in patients with type 2 diabetes mellitus. Am J Med. 2005:118 Supl.5-A:27S-34S.

11. DiIorio C, Yeager K, Shafer PO, Letz R, Henry T, Schomer DL, et a. The epilepsy medication and treatment complexity index: reliability and validity testing. J Neurosci Nurs. 2003; 35(3): 155-62.

12. Dilorio C, Faherty B \& Manteufell B. Cognitive-perceptual factors associated with antiepileptic medication compliance. Res Nurs Health. 1991; 14:329-338. 
Carla Maria Maluf Ferrari

13. Salgado PCB, Souza EAP. Qualidade de vida em epilepsia e percepção de controle das crises. Arq Neuropsiquiatr. 2001; 59(3-A): 537-40.

14. Pais-Ribeiro P, Martins da Silva A, Meneses RF, Falco F. Relationship between optimism, disease variables, and health perception and quality of life in individuals with epilepsy. Epilepsy Behav. 2007;11:33-8.

15. Garnett WR. Antiepileptic drug treatment: outcomes and adherence. Pharmacother. 2000; 20(8 Supl II:) 191S-199S.

16. Zannon CMLC, Seidl EMF Qualidade de vida: aspectos conceituais e metodológicos. Cad. Saude Publica. 2004; 20(2): 580-88.

17. Guerreiro CAM, Guerreiro MM, Cendes F, Lopes-Cendes. Epilepsia. São Paulo: Lemos; 2000. Considerações gerais; p1-10.

18. Moreira SRG. Epilepsia : concepção histórica, aspectos conceituais, diagnóstico e tratamento. Mental. 2004; 2(3):107-22.

19. Yacubian EM. Proposta da classificação das crises e síndromes epilépticas: correlação vídeo-eletrencefalográfica. In:Yacubuian EM, Garzon E, Machado HR, Priel M. Avaliação de pacientes co epilepsia de difícil controle medicamentoseo: uma visão prática e crítica. São Paulo: Lemos; 2002 p.13-34.

20. Site Oficial da Liga Brasileira de Epilepsia [homepage na internet].Disponível em http://www.epilepsia.org.br/epi2002/show_livro1.asp?cap=42.Acesso 10/01/2010.

21. Bustamante VCT, Sakamoto AC. Classificando as crises epilépticas para a programação terpêutica. In:Yacubian EMT. Tratamento medicamentoso das epilepsias. São Paulo: Lemos editoral; 2004.p.17-31.

22. Betting LE, Kobayashi E, Montenegro MA et al. Tratamento de epilepsia: consenso dos especialistas brasileiros. Arq. Neuro-Psiquiatr 2003; 61(4): 10451070 .

23. Garzon E. Epilepsia refratária: conceito e contribuição de novas drogas antiepilépticas e de outras modalidades terapêuticas. Rev Neuroc .2003; 10(2): 49-65.

24. Schmidt D. Drug treatment of eplilepsy: options and limitations. Epilepsy behav. 2009;15:56-65.

25. Guerreiro CAM. História do surgimento e desenvolvimento das drogas antiepilépticas. J Epilepsy Clin Neurophysiol. 2006; 12 (1 suppl 1): 18-21.

26. Villanueva V, Sánchez-Álvarez JC, Peña P, Salas-Puig J, Caballero-Martínez F, Gil-Nagel A. Treatment initiation in epilepsy: an exper consensus in Spain. Epilepsy Behav. 2010; 19(3): 332-42. 
Carla Maria Maluf Ferrari

27. Guerreiro CAM, Guerreiro MM, Cardoso TAMO. Tratamento medicamentoso: quando e como iniciar? In: Costa JC, Palmini A, Yacubian EMT, Cavalheiro EA. Fundamentos neurobiológicos das epilepsias: aspectos clínicos e cirúrgicos. São Paulo. Lemos; 1998. p. 707 - 19.

28. Olson DM. Treatment consideration: role of surgery.Epilepsy Behav 2002;3(6 Suppl 1): 32-40.

29. Nonino-Borges CB, Bustamante VCT, Rabito EI, Inuzuka LM, Sakamoto AC, Marchini JS. Dieta cetogênica no tratamento de epilepsias farmacorresistentes. Rev Nutr. 2004; 17(4): 515-21.

30. Rizzutti S, Campos CJR. Outras alternativas terapêuticas. In: Yacubian EMT. Tratamento medicamentoso das epilepsias. São Paulo: Lemos editoral; 2004.p.208-22.

31. Elger G, Hoppe C, Falkai P, Rush AJ, Elger CE. Vagus nerve stimulation is associated with mood improvements in epilepsy patients. Epilepsy Res. 2000; 42: 203-210.

32. Henry TR. Therapeutic mechanisms of vagus nerve estimulation. Neurology 2002; 59 Sup 4: S3-S14

33. Mapstone TB. Vagus nerve stimulation: current concepts. Neurosurg Focus. 2008; 25(3): 1-4.

34. Handoko KB, Zwart-van Rijkom JEF, Visee HF, Hermes WAJJ, Hekester YA, Egberts TCG. Drug treatment-related factors of inadequate seizure control. Epilepsy Behav. 2008; 13: 545-48.

35. Diretrizes da Organização Pan-americana da Saúde/ Organização mundial da Saúde para políticas de medicamentos e assistência farmacêutica [homepage na internet], disponível em http://www.opas.org.br/medicamentos/. Acesso em 04 nov.2009.

36. Leite SN, Vasconcellos MPC. Adesão à terapêutica medicamentosa: elementos para a discussão de conceitos e pressupostos adotados na literatura. Cien Saude Colet. 2003; 8(3):775-82

37. Faria HTG. Fatores relacionados à adesão do paciente diabético à terapêutica medicamentosa [dissertação]. Ribeirão Preto: Escola de Enfermagem de Ribeirão Preto, 2008.

38. Gagné C, Godin G. Improving self-report measures of non-adherence to HIV medications. Psychol Health. 2005; 20(6): 803-16.

39. Brawley LR, Culos-Redd N. Studying adherence to therapeutic regimens: overview, theories, recommendations. Control Clin Trials.2000; 21: 156-163s. 
Carla Maria Maluf Ferrari

40. World Health Organization, Adherence to long-term therapies: evidences for action 2003 [homepage na internet], disponível em http://www.who.int/medicinedocs/ Acesso em 04 nov. 2010

41. Kidd KE, Altman DG. Adherence in social context. Control Clin Trials. 2000; $21: 184 \mathrm{~S}-87 \mathrm{~S}$.

42. Dewulf NLS. Investigação sobre adesão ao tratamento medicamentoso em pacientes com doenças inflamatórias intestinais [dissertação]. Ribeirão Preto: Faculdade de Medicina de Ribeirão Preto; 2005.

43. Alonso NB, Silva DF, Campos CJR. Aderência em epilepsias: aspectos conceituais e fatores de influência. Arq Neuro Psiquiatr. 1991; 49(2): 147-49

44. Araújo, G. B. S. Adesão ao tratamento anti-hipertensivo: análise conceitual [dissertação]: João Pessoa: Centro de Ciências da Saúde, Universidade Federal da Paraíba; 2002.

45. Henriques MAPH. Adesão ao regime terapêutico em idosos [tese]. Lisboa: Escola Superior de Enfermagem de Lisboa; 2006.

46. Specht V, Elsner H, May TW, Schimichowisk B, Thorbeck R. et al. Post ictal serum levels of antiepileptic drugs for detection of noncompliance. Epilepsy Behav. 2003; (4): 487-95.

47. Ben-Menachen E, Sander JW, Privitera M, Gilliam F. Measuring outcomes of treatment with antiepileptic drugs in clinical trials. Epilepsy Behav. 2010; 18: 24-30

48. Williams, A. B. Adherence to highly active antiretroviral therapy. Nurs Clin North Am .1999; (34): 113-29.

49. Morisky DE, Ang A, Krousel-Wood M, Ward HJ. Predective validity of a medication adherence measure in an outpatient setting. J clin Hypertens. 2008; 10(5):1-7.

50. Shalansky SJ, Levy AR, Ignaszewski AP. Self-reported Morisky score for identifying nonadherence with cardiovascular medications. Ann Pharmacother. 2004; 38(9): 1363-8

51. Phatak HM, Thomas J. Relationships between beliefs about medications and nonadherence to prescribed chronic medications. Ann Pharmacother .2006; 40(10):1737-4.

52. Guilera M, Fuentes M, Griffols M, Ferrer J, Badia J, OPTIMA study investigators. Does an educational leaflet improve self-reported adherence to therapy in osteoporosis? The OPTIMA study. Osteoporos int. 2006; 17: 664-71. 
Carla Maria Maluf Ferrari

53. Gao X, Nau DP, Rosenbluth SA, Scott V, Woodward C. The relationship of disease severity, health beliefs, and medication adherence among HIV patients. AIDS care. 2000; 12(4): 387-98.

54. Ungari AQ. Adesão ao tratamento farmacológico de pacientes hipertensos seguidos no núcleo de saúde da família do Município de Ribeirão Preto. [dissertação]. Ribeirão Preto: Faculdade de medicina de Ribeirão Preto, Universidade de São Paulo; 2007.

55. Garcia RAC. Os fatores de aderência ao tratamento farmacológico de hiperlipidemias em pacientes atendidos pela secretaria Municipal de Ribeirão Preto [dissertação]. Ribeirão Preto: Faculdade de Medicina de Ribeirão Preto, Universidade de São Paulo; 2003.

56. McAuley JW, McFadden LS, Elliott JO, Shneker BF. An evaluation of selfmanagement behaviors and medication adherence in patients with epilepsy. Epilepsy Behav. 2008; 13: 637-41.

57. Cramer JA, Glassman M, Rienzi V. The relationship between poor medication compliance and seizures. Epilepsy Behav 2002; 3: 338-42.

58. Melchiors AC, Correr CJ, Fernández-Llimoset F. Tradução e validação para o português do medication regimen complexity índex. Arq Bras Cardiol 2007; 89(4): 210-218.

59. Beaton DE, Bombardier C, Guilleman F, Ferraz MB. Guidelines for process of cross-cultural adaptation of self-report measures.Spine. 2000; 25(24): 3186-191.

60. Ferrari CMM, Castro LHM, Sousa RMC, Settervall CHC, Moura RM, Coutinho PA. Validity and reliability of the Portuguese version of Epilepsy Medication Treatment Complexity Index (EMTCI) for Brazil. Epilepsy Behav. 2011; Prelo.

61. Abreu IS. Qualidade de vida relacionada à saúde de pacientes em hemodiálise no município de Guarapuava-PR. [dissertação]. Escola de Enfermagem da Universidade de São Paulo; 2005.

62. Farquhar M. Definitions of quality of life: a taxonomy. J Adv Nurs. 1995; (22):502-8

63. Minayo MCS; Harz ZMA; Buss PM. Qualidade de vida e saúde: um debate necessário. Ciencias da Saude. 2000; 5(1): 7-18.

64. Gianchello AL. Health outcomes research in Hispanics/Latinos. J Med Syst. 1996; 21(5): 235-54.

65. Fleck MPA, Louzada S, Xavier M, Chachamovic E, Vieira G, Sandra L, et al. Aplicação da versão em português do instrumento de avaliação de qualidade de vida da Organização Mundial de Saúde (WHOQOL-100). Rev Saude Publica. 1999; 33(2): 198-205. 
Carla Maria Maluf Ferrari

66. Souza EAP. Questionário de qualidade de vida na epilepsia.Arq Neuropsiquiatr. 2001; 59(3-A):541-44.

67. Schachter SC. Epilepsy: quality of life and cost of care. Epilepsy Behav. 2000; (1): 120-27.

68. Cramer JA. A clinmetric approach to assessing quality of life in epilepsy. Epilepsia 1993; 34 supl 4: S8-S13.

69. Cramer JA, Perrine K, Devinsky O. Development and cross-cultural translations of a 31-item quality of life in epilepsy inventory. Epilepsia. 1998; 39(1):81-88.

70. Devinsky O, Vickrey BG, Cramer JA, Perrine K, Hermann B, Meador k, et al. Development of the quality of life in epilepsy (QOLIE) inventory. Epilepsia. 1995; (36):1089-1104.

71. Silva TI, Marques CM, Alonso NB, Azevedo AM, Westphal-Guitti AC, Paschalicchio TF, et al. Tradução e adaptação cultural do Quality of Life in Epilepsy (QOLIE-31). J Epilepsy Clin Neurophysiol. 2006; 12(2):107-110.

72. Silva TI, Marques CM, Alonso NB, Azevedo AM, Westphal-Guitti AC, Paschalicchio TF. Validity and reliability of the Portuguese version of the quality of life in epilepsy inventory (QOLIE-31) for Brazil. Epilepsy Behav . 2007; (10): 234-41.

73. May TW, Pfäfflin M, Cramer JA. Psychometric properties of the German translation of the QOLIE-31. Epilepsy Behav. 2001;(2):106-114.

74. Kubota H, Awaya Y. Assessment of health-related quality of life and influencing factors using QOLIE-31 in Japanese patients with epilepsy. Epilepsy Behav. 2010; 18(4):381-87.

75. Torres X, Arroyo S, Araya S, de Pablo J. The spanish version of the quality of life in epilepsy inventory (QOLIE-31): translation, validity and reliability. Epilepsia. 1999; 40 (9):1299-1304.

76. Picot MC, Crespel A, Daures JP, Baldy-Moulinier M, El Hasnaoui A. Psychometric properties of the french translation of the QOLIE-31.Epilepsy Behav. 2001; 2(2): 106-114

77. Beghi E, Niero M, Roncolato M. Validity and reliability of the italian version of the quality of life in epilepsy inventory. Seizure. 2005; 14(7):453-58.

78. Tlusta E, Kubena A, Salek S, Vlcek J. Psychometric properties of the czech versio of the quality of life inventory (QOLIE-31). Epilepsy Behav. 2007; 10 : 407-11.

79. Silva NN. Amostragem probabilistica: um curso introdutório. São Paulo: Universidade de São Paulo, 2001. 120p. 
Carla Maria Maluf Ferrari

80. Bowling A. Theory of measurement. In: Bowling A. Measuring Health - a review of quality of lifes measurement scales. 2.ed. London: Buckingham Open University Press, 1997. cap. 2, p.9-15.

81. Li Li Min, Fernades PT, Noronha ALA, Marques LHN, Borges MA, Cendes F. Projeto demosntrativo no Brasil: avaliação situacional. Arq Neuropsiquiquiatr. 2007; 65 supl 1: 5-13

82. Ministério da Saúde.Secretaria Executiva. DATASUS. Informações de saúde [online]. Brasilia; 2009. Disponível em: http/ http// www.datasus.gov.br/ Acesso:12 Jan.2010.

83. Pennell PB, Thompson P. Gender-specific psychosocial impact of living with epilepsy. Epilepsy Behav. 2009; 15 (2 suppl 1): S20-S25.

84. Kristensen J, Vestergaard M, Pedersen MG, Pedersen CB, Olsen J, Sidenius P. Incidence and prevalence of epilepsy in Denmark. Epilepsy Res. 2007; 76(1): 60-65.

85. Kobau R, DiIorio CA, Anderson LA, Price PH. Further validation and reliability testing of the Attitudes and Beliefs about Living with Epilepsy (ABLE) components of the CDC Epilepsy Program Instrument on Stigma. Epilepsy Behav .2006; 8 (3): 552-59

86. Kubau R,Dilorio CA, Price PH, Bazil CW,Barkley GL,Tatum W, et al. Prevalence of epilepsy and health status of adults with epilepsy in Georgia and Tennessee: Behavioral Risk Factor Surveillance System. Epilepsy Behav. 2004; 5 (3): 358-66

87. Sachedo RC, Gates JR, Bazil CW, Barkley GL, Tatum W, D'Souza J, et al. Improved of quality of life in patients with partial seizures after conversion to oxcarbazepine monotherapy. Epilepsy behav. 2006; 9: 457-63

88. Fundação Sistema Estadual de Análise de Dados. Secretaria de Planejamento e Desenvolvimento regional. SEADE. Disponível em: http//www.seade.gov.br/ Acesso em:13 Jan.2010.

89. Faria JB, Seidl EMF. Religiosidade e enfrentamento em contextos da saúde e doença: revisão da literatura. Psicologia Revisão e Crítica. 2005; 18(3): 381-89

90. Bishop M, Allen CA.The impact of epilepsy on quality of life: a qualitative analysis. Epilepsy Behav. 2003; 4(3): 226-33.

91. Aydemir N, Trung DV,Snape D, Baker GA, Jacoby A, CREST Study Team. Multiple impacts of epilepsy and contributing factors: Findings from an ethnographic study in Vietnam. Epilepsy Behav. 2009;16(3): 512-20. 
Carla Maria Maluf Ferrari

92. Nubukpo P, Clément JP, Houinato D, Radji A, Grunitzky EK, Avodé G, et al. Psychosocial issues in people with epilepsy in Togo e Benin (West Africa). II. Quality of life measured using QOLIE-31 scale. Epilepsy Behav. 2004; (5): 728-34.

93. Jae-Koo Y, Ki-Young J, Kun-Woo P, Dae-Hie L,Sang Kun 1, Il Kuen 1,et al. Familiarity with, understanding of, and attitudes toward epilepsy among people with epilepsy and healthy controls in South Korea . Epilepsy Behav. 2009; 16(2): 260-67.

94. Mantoan MAS, Caboclo LOSF, Guilhoto LMFF, Lin K, Noffs MHS,Tudesco ISS et al. Correlation between memory, proton magnetic resonance spectroscopy, and interictal epileptiform discharges in temporal lobe epilepsy related to mesial temporal sclerosis. Epilepsy Behav. 2009; 16(3): 447-53.

95. Andrade-Valença LPA, Valença MM, Velasco TR. Epilepsia do lobo temporal mesial associada à eslerose hipocampal. J Epilepsy Clin Neurophysio. 2006;12(1): 31-36.

96. Hsiu-Fang C, Yun-Fang T, Yea-Pyng L, Mo-Song S, Jui-Chen. The relationships among medicine symptom distress, self-efficacy, patient-provider relationship, and medication compliance in patients with epilepsy. Epilepsy Behav. 2010; 19(1): 43-9.

97. Doughty J, Baker GA, Jacoby A, Lavaud V. Compliance and satisfaction with switching from an immediate-release to sustained-release formulation of valproate in people with epilepsy, Epilepsy Behav. 2003; 4: 710-16

98. Bautista RED, Glen ET. Seizure severity is associated with quality of life independent of seizure frequency. Epilepsy Behav. 2009; (16): 325-29.

99. Mc Auley JW, McFadden LS, Elliot JO, Sheneker BF. An evaluation of selfmanagement behaviors and medication adherence in patients with epilepsy. Epilepsy Behav. 2008; 13: 637-41.

100. Cendes F, Kibayashi E. epilepsia do lobo temporal. In: Guerreiro CAM, Guerreiro MM,editores. Epilepsia.São Paulo:Lemos;2000.p.201-13.

101. Kaminow L, Schimschock JR, Hammer AE, Voung A.Lamotrigine monotherapy compared with carbamazepine, phenytoin, or valproate monotherapy in patients with epilepsy. Epilepsy Behav. 2003; 4(6): 659-66.

102. Gopinath B, Radhakrishnan K, Sarma PS, Jayachandran D, Alexander A. A questionnaire survey about doctor-patient communication, compliance and locus of control among South Indian people with epilepsy . Epilepsy Behav. 2000; 29(1): 73-82. 
Carla Maria Maluf Ferrari

103. Dewulf NLF, Monteiro RA, Passos ADC, Vieira EM, Troncon LEA. Adesão ao tratamento medicamentoso em doenças gastrintestinais crônicas acompanhados no ambulatório de um hopital iniversitário. Rev Bras Cienc Farm. 2006; 42(4): 575-84.

104. George J, Yee-Teng P, Bailey MJ, Kong DCM, Stewart K. Development and validation of the medicatiom regimen complexity index. Ann Pharmacother. 2004; 38: 1369-76.

105. Richardson SP, Farias ST, Lima III AR, Alsaadi TM. Improvement in seizure control and quality of life in medically refractory epilepsy patients converted from polypharmacy to monotherapy. Epilepsy Behav. 2004; 5(3): 343-47.

106. Ettinger AB, Baker GA. Best clinical and research practice in epilepsy of older people: Focus on antiepileptic drug adherence.Epilepsy Behav. 2009; 15 (2 Suppl): S60-S63

107. Figueiredo RM, Sinkoo VM, Tomazin CC, Gallani MCBJ, Colombrini MRC. Adesão de pacientes com AIDS ao tratamento com antiretrovirais: dificuldades relatadas e propoeição de medidas atenuantes em um hospital escola. Rev Latino-Am. Enfermagem. 2001; 9(4): 50-5.

108. Martins HH, Alonso NB, GuilhotoLMFF, Guaranha MSB, Yacubian EMT. Adherence to treatment in patients with Juvenile Myoclonic Epilepsy: correlation with quality of life and adverse effects of medication. J Epilepsy Clin Neurophysiology .2009; 15(4): 192-6.

109. Marques PAC, Pierin AMG. Fatores que influenciam a adesão de pacientes com câncer à terapia antineoplásica oral.Acta Paul Enferm. 2008; 21(2): 323-9.

110. Strelec MAAM, Pierin AMG,Mion Jr D. A influência so conhecimento sobre a doença e a atitude frente a tomada dos remédios no controle da hipertensão arterial. Arq Bras Cardiol. 2003;81(4):343-8.

111. Medeiros ARC.Adesão ao tratamento anti-hipertensivo em unidade de saúde da família de João Pessoa-PB [dissertação].João Pessoa: Centro de Ciências da Saúde,Universidade Federal da Paraíba; 2006.

112. Cornélio RCAC, Pinto ALT, Pace FHL, Moraes JP, Chebli JMF. Não adesão ao tratamento em pacientes com doença de Chron: prevalência e fatores de risco. Arq Gastroenterol. 2009 ; 46(3): 183-90.

113. Araújo MFM, Gonçalves TC, Damasceno MMC,Caetano JA. Aderência de diabéticos ao tratamento medicamentoso com hipoglicemiantes orais. Esc Anna Nery Rev Enferm. 2010; 14(2): 361-7.

114. Pierin AMG, Mion Jr D, Fukushima JT, Pinto AR, Kaminaga MM. O perfil de um grupo de pessoas hipertensas de acordo com conhecimento e gravidade da doença. Rev Esc Enf. 2001; 35(1): 11-8. 
Carla Maria Maluf Ferrari

115. Gomes R, Nascimento EF, Araújo FC. Porque os homens buscam menos os serviços de saúde do que as mulheres? As explicações de homens com baixa escolaridade e homens com ensino superior. Cad Saude Publica. 2007; 23(3): 564-74.

116. Costa-junior FM, Maia ACB. Concepções de homens hospitalizado sobre a relação gênero e saúde. Psic.: Teor e Pesq 2009; 25(1): 55-63.

117. Colombrini MRC, Lopes MHBM, Figueiredo RM. Adesão à terapia antiretroviral para HIV/AIDS. Rev Esc Enferm USP. 2006; 40(4): 576-81.

118. Barbosa RGB, Costa LNK. Índices de adesão ao tratamento anti-hipertensivo no Brasil e mundo . Rev Bras Hipertens. 2006;13(1):35-8.

119. Manjunath R, Davis KL, Candrilli SD, Ettinger AB. Association of antiepileptic drug nonadherence with risk of seizure in adults with epilepsy. Epilepsy Behav. 2009;(14): 372-8.

120. Krapek K, King K, Warren SS, George KG, Caputo DA, Mihelich K, et al. Medication Adherence and Associated Hemoglobin A1c in Type 2 Diabetes. The Annals of Pharmacotherapy. 2004;38, (9):1357-62

121. Michael P, Rumsfeld MD, Masoud FA, McClure DL, Plomondon ME, Steiner JF, Magid DJ. Effect of medication nonadherence on hospitalization and mortality among patients with diabetes mellitus. Arch Intern Med. 2006; 25: 1836-41.

122. Loring DW, Meador KJ, Lee GP. Determinants in quality of life in epilepsy. Epilepsy Beh. 2004; (5): 976-80.

123. Bastos MC, Van der Laan F, Gitaí LLG, Gamaleira FT, Silva LHBR. Epilepsia mioclônica juvenil: estudo clínico, epidemiológico, terapêutico e da qualidade de vida. J Epilepsy Clin Neurophysiol. 2009;15(2): 65-9.

124. Piazzini A, Beghi E, Turner K, Ferraroni M, The LICE Quality of Life Group. Health related quality of life in epilepsy: findings obtained with a new italian instrument. Epilepsy Behav. 2008;(13): 119-26.

125. Henriques R. Desigualdade racial no Brasil: evolução das condições de vida na década de 90. Instituto de Pesquisa Econômica Aplicada. Disponível em:http://desafios2.ipea.gov.br/pub/td/2001/td_0807.pdf. Acesso em: 12.jan.2010.

126. Szaflarski M, Szaflarski JP, Privitera MD, Ficker DM, Horner RD1. Racial/ethnic disparities in the treatment of epilepsy: What do we know? What do we need to know? Epilepsy Behav. 2006; 9(2):243-64.

127. Bautista RED, Jain D. Detecting health disparities among caucasians and african-americans with epilepsy. Epilepsy Behav. 2011;22(1); 52-6. 
Carla Maria Maluf Ferrari

128. Olinto MTA, Olinto BA. Raça e desigualdade entre as mulheres: um exemplo no sul do Brasil. Cad Saude Publica. 2000;16(4): 1137-142.

129. Paschal AM, Ablah E, Wetta-hall R, Molgaard CA, Liow K. Stigma and safe havens: a medical sociological perspective on african-american female epilepsy patients. Epilepsy Behav. 2005; 7: 106-15.

130. Baca CB, Cheng EM, Spencer SS, Vassar S, Vickrey BG, Multicenter Study of Epilepsy Surgery.Epilepsy Behav. 2009; 15: 425-55.

131. Sarmento MRS, Minayo-Gomes C. A epilepsia, o epiléptico e o trabalho: relações conflitantes.Cad Saude Publica. 2000; 16(1): 183-93

132. Smeets VMJ,Van Lierop BAG, Vanhoutvin JPG, et al. Epilepsy and employment: Literature review. Epilepsy Behav .2007; 10(3): 354-62.

133. Clarke BM, Upton ARM, Castellanos C. Woks believe and work status in epilepsy. Epilepsy Behav.2006; 9: 119-25.

134. Bautista RED, Wludyka P. Factors associated with employment in epilepsy patients. Epilepsy Behav. 2007; 10 (1): 89-95.

135. Baker GA, Gagnon D, Mc Nulty P. The relatioship between seizure frequency, seizure type and quality of life: findings from the european countries. Epilepsy Res. 1998; 30:231-40.

136. Birberck GL, Hays RD, Cui X, Vickrey BG. Seizure reduction and quality of life improvements in people with epilepsy. Epilepsia 2002; 43: 535-38.

137. Leidy K, Elixhauser A, Vickrey B, E. Means, William MK. Seizure frequency and health-related quality of life in adults with epilepsy Neurology. 1999; 53: 162-66.

138. Buschmann F, Wagner K, Metternich B, Biethahn S, Zentner J, SchulzeBonhage A. The impact of extratemporal epilepsy surgery on quality of life.Epilepsy Behav. 2009; 15:166-69.

139. Auriel E, Landov H, Blatt I, Theitler J, Gandelman-Marton R, Chistik V, et al. Quality of life in seizure-free patients with epilepsy on monotherapy. Epilepsy behav. 2009; 14: 130-33.

140. Allain H, Schück S, Schück and F. Nachit-Ouinekh et al., Improvement in quality of life after initiation of lamotrigine therapy in patients with epilepsy in a naturalistic treatment setting, Seizure. 16 (2007), pp. 173-84.

141. Yuhua Z, Qin Z, Thashi T, Nachit-Ouinekh F, Plouin P, Brunon AM, et al. Prevalence of convulsive epilepsy and health-related quality of life of the population with convulsive epilepsy in rural areas of Tibet Autonomous Region in China: an initial survey, Epilepsy Behav. 2008;12: 373-81. 
142. Baker GA, Jacoby A, Buck D, Stalgis C, Monnet D. Quality of life of people with epilepsy: a European study, Epilepsia. 1997; 38: 353-62.

143. Charyton C, Elliot JO, Bo Lu, Moore LJ. The impact of support on health related quality of life in person with epilepsy. Epilepsy Behav. 2009; 16:640-45.

144. Saburi GL, Mapanga KG, Mapanga MB. Perceived family reactions and quality of life of adults with epilepsy. J Neurosc Nurs.2006; 38(3): 141-44.

145. Ellis N, Upton D, Thompson P. Epilepsy and the family: a review of current literature. Seizure. 2000; 9: 22-30.

146. Bressi C,Cornahggia CM, Beghi M, Porcellana M, Iandoli II, Invernizzi G. Epilepsy and family expressed emotion: Results of a prospective study. Seizure.2007;16 (5):417-23. 


$$
1
$$




\author{
APÊNDICE A \\ TERMO DE CONSENTIMENTO LIVRE E ESCLARECIDO \\ HOSPITAL DAS CLÍNICAS DA FACULDADE DE MEDICINA DA \\ UNIVERSIDADE DE SÃO PAULO-HCFMUSP \\ DADOS DE IDENTIFICAÇÃO DO SUJEITO DA PESQUISA \\ OU RESPONSÁVEL LEGAL
}

1. NOME:

DOCUMENTO DE IDENTIDADE N: SEXO : $\mathrm{M} \square \mathrm{F} \square$

DATA NASCIMENTO:

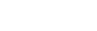
L ENDEREÇO: $\mathrm{N}^{\circ}$ APTO:

BAIRRO: CIDADE CEP:

TELEFONE: DDD ( )

2.RESPONSÁVEL LEGAL:

NATUREZA (grau de parentesco ,tutor,curador etc.)

DOCUMENTO DE IDENTIDADE No: SEXO : $\quad M \square \quad F \quad$

DATA NASCIMENTO

ENDEREÇO: $\mathrm{N}^{\mathrm{o}}$ APTO:

BAIRRO: CIDADE CEP:

TELEFONE: DDD

\title{
DADOS SOBRE A PESQUISA
}

TÍTULO DO PROTOCOLO DE PESQUISA: “Adesão ao tratamento medicamentoso e qualidade de vida de indivíduos com epilepsia em tratamento ambulatorial."

1. PESQUISADOR RESPONSÁVEL: Dr Luiz Henrique Martins Castro

CARGO/FUNÇÃO: Médico

UNIDADE DO HCFMUSP: Divisão Clínica Neurológica.

2.PESQUISADOR EXECUTANTE: Enfa Carla Maria Maluf Ferrari

3. AVALIAÇÃO DO RISCO DA PESQUISA:

$\begin{array}{lll}\text { RISCO MÍNIMO } & \mathrm{x} & \text { RISCO MÉDIO } \square \\ \text { RISCO BAIXO } & \square & \text { RISCO MAIOR } \square\end{array}$

4.DURAÇÃO DA PESQUISA : 12 meses. 


\section{HOSPITAL DAS CLÍNICAS DA FACULDADE DE MEDICINA DA UNIVERSIDADE DE SÃO PAULO-HCFMUSP}

O objetivo deste estudo é conhecer quais as medicações que o paciente toma, quantidade de comprimidos, número de vezes e ações para tomar o remédio. Além disso, desejamos saber se as medicações prescritas pelo seu médico estão sendo tomadas corretamente e conhecer como é a qualidade de vida de pessoas que tem epilepsia. Nosso propósito é, com essas informações, contribuir para melhorar a assistência prestada aos pacientes com epilepsia.

Nós necessitamos que o $\mathrm{Sr}$ (a) responda perguntas sobre sua doença, tratamento e, também, sobre sua vida. Se o $\operatorname{Sr}(a)$ concordar em participar da pesquisa é garantida sua liberdade de deixar de participar do estudo em qualquer momento, sem nenhum prejuízo à continuidade de seu tratamento no hospital. Todas as informações obtidas serão analisadas em conjunto com outros pacientes, não sendo divulgada a identificação de nenhum participante. Os pesquisadores se comprometem em utilizar os dados e o material coletado somente para pesquisa. Não haverá gastos pessoais em qualquer fase do estudo, porém também não há compensação financeira devido à sua participação. $\mathrm{O} \operatorname{Sr}(\mathrm{a})$ terá o direito de conhecer os resultados da pesquisa em qualquer momento, mesmo antes do seu término (resultados parciais).

Em qualquer etapa do estudo o $\mathrm{Sr}$ (a) terá acesso aos profissionais responsáveis pela pesquisa para esclarecimento de eventuais dúvidas: Pesquisador responsável Dr Luiz Henrique Castro que pode ser encontrado às sextas-feiras no período da tarde, no ambulatório e a Enfermeira Carla Maria Maluf Ferrari,como pesquisadora que realizará as entrevistas e que pode ser encontrada na Rua : Raul Pompéia No 144, $6^{\circ}$ andar, tel: 3165 2631 ou cel: 9995-9089. Além disso, se o Sr (a) tiver alguma consideração ou dúvida sobre a ética desta pesquisa, entre em contato com o Comitê de Ética em Pesquisa (CEP) - Rua Ovídio Pires de Campos, 225 - $5^{\circ}$ andar - tel: 3069-6442 ramais 16, 17, 18 ou 20, FAX: 3069-6442 ramal 26. E-mail: cappesq@hcnet.usp.br.

Acredito ter sido suficientemente esclarecido(a) a respeito das informações que li ou que foram lidas para mim, descrevendo o estudo: "Adesão ao tratamento medicamentoso e qualidade de vida de indivíduos com epilepsia em tratamento ambulatorial."

Eu discuti com a Enf ${ }^{\natural}$ Carla Maria Maluf Ferrari sobre a minha decisão em participar nesse estudo. Ficaram claros para mim quais são os propósitos do estudo, os procedimentos a serem realizados, seus desconfortos e riscos, as garantias de confidencialidade e de esclarecimentos permanentes. Ficou claro também que minha participação é isenta de despesas e que tenho garantia do acesso a tratamento hospitalar quando necessário. Concordo voluntariamente em participar deste estudo e poderei retirar o meu consentimento a qualquer momento, antes ou durante o mesmo, sem penalidades ou prejuízo ou perda de qualquer benefício que eu possa ter adquirido, ou no meu atendimento neste Serviço.

Assinatura do paciente/representante legal

Declaro que obtive de forma apropriada e voluntária o Consentimento Livre e Esclarecido deste paciente ou representante legal para a participação neste estudo. 


\section{APÊNDICE B}

TESTE DE MORISKY

\section{ENTREVISTADOR:}

Nome do paciente: Data:

Local: ( ) Liga ( ) Ambulatório

Registro no HC:

Registro no Ambulatório/Liga de Epilepsia:

1.Você alguma vez esquece de tomar seu remédio

2. Você às vezes é descuidado para tomar o seu remédio

3. Quando você se sente melhor, às vezes você para de tomar seu remédio

4. Às vezes, se você se sente pior quando toma o remédio, você para de tomá-lo

Total de respostas negativas

Total de resposta afirmativas
( ) $\operatorname{sim}($ )não

( ) $\operatorname{sim}($ )não

( ) $\operatorname{sim}($ )não

( ) $\operatorname{sim}$ ( )não

\section{Classificação da adesão terapêutica do respondente}

( ) Baixa adesão ( três ou quatro questões afirmativas).

( ) média adesão (uma ou duas questões afirmativas)

( ) alta adesão (negativas as quatro questões) 


\section{APÊNDICE C}

\section{QOLIE -31 - ( Quality of Life in Epilepsy Inventory)}

Nome do paciente:

Data:

Entrevistador:

Registro no HC:

Registro no ambulatório/liga de epilepsia:

Estas questões são sobre sua saúde e atividades do dia-a-dia. Responda cada questão circulando a resposta que mais se aproxime da forma como está sua saúde. Caso não esteja seguro da resposta, responda da forma mais honesta possível.

1. Em geral, como você classificaria sua Qualidade de Vida? Circule um número na escala que varia de 0 a 10, onde 0 corresponde a Pior Qualidade de Vida possível e 10 a Melhor Qualidade de Vida Possível.

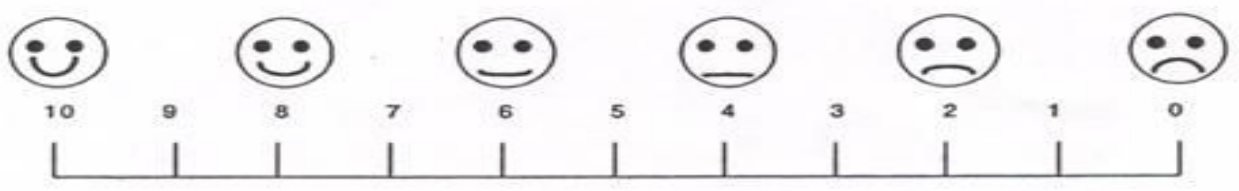

Melhor Qualidade de Vida possível
Pior qualidade de vida possível 
Carla Maria Maluf Ferrari

As questões seguintes são sobre como você tem se sentido e como as coisas têm sido para você nas últimas 4 semanas. Para cada questão indique a resposta que mais se aproxime de como tem se sentido. Circule um número na escala que varia de 1 (todo tempo) a 6 (nunca). Com que freqüência, nas últimas 4 semanas, você:

\begin{tabular}{|c|c|c|c|c|c|c|}
\hline & $\begin{array}{c}\text { Todo } \\
\text { Tempo }\end{array}$ & $\begin{array}{l}\text { A maior } \\
\text { parte do } \\
\text { tempo }\end{array}$ & $\begin{array}{c}\text { Uma boa } \\
\text { parte do } \\
\text { tempo }\end{array}$ & $\begin{array}{c}\text { Alguma } \\
\text { parte do } \\
\text { tempo }\end{array}$ & $\begin{array}{c}\text { Uma pequena } \\
\text { parte do } \\
\text { tempo }\end{array}$ & Nunca \\
\hline $\begin{array}{l}\text { 2. Sentiu-se cheio de } \\
\text { disposição, de ânimo? }\end{array}$ & 1 & 2 & 3 & 4 & 5 & 6 \\
\hline 3. Sentiu-se muito nervoso? & 1 & 2 & 3 & 4 & 5 & 6 \\
\hline $\begin{array}{l}\text { 4. Sentiu-se tão triste que } \\
\text { nada o animava? }\end{array}$ & 1 & 2 & 3 & 4 & 5 & 6 \\
\hline $\begin{array}{l}\text { 5. Sentiu-se calmo ou } \\
\text { tranqüilo? }\end{array}$ & 1 & 2 & 3 & 4 & 5 & 6 \\
\hline $\begin{array}{l}\text { 6. Sentiu-se cheio de } \\
\text { energia? }\end{array}$ & 1 & 2 & 3 & 4 & 5 & 6 \\
\hline $\begin{array}{l}\text { 7. Sentiu-se desanimado ou } \\
\text { abatido? }\end{array}$ & 1 & 2 & 3 & 4 & 5 & 6 \\
\hline 8. Sentiu-se esgotado? & 1 & 2 & 3 & 4 & 5 & 6 \\
\hline 9. Sentiu-se feliz? & 1 & 2 & 3 & 4 & 5 & 6 \\
\hline 10. Sentiu-se cansado? & 1 & 2 & 3 & 4 & 5 & 6 \\
\hline $\begin{array}{l}\text { 11. Preocupou-se em ter } \\
\text { outra crise? }\end{array}$ & 1 & 2 & 3 & 4 & 5 & 6 \\
\hline $\begin{array}{l}\text { 12. Teve dificuldade de } \\
\text { raciocinar e resolver } \\
\text { problemas ( como fazer } \\
\text { planos, tomar decisões, } \\
\text { aprender coisas novas )? }\end{array}$ & 1 & 2 & 3 & 4 & 5 & 6 \\
\hline $\begin{array}{l}\text { 13. Você diminuiu suas } \\
\text { atividades sociais, como } \\
\text { visitar amigos ou parentes } \\
\text { próximos por problemas } \\
\text { com a sua saúde? }\end{array}$ & 1 & 2 & 3 & 4 & 5 & 6 \\
\hline
\end{tabular}


14. Como tem sido sua Qualidade de Vida nas últimas 4 semanas, ou seja, como as coisas têm sido para você? Circule na escala um número que varia de 1 (excelentes) a 5 (péssimas)

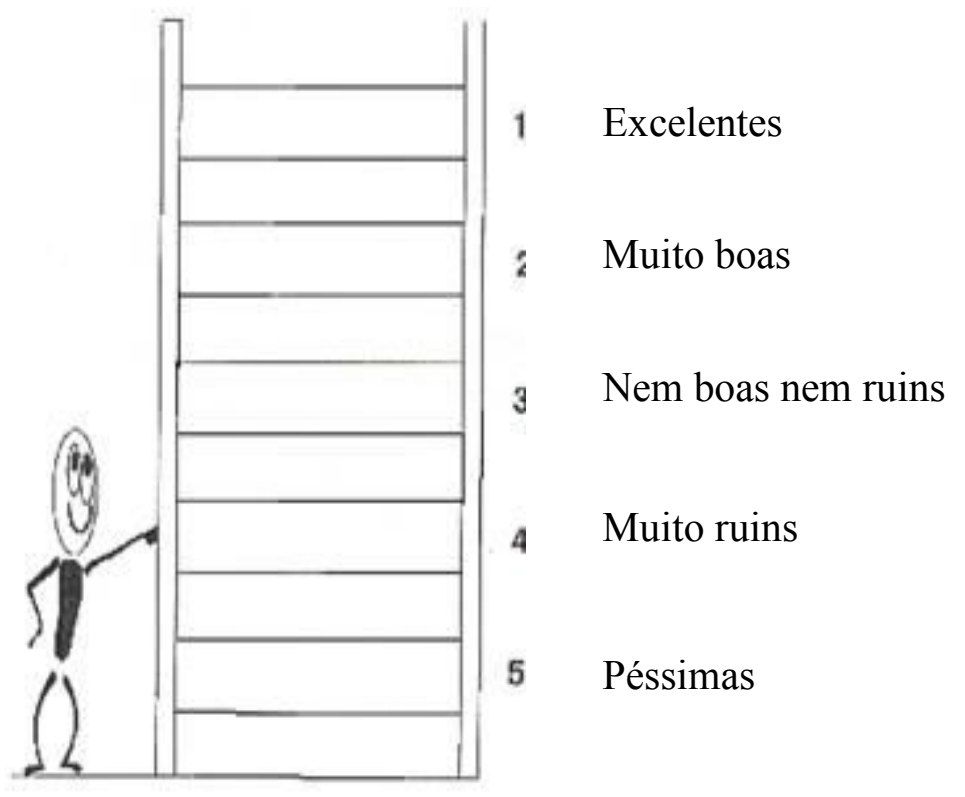

15. Nas últimas 4 semanas, você teve problemas com sua memória, ou seja problemas para lembrar das coisas? Circule um número na escala que varia de 1 (Bastante Problema) a 4 (Nenhum Problema).

\begin{tabular}{|c|c|c|c|}
\hline $\begin{array}{c}\text { Sim, bastante } \\
\text { problema }\end{array}$ & Sim, algum problema & $\begin{array}{c}\text { Sim, só um pouco de } \\
\text { problema }\end{array}$ & $\begin{array}{c}\text { Não, nenhum } \\
\text { problema }\end{array}$ \\
\hline 1 & 2 & 3 & 4 \\
\hline
\end{tabular}

16. Nas últimas 4 semanas, você teve problemas com sua memória ( ou seja, lembrar-se das coisas que as pessoas disseram ) no seu trabalho ou atividades diárias?

\begin{tabular}{|c|c|c|c|c|c|}
\hline Todo Tempo & $\begin{array}{c}\text { A maior parte } \\
\text { do tempo }\end{array}$ & $\begin{array}{c}\text { Uma boa parte } \\
\text { do tempo }\end{array}$ & $\begin{array}{c}\text { Alguma parte do } \\
\text { tempo }\end{array}$ & $\begin{array}{c}\text { Uma pequena parte } \\
\text { do tempo }\end{array}$ & Nunca \\
\hline 1 & 2 & 3 & 4 & 5 & 6 \\
\hline
\end{tabular}


Carla Maria Maluf Ferrari

As perguntas seguintes estão relacionadas a problemas de concentração. Nas últimas 4 semanas, com que freqüência você teve problemas para concentrar-se (ou seja, manter-se pensando em uma determinada atividade) e o quanto esses problemas interferiram no seu dia-a-dia.

\begin{tabular}{|l|l|l|l|l|l|l|}
\cline { 2 - 7 } \multicolumn{1}{c|}{} & $\begin{array}{c}\text { Todo } \\
\text { Tempo }\end{array}$ & $\begin{array}{c}\text { A maior } \\
\text { parte do } \\
\text { tempo }\end{array}$ & $\begin{array}{c}\text { Uma boa } \\
\text { parte do } \\
\text { tempo }\end{array}$ & $\begin{array}{c}\text { Alguma } \\
\text { parte do } \\
\text { tempo }\end{array}$ & $\begin{array}{c}\text { Uma } \\
\text { pequena } \\
\text { parte do } \\
\text { tempo }\end{array}$ & Nunca \\
\hline $\begin{array}{l}\text { 17. Problemas para } \\
\text { concentrar-se durante uma } \\
\text { leitura. }\end{array}$ & 1 & 2 & 3 & 4 & 5 & 6 \\
\hline $\begin{array}{l}\text { 18. Problemas para manter sua } \\
\text { atenção em alguma atividade } \\
\text { por algum tempo. }\end{array}$ & 1 & 2 & 3 & 4 & 5 & 6 \\
\hline
\end{tabular}

As perguntas seguintes estão relacionadas em como você tem se sentido em relação às suas crises.

\begin{tabular}{|l|c|c|c|r|r|}
\cline { 2 - 6 } \multicolumn{1}{c|}{} & $\begin{array}{c}\text { Sim, } \\
\text { bastante }\end{array}$ & $\begin{array}{c}\text { Sim, } \\
\text { moderadamente }\end{array}$ & $\begin{array}{c}\text { Sim, só um } \\
\text { pouco }\end{array}$ & $\begin{array}{c}\text { Sim, às } \\
\text { vezes }\end{array}$ & \multicolumn{1}{c|}{$\begin{array}{c}\text { Não, } \\
\text { nenhum }\end{array}$} \\
\hline 19. No lazer. & 1 & 2 & 3 & 4 & 5 \\
\hline 20. Na direção de veículos & 1 & 2 & 3 & 4 & 5 \\
\hline
\end{tabular}

Indique o quanto os seguintes problemas abaixo o incomodam. Circule um número na escala que varia de 1 (Não Incomoda) a 5 (Incomoda Extremamente)

\begin{tabular}{|l|c|c|c|c|c|}
\cline { 2 - 6 } \multicolumn{1}{c|}{} & $\begin{array}{c}\text { Sim, } \\
\text { bastante }\end{array}$ & $\begin{array}{c}\text { Sim, } \\
\text { moderadamente }\end{array}$ & $\begin{array}{c}\text { Sim, só um } \\
\text { pouco }\end{array}$ & $\begin{array}{c}\text { Sim, às } \\
\text { vezes }\end{array}$ & $\begin{array}{c}\text { Não, } \\
\text { nenhum }\end{array}$ \\
\hline $\begin{array}{l}\text { 21. Você tem medo de ter outra } \\
\text { crise nas próximas 4 semanas? }\end{array}$ & 1 & 2 & 3 & 4 & \\
\hline $\begin{array}{l}\text { 22. Você se preocupa em } \\
\text { machucar-se durante uma crise? }\end{array}$ & 1 & 2 & 3 & 4 & \\
\hline $\begin{array}{l}\text { 23. Preocupa-se em se } \\
\text { envergonhar ou ter problemas } \\
\text { sociais devido a crise? }\end{array}$ & 1 & 2 & 3 & 4 & \\
\hline $\begin{array}{l}\text { 24. Você se preocupa pelos efeitos } \\
\text { colaterais que a medicação possa } \\
\text { lhe causar se tomada por um longo } \\
\text { período, ou seja, que ela possa } \\
\text { fazer mal para seu organismo? }\end{array}$ & 1 & 2 & 3 & 4 & \\
\hline
\end{tabular}




\begin{tabular}{|l|r|r|r|r|r|}
\cline { 2 - 5 } \multicolumn{1}{c|}{} & \multicolumn{1}{c|}{$\begin{array}{c}\text { Sim, } \\
\text { incomoda } \\
\text { extremamente }\end{array}$} & $\begin{array}{c}\text { Sim, } \\
\text { incomoda } \\
\text { bastante }\end{array}$ & $\begin{array}{c}\text { Sim, } \\
\text { incomoda só } \\
\text { um pouco }\end{array}$ & $\begin{array}{c}\text { Sim, } \\
\text { incomoda } \\
\text { às vezes }\end{array}$ & $\begin{array}{c}\text { Não } \\
\text { incomoda }\end{array}$ \\
\hline 25. As crises epilépticas. & 5 & 4 & 3 & 2 & 1 \\
\hline $\begin{array}{l}\text { 26. Problemas de Memória, ou } \\
\text { seja, dificuldade para lembrar das } \\
\text { coisas. }\end{array}$ & 5 & 4 & 3 & 2 & 1 \\
\hline 27. Dificuldade no trabalho. & 5 & 4 & 3 & & \\
\hline $\begin{array}{l}\text { 28. Dificuldades sociais, ou seja, } \\
\text { sentir-se impedido de se relacionar } \\
\text { com outras pessoas ou fazer } \\
\text { atividades fora de casa. }\end{array}$ & 5 & 4 & 3 & & \\
\hline $\begin{array}{l}\text { 29. Efeitos colaterais da medicação } \\
\text { no organismo. }\end{array}$ & 5 & 4 & 3 & & \\
\hline $\begin{array}{l}\text { 30. Efeitos colaterais da medicação } \\
\text { no raciocínio, para pensar, para se } \\
\text { concentrar. }\end{array}$ & 5 & 4 & 3 & & 1 \\
\hline
\end{tabular}

31. Quanto você acha que sua saúde está boa ou ruim? No termômetro abaixo a melhor saúde possível corresponde a $\mathbf{1 0 0}$ e a pior saúde possível corresponde a $\mathbf{0}$. Circule um número na escala que melhor indica como você se sente em relação a sua saúde. Ao responder, considere a epilepsia com sendo parte da sua saúde.

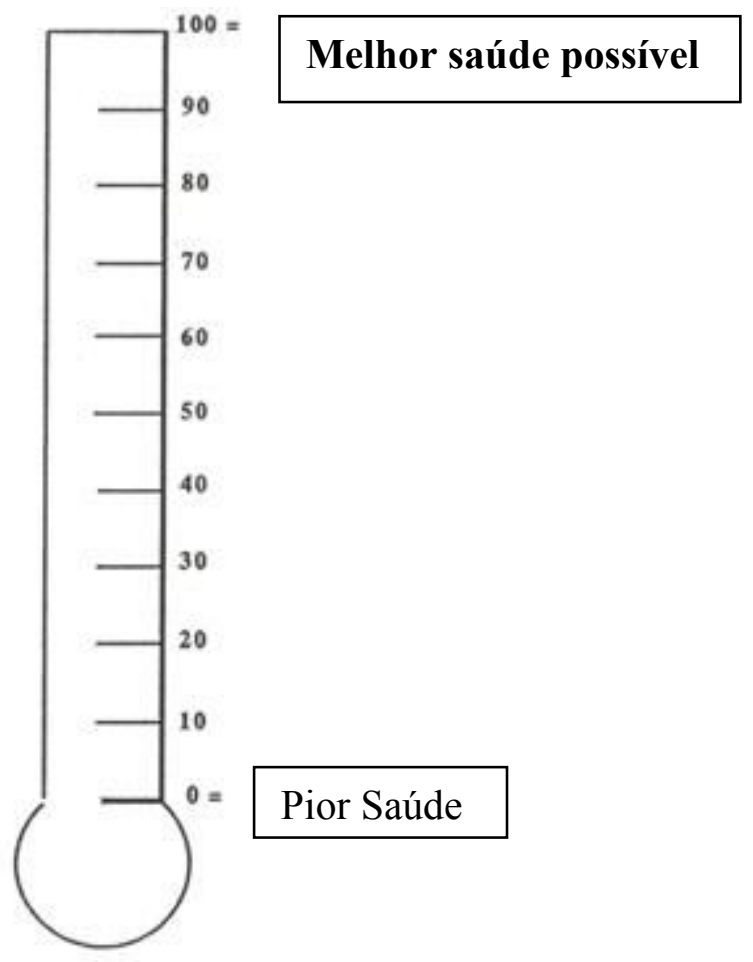




\section{APÊNDICE D}

\section{CASO $\mathrm{N}^{\mathrm{O}}$}

\section{FORMULÁRIO PARA ENTREVISTA}

\section{DIAGNÓSTICO:}

\section{ETIOLOGIA:}

Entrevistador assinale o local que o paciente faz acompanhamento médico:

1. Liga de epilepsia

2.Ambulatório

\section{IDENTIFICAÇÃO}

1.1 Nome:

1.2 Idade:
1.3 Sexo:
1( ) Masculino
2( ) Feminino

Bairro em que reside:

1.4 Vínculo conjugal

Você vive em companhia de cônjuge ou companheiro?
1. ( ) Sim 2.( ) Não

Caso não, já viveu anteriormente?

$\begin{array}{ll}\text { 1. ( ) } \operatorname{Sim} & \text { 2. ( ) Não }\end{array}$

1.5 Qual a cor da sua pele? 1.( ) branca 2.( )parda 3.( )preta/negra 4.( ) amarela 5.( ) Outra

1.6 Qual sua religião? 1. ( ) Protestante/evangélica
2. ( ) Católica
3. ( ) Espírita
4. ( ) Nenhuma
5. ( ) Outra 


\section{DADOS SOCIOECONÔMICOS}

2.1 Estudou até série do ensino

2.2 Situação ocupacional: 1. ( ) empregado
2. ( ) empregador
3. ( ) autônomo
4. ( ) auxilio-doença
5. ( ) aposentado
6. ( ) desempregado

2.3 Ocupação: (escrever como o entrevistado se qualifica: se ajudante ou auxiliar definir do que, especificar o setor econômico. Se aposentado ocupação que desenvolveu atuou por mais tempo)

\subsection{Renda per capta Familiar}

1.Qual os ganhos das pessoas que moram com você, qual a renda somada de todos da família no último mês? (incluir todas as possíveis fontes) R\$

1.( ) Não sabe

2.( ) Não quer informar

4. Quantas pessoas são dependentes dessa renda:

\section{VARIÁVEIS RELACIONADAS À DOENÇA}

3.1 A quanto tempo o $\operatorname{Sr}(a)$ sabe que tem epilepsia? (quando foi informado pela primeira vez) anos meses

3.2 Quanto tempo faz que o $\operatorname{Sr}(a)$ toma o medicamento para a epilepsia? meses ou anos

3.3. Freqüência das crises nos últimos 30 dias:

Data da última crise

3.4. Percepção do controle das crise

1.( ) Controlada

2.( ) Nem sempre controlada (menos freqüente e ou menos grave)

3. ( ) Não controlada

\section{VARIÁVEIS RELACIONADAS AO APOIO FAMILIAR}

4.1 Você tem algum familiar e/ou algum amigo que o auxilia no tratamento?
1.( ) Sim
2. ( )Não

4.2 Caso SIM, qual a freqüência?
1. ( ) Sempre
2. ( ) Quase sempre
3. ( ) raramente 


\section{5. É FÁCIL CONSEGUIR UMA CONSULTA NA ( ) LIGA （） AMBULATÓRIO \\ $\begin{array}{lll}\text { 1. ( ) } \operatorname{Sim} & \text { 2. ( ) Às vezes } & \text { 3. ( ) Não }\end{array}$}

\section{SATISFAÇÃO COM O SERVIÇO DE SAÚDE}

6.1 De quanto em quanto tempo o $\operatorname{Sr}($ a) vem a consulta:

1. ( ) Uma vez ao mês

2. ( ) A cada 02 meses

3. ( ) A cada 03 meses

4. ( ) Outro:

6.2. Com relação ao atendimento médico:

1. ( ) É muito bom

2. ( ) É bom

3. ( ) É ruim

4. ( ) Não opinou

6.3 Você sabe quem é o enfermeiro (a)? 1. ( ) Sim 2. ( ) Não

Caso afirmativo

6.4. Com relação ao atendimento do enfermeiro (a):

1.( ) É muito bom

2.( ) É bom

3. ( ) É ruim

4. ( ) Não opinou

6.5 Quando o $\mathrm{Sr}$ (a) tem algum problema de saúde e procura liga/ambulatório para consultar

1. ( ) Sempre tem vaga

2. ( ) Na maioria das vezes tem vaga

3. ( ) De vez em quando tem vaga

4. ( ) Nunca tem vaga

5. ( ) Não precisou

6.6 Quanto aos medicamentos normalmente, você:

( ) Retira na farmácia do $\mathrm{HC} \quad(\quad$ ) recebe o medicamento em casa

( ) Outro:

1. ( ) Consegue todos os medicamentos prescritos

2. ( Consegue parte dos medicamentos prescritos

3. ( ) Não consegue os medicamentos prescritos

6.7 E quando não consegue a medicação:

1.( ) Fica sem tomar

2 ( ) Compra a medicação

3 ( ) Outro:

6.8 Depois que o $\operatorname{Sr}($ a) começou a vir no ambulatório:

1. ( )Está muito melhor

2. ( ) Esta melhor

3. ( ) Está um pouco melhor

4. ( ) Não melhorou nada

5. ( ) Não sabe 


\section{APÊNDICE E}

\section{ÍNDICE DE COMPLEXIDADE DO TRATAMENTO MEDICAMENTOSO EM EPILEPSIA (ICTME)}

\section{( ) LIGA ( ) AMBULATÓRIO}

Identificação do entrevistador: Identificação do paciente:

REGISTRO NO HC: Registro no ambulatório:

Instruções para o uso:

Preencha uma folha separada para cada medicamento ou tratamento que você esteja tomando ou usando atualmente para o controle da sua epilepsia.

\section{Informação Geral do Medicamento}

a) Nome do medicamento/tratamento

b) Quantidade de medicamento/tratamento de um total de

c) Quantos comprimidos deste medicamento você toma todos os dias?

d) Como este medicamento é tomado? (Favor anotar a quantidade em $\mathrm{mg}$ )

Freqüência de Administração

Com que freqüência você toma ou usa este medicamento/tratamento? Indique quais opções se aplicam:

( ) diariamente (1)

( ) todas as manhãs (1)

( ) todas as noites/antes de dormir (1)

( ) $2 \mathrm{x}$ dia (2)

( ) $3 x$ dia (3)

( ) $4 \mathrm{x}$ dia (4)

( ) dia sim, dia não (2)

( ) após as refeições/antes de dormir (4)

( ) antes das refeições/antes de dormir (4)

Outro. Especificar:

Some os números de todas as respostas assinaladas para a pontuação Total da Freqüência:

Instruções Especiais

Você segue instruções especiais sobre como tomar esse medicamento para o ataque epiléptico/usar esse tratamento?

Indique quais opções que se aplicam:

( ) Dosagem diferente no mesmo dia.

( ) Em horário diferente ao dos antiácidos

( ) Antes de levantar

( ) A dose pode mudar se eu tiver um ataque epiléptico

( ) Doses diárias alternadas

( ) Outra instrução especial: Especificar:

Some o número de respostas marcadas para a pontuação total de Instruções Especiais: coloque 0 )

Ações de Administração:

Você precisa fazer algo especial para ajudá-lo (a) a tomar este medicamento/tratamento?

Coloque o número de vezes ao dia que você faz isto no parêntese.

( ) toma com alimentos

quebra o comprimido na metade ou em

pedacinhos

( $)$ creme/pomada

) comprimidos esmagados

) toma mais de um comprimido quando toma

uma dose

) toma comprimidos com diferentes mg ao

( ) A dose pode mudar dependendo do período menstrual

( ) Em horários diferentes dos outros medicamentos

( ) Passar o magneto sobre o gerador um número específico de vezes no início das crises toma de estômago vazio ) abre as cápsulas

) deve levar o medicamento/tratamento em todos os momentos

(_ $)$ sublingual (derrete sob a língua)

(_ mistura na comida Ex:pudins

) administra pelo reto

tomar uma dose

(__ ) outras instruções especiais. Especifique:

Some todos os números nos parênteses para o total das ações na Administração: coloque 0 ) coloque (0) 


\section{APÊNDICE F \\ INSTRUÇÕES PARA APLICAR OS INSTRUMENTOS \\ ICTME}

O instrumento deve ser aplicado por um entrevistador treinado e na presença do paciente. É utilizada uma folha para cada medicamento. O questionário (Apêndice E) apresenta quatro seções que se referem a informações gerais sobre o medicamento, freqüência da administração, instruções especiais e ações para administração.

O entrevistador deverá discutir cada item com o paciente, a fim de obter as informações necessárias para as quatro seções do instrumento.

\section{$1^{\text {a }}$ Seção: Informações gerais sobre a medicação.}

Colocar o nome genérico do medicamento, quantidade em relação ao número total de medicamentos prescritos, número de comprimidos tomado por dia e a dosagem.

\section{2 a Seção: Freqüência que toma a medicação:}

Esta seção refere-se à quantidade de vezes e/ou horários das medicações, são possíveis dezesseis horários diferentes correspondentes a períodos tradicionalmente prescritos, por ex: duas vezes ao dia, a cada 04 horas, antes de dormir, etc.

Cada horário tem uma pontuação específica e o valor está ao lado da alternativa assinalada, a opção selecionada deve estar relacionada somente ao intervalo ou horários e não ao número de comprimidos. Por exemplo, nos casos dos pacientes que tomam um comprimido ao dia ou dois ou mais comprimidos ao dia, a opção de escolha será relacionada à freqüência de ingestão do medicamento que nesse caso é diária ou todas as manhãs, conforme resposta do paciente, portanto 01 (hum) ponto será atribuído segundo o questionário, ou se a opção for 01 comprimido 04 (quatro) vezes ao dia, o valor dessa resposta é 04 .

\section{$3^{\mathrm{a}}$ Seção: Instruções especiais}

Essas instruções são freqüentemente solicitadas ao indivíduo com epilepsia, as quais incluem diferentes doses da mesma medicação no mesmo dia, ou em dias alternados- tomar em horários diferentes de outras medicações, etc.

Atribuir um ponto para cada opção selecionada ou zero se nenhuma opção for selecionada.

\section{4 a Seção: Ações de administração}

Nesta seção estão listadas 13 (treze) ações diferentes, por ex: tomar a medicação com a comida, dividir o comprimido ao meio- misturar com a comida.

Colocar nos parênteses o número de vezes ao dia que a ação é realizada.

Calcule o valor total desta seção somando os valores entre os parentes e do índice, somando todos os valores das três últimas seções. Pacientes que necessitam de várias medicações, portanto com mais de um medicamento prescrito em seu regime terapêutico, deverão ter os escores totais de todas as drogas prescritas somados, obtendo-se assim um único escore que indicará a complexidade de seu tratamento. 


\section{TESTE DE MORISKY}

O questionário de Morisky consiste de quatro perguntas, com respostas dicotômicas ( $\operatorname{sim}$ e não) assinale nos parênteses a resposta do paciente, some as repostas afirmativas e assinale a classificação da adesão terapêutica do respondente, conforme instruções no próprio instrumento (Apêndice B). Considera-se alta adesão quando as respostas são negativas para as quatro questões- média adesão quando as repostas são afirmativas em uma ou duas questões e baixa adesão quando três ou quatro respostas são afirmativas

\section{QOLIE- 31}

O QOLIE- 31 contêm 31 questões, distribuídas em sete domínios: preocupação com as crises- qualidade de vida em geral- bem-estar emocional- energia e fadiga- função cognitiva- efeito medicamentoso e função social. A questão 31 foi elaborada para uma avaliação genérica de saúde.

As questões devem ser lidas junto com o paciente pausadamente, as respostas são do tipo likert, recebem um número que varia de 01 a 06 e a esta numeração é atribuído um valor, que está na tabela de Escores para correção do QOLIE-31, apresentada no Anexo C.

Para avaliação de cada domínio, faz-se a soma total da pontuação das questões correspondentes e divide-se pelo número de questões. Após obter os escores finais multiplica-se pelo peso atribuído a cada domínio Formula para o Calculo do Escore Total do QOLIE-31, a pontuação varia de zero a 100, sendo que quanto mais próximo de 100 , melhor qualidade de vida do paciente. 


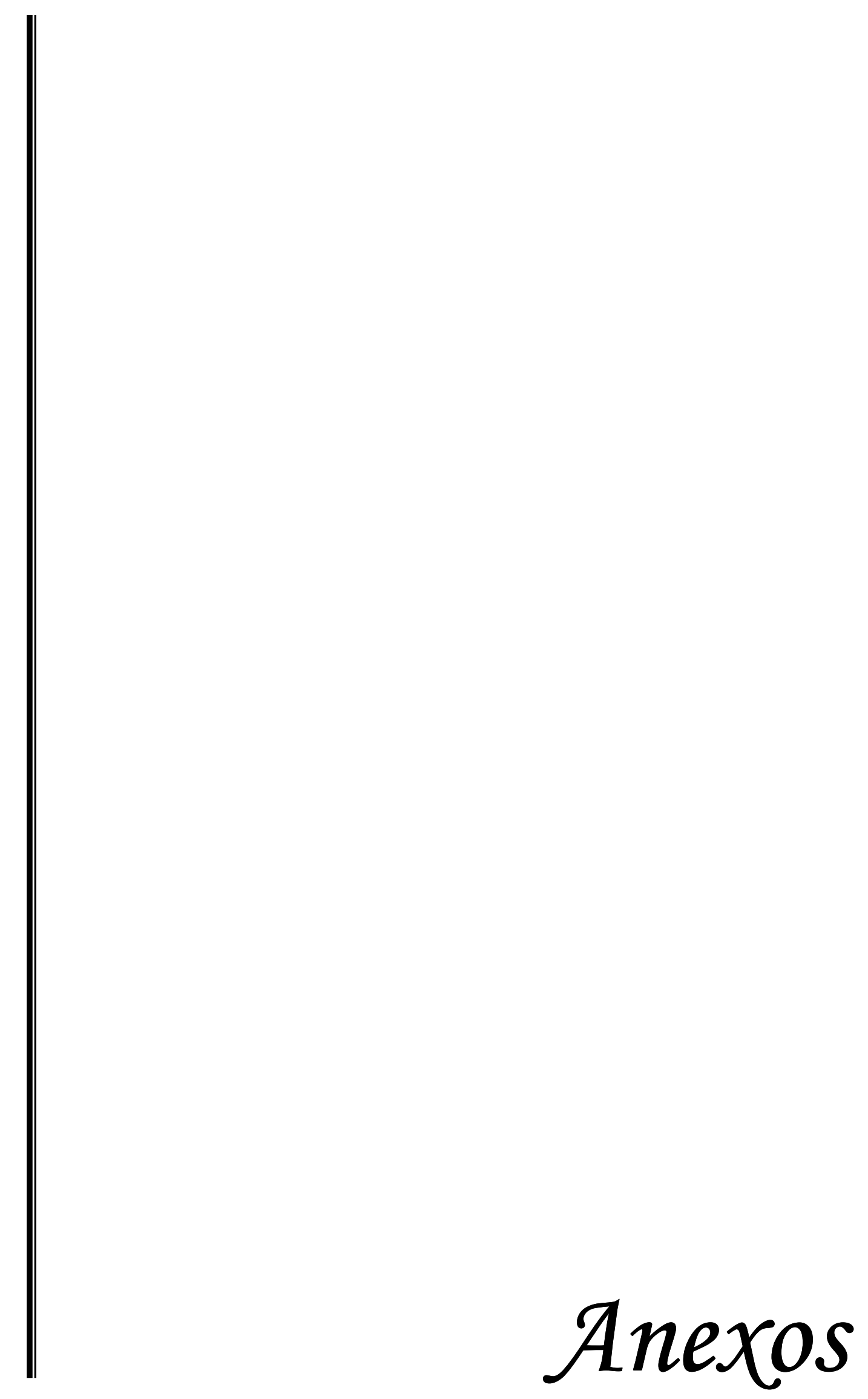


ANEXO A

Tabela de correção do escore QOLIE-31

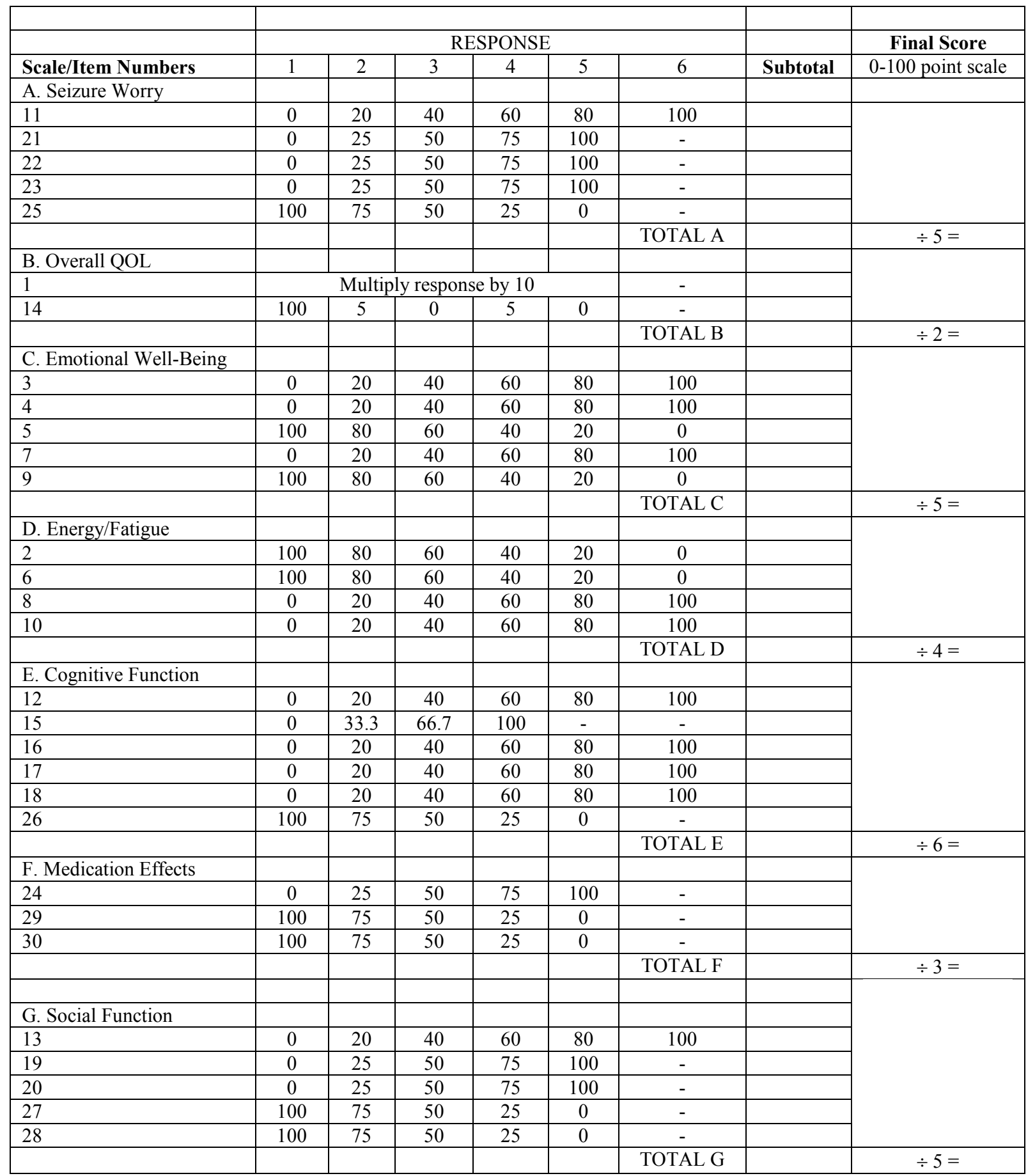

Note: The total number of items in each scale is listed as the divisor for each subtotal.

However, due to missing data, the divisor might actually be lower. 
FORMULA PARA O CALCULO DO ESCORE TOTAL DO QOLIE-31

\begin{tabular}{|l|l|l|r|r|}
\hline QOLIE-31 Scale & Final Scale Score & Weight & Subtotal & \\
\hline Seizure Worry & & X $0.08=$ & & A \\
\hline Overall QOL & & X 0.14 $=$ & & B \\
\hline Emotional Well-Being & & X $0.15=$ & & C \\
\hline Energy/Fatigue & & X $0.12=$ & & D \\
\hline Cognitive Functioning & & X $0.27=$ & & E \\
\hline Medication Effects & & X $0.03=$ & & G \\
\hline Social Functioning & & X0.21 $=$ & & \\
\hline & & & & \\
\hline $\begin{array}{l}\text { OVERALL SCORE }= \\
\text { Sum of subtotals A-G }\end{array}$ & & TOTAL $=$ & & \\
\hline
\end{tabular}

T-scores are linear transformations of the scores that produce a mean of 50 and standard deviation of 10 for a cohort. T-scores may be computed using the following formula:

$\mathrm{T}$-score $=50+[10$ (observed final scale score minus scale mean $)]$

[(Scale standard deviation) $]$ 
ANEXO B

Aprovação do COEP

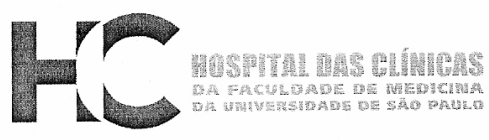

APROVAÇĀO

A Comissão de Ética para Análise de Projetos de Pesquisa CAPPesa da Diretoria Clínica do Hospital das Clínicas e da Faculdade de Medicina da Universidade de São Paulo, em sessão de 06/05/2009, APROVOU o Protocolo de Pesquisa $n^{\circ}$ 0210/09, intitulado: "ADESÃO AO TRATAMENTO MEDICAMENTOSO E QUALIDADE DE VIDA DE INDIVÍDUOS COM EPILEPSIA EM TRATAMENTO AMBULATORIAL" apresentado pelo Departamento de NEUROLOGIA inclusive o Termo de Consentimento Livre e Esclarecido.

Cabe ao pesquisador elaborar 'e apresentar à CAPPesq, os relatórios parciais e final sobre a pesquisa (Resolução do Conselho Nacional de Saúde $n^{\circ}$ 196, de 10/10/1996, inciso IX.2, letra "c").

Pesquisador (a) Responsável: Dr. Luiz Henrique Martins Castro

Pesquisador (a) Executante: Carla Maria Maluf Ferrari

Orientador (a): Profa. Dra. Regina Márcia Cardoso de Sousa

CAPPesq, 07 de Maio de 2009

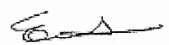

Prof. Dr. Eduardo Massad Presidente da Comissão de Ética para Análise de Projetos de Pesquisa

Comissão de Ética para Análise de Projetos de Pesquisa do HCFMUSP e da FMUSP Diretoria Clínica do Hospital das Clínicas da Faculdade de Medicina da Universidade de São Paulo Rua Ovídio Pires de Campos, 225, $5^{\circ}$ andar - CEP 05403010 - São Paulo - SP Fone: 01130696442 Fax: 01130696492 e-mail: cappesq@hcnet.usp.br / secretariacappesq2@hcnet.usp.br 